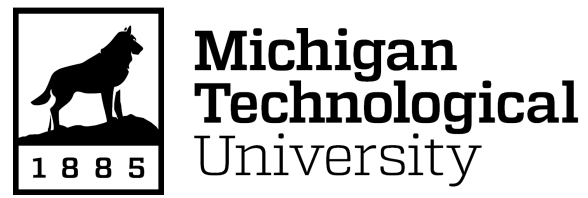

Michigan Technological University Digital Commons @ Michigan Tech

Dissertations, Master's Theses and Master's Reports

2019

\title{
MODELING CHEVY VOLT GEN II SUPERVISORY CONTROLLER IN CHARGE SUSTAINING OPERATION
}

Saurabh Bhasme

Michigan Technological University, sbhasme@mtu.edu

Copyright 2019 Saurabh Bhasme

\section{Recommended Citation}

Bhasme, Saurabh, "MODELING CHEVY VOLT GEN II SUPERVISORY CONTROLLER IN CHARGE SUSTAINING OPERATION", Open Access Master's Report, Michigan Technological University, 2019.

https://doi.org/10.37099/mtu.dc.etdr/778

Follow this and additional works at: https://digitalcommons.mtu.edu/etdr

Part of the Acoustics, Dynamics, and Controls Commons, and the Navigation, Guidance, Control, and Dynamics Commons 


\title{
MODELING CHEVY VOLT GEN II SUPERVISORY CONTROLLER IN CHARGE SUSTAINING OPERATION
}

\author{
By \\ Saurabh Sudhakar Bhasme \\ A REPORT \\ Submitted in partial fulfillment of the requirements for the degree of \\ MASTER OF SCIENCE \\ In Mechanical Engineering
}

MICHIGAN TECHNOLOGICAL UNIVERSITY

2019

(C) 2019 Saurabh S. Bhasme 
This report has been approved in partial fulfillment of the requirements for the Degree of MASTER OF SCIENCE in Mechanical Engineering.

Department of Mechanical Engineering-Engineering Mechanics

\author{
Report Co-Advisor: Dr. Mahdi Shahbakhti \\ Report Co-Advisor: Dr. Darell Robinette \\ Committee Member: Dr. Bo Chen \\ Department Chair: Dr. William W. Predebon
}




\section{Contents}

List of Figures $\quad$ vi

List of Tables $\quad$ xii

Acknowledgements $\quad$ xiv

List of Abbreviations $\quad$ XV

Abstract $\quad$ xvii

1 Introduction 1

1.1 General Trends in HEV . . . . . . . . . . . . . . . . . . . . . . . 3

1.2 The NEXTCAR project . . . . . . . . . . . . . . 6

1.3 Objective of Technical Report . . . . . . . . . . . . . . 8

1.4 Vehicle Specifications . . . . . . . . . . . . . . . . . . . 10

1.5 Literature Review . . . . . . . . . . . . . . . . . . . . . . . . 12

1.6 Report Organization . . . . . . . . . . . . . . . . . 17 
2.1 Model Overview . . . . . . . . . . . . . . . . . . . . . . . . 19

2.2 Load due to road gradient . . . . . . . . . . . . . . . . . 23

2.3 Transmission spin loss model . . . . . . . . . . . . . . . . . 26

2.4 Friction Brake Model . . . . . . . . . . . . . . . . . . . . 27

3 Powertrain Controller Modeling $\quad 29$

3.1 Driver Model . . . . . . . . . . . . . . . . . . . . . . . 29

3.2 Vehicle drive modes . . . . . . . . . . . . . . . . . . . . . . 30

3.3 State-flow approach for drive modes modeling . . . . . . . . . . . 34

3.4 Artificial Neural Network (ANN) design for drive modes prediction . 41

3.5 Charge sustaining (CS) torque distribution model . . . . . . . . . . 44

4 Model Validation $\quad 50$

4.1 Standard FTP Drive cycles . . . . . . . . . . . . . . . . 50

4.2 MTU drive cycle . . . . . . . . . . . . . . . . . . . 54 
5 Simulation of driving behavior

6 Conclusion and Future Works $\quad 66$

6.1 Conclusion . . . . . . . . . . . . . . . . 66

6.2 Future Works . . . . . . . . . . . . . . . . 68

$\begin{array}{ll}\text { References } & 70\end{array}$

A Summary of Program \& Data Files $\quad 73$

A.1 Chapter $1 \ldots \ldots \ldots \ldots$. . . . . . . . . . . . . . . . . . .

A.2 Chapter $2 \ldots \ldots \ldots \ldots \ldots$. . . . . . . . . . . . . . . . . . . .

A.3 Chapter $3 \ldots \ldots \ldots \ldots$. . . . . . . . . . . . . 76

A.4 Chapter $4 \ldots \ldots \ldots \ldots$. . . . . . . . . . . . . . . . 78

A.5 Chapter $5 \ldots \ldots \ldots \ldots \ldots$. . . . . . . . . . . . . . 82

B MTU drive cycle validations $\quad 84$ 


\section{List of Figures}

1.12016 US GHG emissions by sector $[1] \ldots \ldots$. . . . . . . . . . 1

1.22016 US GHG emissions in Automotive sector [1] . . . . . . . . . . 2

1.3 Production share by vehicle type from MY 1975 to MY 2017 [2] . . . 3

1.4 A comparison between technologies implemented in light-duty vehicles $[2] \ldots \ldots \ldots \ldots \ldots \ldots$

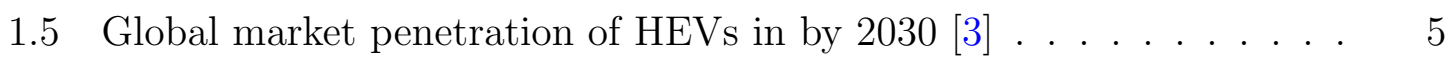

1.6 Comparison of cost of ownership [4] . . . . . . . . . . . 5

1.7 U.S. consumer satisfaction of vehicle ownership [4] . . . . . . . 6

1.8 Adjusted fuel economy comparison for various light-duty vehicle type

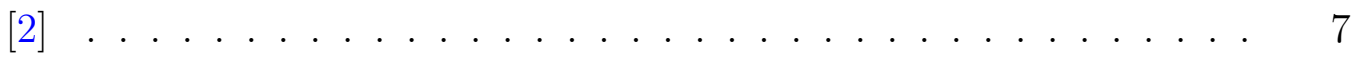

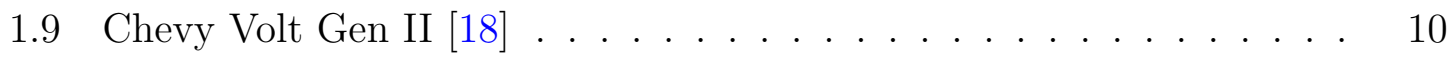

1.10 Axle torque and vehicle speed operating points for extended range modes $[5] \ldots \ldots \ldots \ldots \ldots$

1.11 Axle torque and vehicle speed operating points for charge depletion modes $[5] \ldots \ldots \ldots \ldots \ldots$ 
1.12 Torque distribution between MGA and MGB unit during CD driving

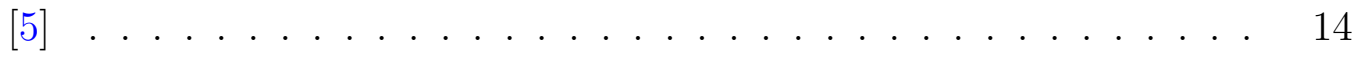

1.13 Engine fuel cut-off points during extended range modes [5] . . . . . . 14

1.14 Engine starting points based on vehicle battery SOC [6] . . . . . . 15

1.15 Organization of Report . . . . . . . . . . . . . . . . . . 18

2.1 Schematic of Chevy Volt Gen II VD\&PT model . . . . . . . . . . . . 20

2.2 Fully predictive powertrain control layout . . . . . . . . . . . . 21

2.3 HEV supervisory control layout . . . . . . . . . . . . . . . 22

2.4 Road gradient load model . . . . . . . . . . . . . . . . 23

2.5 MTU drive cycle . . . . . . . . . . . . . . . . . . 25

2.6 Road gradient profile for MTU drive cycle . . . . . . . . . . . 25

2.7 Transmission spin loss model . . . . . . . . . . . . . . . 26

2.8 Friction brake model . . . . . . . . . . . . . . . . . . . 27

3.1 PI based driver model . . . . . . . . . . . . . . . . . 30

3.2 Chevy Volt Gen II vehicle powertrain layout . . . . . . . . . . . . . . 31

3.3 Chevy Volt Gen II - One Motor EV (1EV) . . . . . . . . . . . . . 32 
3.4 Chevy Volt Gen II - Two Motor EV (2EV) . . . . . . . . . . . . . . . 32

3.5 Chevy Volt Gen II - Low Extended Range (LER) . . . . . . . . . . . 33

3.6 Chevy Volt Gen II - Fixed Extended Range (FER) . . . . . . . . . . 33

3.7 Chevy Volt Gen II - High Extended Range (HER) . . . . . . . . . . . 34

3.8 Vehicle operating points based on drive mode . . . . . . . . . . 35

3.9 Regions extracted from the vehicle operating point for each driving mode............................ 35

3.10 State-flow chart for drive mode selection during vehicle acceleration . $\quad 37$

3.11 State-flow chart for drive mode selection during vehicle deceleration . 38

3.12 ANN model for predicting vehicle drive mode . . . . . . . . . . . . 42

3.13 Confusion matrix for validation data . . . . . . . . . . . . . 42

3.14 Confusion matrix for test data . . . . . . . . . . . . . . 43

3.15 Flow chart for torque blending logic during vehicle acceleration . . . . 47

3.16 Flow chart for torque blending logic during vehicle deceleration $\ldots 49$ 
4.1 Validation of control model for UDDS CS drive cycle using ANL Data ( $\epsilon=$ average error, $\sigma_{e}=$ standard deviation of error $)$. See Appendix A (Filename: 61607020.mat) for details of experimental data . . . . . 51

4.2 Validation of control model for HWFET CS drive cycle using ANL Data $\left(\epsilon=\right.$ average error, $\sigma_{e}=$ standard deviation of error). See Appendix A (Filename: 61607018.mat) for details of experimental data . 52

4.3 Validation of control model for US06 CS drive cycle using ANL Data ( $\epsilon=$ average error, $\sigma_{e}=$ standard deviation of error $)$. See Appendix A (Filename: 61607008.mat) for details of experimental data . . . . .

4.4 Validation of control model for MTU drive cycle in Normal-CS (Ini$\underline{\text { tial SOC }=15 \%)}$ mode using MTU APSRC Data $(\epsilon=$ average error, $\sigma_{e}=$ standard deviation of error). See Appendix A (Filename: MTU DC 052218 0430pm Beta Normal Undergrad CS.mat) for details of experimental data . . . . . . . . . . . . . . . .

4.5 Validation of control model for MTU drive cycle in Hold-CS (Initial $\underline{\mathrm{SOC}=50 \%) \text { mode with active cruise control using MTU APSRC }}$ Data $\left(\epsilon=\right.$ average error, $\sigma_{e}=$ standard deviation of error). See Appendix A (Filename: MTU DC 060110181400 ALPHA 50 CS 2person.mat) for details of experimental data . . . . . . . . . . . 
4.6 Validation of control model for MTU drive cycle in Hold-CS (Initial SOC $=50 \%)$ mode without active cruise control using MTU $\operatorname{APSRC}$ Data $\left(\epsilon=\right.$ average error, $\sigma_{e}=$ standard deviation of error). See Appendix A (Filename: MTU DC 0531180115 Undergraduate CS 0115pm 0520 2persons.mat) for details of experimental data . .

5.1 Scatter plot of combined city and highway fuel consumption for 4000 real world trips $[14] \ldots \ldots \ldots \ldots \ldots \ldots \ldots$

5.2 Driver model response for tuned PI gains to represent drivers behavior during tip-in acceleration events (a) Driver A, (b) Driver B. See Appendix A (Filename: Normal10to40.mat and Aggr10to40.mat) for details of experimental data $\ldots \ldots \ldots \ldots \ldots$

5.3 Driver model response for tuned PI gains to represent different driving behaviors (a) Driver A, (b) Driver B ( $\epsilon=$ average error, $\sigma_{e}=$ standard deviation of error). See Appendix A (Filename: New ACC MTU AGGR DRIVE.mat) for details of experimental data . . . . .

B.1 Validation of control model for MTU drive cycle in Normal-CS (Initial SOC $=15 \%)$ mode using MTU APSRC Data $(\epsilon=$ average error, $\sigma_{e}=$ standard deviation of error) Details in Appendix A (Filename: MTU DC 052318 1142am Normal CS 2person.mat) . . . . . . . . . 
B.2 Validation of control model for MTU drive cycle in Normal-CS (Initial $\mathrm{SOC}=15.5 \%)$ mode with active cruise control using MTU APSRC Data $\left(\epsilon=\right.$ average error, $\sigma_{e}=$ standard deviation of error $)$ Details in Appendix A (Filename: MTU DC 0529180357 Undergraduate 015 DC CS 1Person.mat) . . . . . . . . . . . . . .

B.3 Validation of control model for MTU drive cycle in Normal-CS (Initial $\mathrm{SOC}=16 \%)$ mode with active cruise control using MTU APSRC Data $\left(\epsilon=\right.$ average error, $\sigma_{e}=$ standard deviation of error $)$ Details in Appendix A (Filename: MTU DC 053118 Normal Undergraduate CS 0400pm 0162 2persons.mat) $\ldots \ldots \ldots \ldots \ldots$

B.4 Validation of control model for MTU drive cycle in Hold-CS (Initial $\mathrm{SOC}=16.5 \%$ ) mode with active cruise control using MTU APSRC Data $\left(\epsilon=\right.$ average error, $\sigma_{e}=$ standard deviation of error) Details in Appendix A (Filename: MTU DC 053118 Normal Undergraduate CS 0300pm 0164 2persons.mat) . . . . . . . . . . . . . . 


\section{List of Tables}

1.1 Specifications of Chevy Volt Gen II [19] . . . . . . . . . . . . . . . 11

3.1 Mode transition hysteresis for the vehicle drive mode shift . . . . . . 41

4.1 Vehicle fuel and electrical energy consumption comparison of model with ANL experimental data . . . . . . . . . . . . . . . 54

4.2 Vehicle fuel \& electrical energy consumption comparison of model with MTU APSRC experimental data . . . . . . . . . . . . . . . . 59

5.1 PI gains for different driving behaviors . . . . . . . . . . . . 63

5.2 Energy consumption comparison for Drivers A and B . . . . . . 65

A.1 Figure Files . . . . . . . . . . . . . . . . . . . 73

A.2 Figure Files . . . . . . . . . . . . . . . . . . . . . 74

A.3 Visio Files . . . . . . . . . . . . . . . . . . . . . . . 74

A.4 Figure Files . . . . . . . . . . . . . . . . . . . 75

A.5 Visio Files . . . . . . . . . . . . . . . . . . . . . 75

A.6 Figure Files . . . . . . . . . . . . . . . . . . . . . . . . 76

A.7 Visio Files . . . . . . . . . . . . . . . . . . . . . . . 77 
A.8 MATLAB Figure Files . . . . . . . . . . . . . . . . . . . . . . . 78

A.9 MATLAB Figure Files . . . . . . . . . . . . . . . . . . . 79

A.10 MATLAB/Simulink Files . . . . . . . . . . . . . . . 80

A.11 Vehicle Data Files . . . . . . . . . . . . . . . . . . . . . . . 80

A.12 Data Files . . . . . . . . . . . . . . . . . . . 81

A.13 Figure Files . . . . . . . . . . . . . . . . . . . . . . . . . . . 82

A.14 MATLAB Figure Files . . . . . . . . . . . . . . . . . . . . . . . . . . 82

A.15 Data Files . . . . . . . . . . . . . . . . . . . . . 83

B.1 Data Files . . . . . . . . . . . . . . . . . . . . . 88 


\section{Acknowledgements}

I would like to extend my gratitude to my advisers Dr. Mahdi Shahbakhti and Dr. Darrell Robinette for giving me opportunity to become a part of the NEXTCAR project and for guiding me throughout my research work and helping me develop hard and soft skills for becoming a professional engineer.

I would like to thank Dr. Bo Chen for being the part of the report committee.

I would also like to thank my peers \& professors working in project NEXTCAR, Dr. Jeff Naber, Chris Morgan, Pradeep Bhat, Joe Oncken, Sadra Hemmati and Nehal Doshi for their support, encouragement and advice.

I would like to thank MTU APSRC \& MEEM department for providing necessary facilities required to conduct my work for this project.

I would also like to thank my family \& friends who stood by me, supported \& motivated me throughout my academic journey. 


\section{List of Abbreviations}

\begin{tabular}{ll} 
GM & General Motors \\
ARPA-E & Advanced Research Projects Agency - Energy \\
NEXTCAR & NEXT-Generation Energy Technologies for Connected \& Automated \\
& On-Road Vehicles \\
MTU & Michigan Technological University \\
APSRC & Advanced Power Systems Research Center \\
ANL & Argonne National Laboratory \\
EPA & Environmental Protection Agency \\
FTP & Federal Test Procedure \\
UDDS & Urban Dynamo meter Driving Schedule \\
HWFET & Highway Fuel Economy Test \\
CAFE & Corporate Average Fuel Economy \\
OEM & Original Equipment Manufacturer \\
GHG & Green House Gases \\
SUV & Sports Utility Vehicle \\
GDI & Gasoline Direct Injection \\
HEV & Hybrid Electric Vehicle \\
BEV & Battery Electric Vehicle \\
EV & Electric Vehicle \\
\hline
\end{tabular}




\begin{tabular}{ll} 
PHEV & Plug-in Hybrid Electric Vehicle \\
SOC & State Of Charge \\
ICE & Internal Combustion Engines \\
TPIM & Transmission Power Inverter Module \\
MPC & Model Predictive Control \\
CD & Charge Depletion \\
CS & Charge Sustaining \\
MGA & Motor/Generator Unit A \\
MGB & Motor/Generator Unit B \\
LER & Low Extended Range \\
FER & Fixed Extended Range \\
HER & High Extended Range \\
BSFC & Brake Specific Fuel Consumption \\
MIL & Model in the Loop \\
SIL & Software in the Loop \\
HIL & Hardware in the Loop \\
PI & Proportional \& Integral \\
PS1 & Planetary Gear Set 1 \\
PS2 & Planetary Gear Set 2 \\
Li-ion & Lithium-ion \\
ANN & Artificial Neural Network \\
\hline
\end{tabular}




\section{Abstract}

This report is focused on development of Chevy Volt Gen II powertrain supervisory controller modeling for charge sustaining operation of the vehicle. The modeling process incorporated vehicle parameters and maps provided by GM. The overall powertrain model along with the supervisory controller is developed in MATLAB/SIMULINK programming platform. The powertrain model includes all components which are the IC engine, two electric motors \& associated TPIM, Battery, transmission auxiliary pump and spin-losses. The supervisory controller includes the vehicle drive mode selection model, the torque blending logic for charge sustaining along with friction brake modeling. The model has been developed to perform energy analysis and comparison based on on-road vehicle experimental data. The overall model validation is done using the three standard FTP driving schedules and a driving schedule developed by MTU. The model successfully predicts total energy consumption within $5 \%$ of the experimental data, in conformity to required model fidelity. 


\section{Introduction}

According to Environmental Protection Agency (EPA) of US, the transportation sector contributed nearly $28.5 \%$ towards the total US greenhouse gas emissions in 2016, resulting in one of the largest contributor (shown in Figure 1.1). The biggest contributor from the transportation group is the light-duty vehicles sector which comprises over 60\% [1] (shown in Figure 1.2). With increase in demand of these vehicles as shown in Figure 1.3, its a necessity for every automobile manufacturer to improve its Corporate Average Fuel Economy (CAFE), specially focusing on lightduty vehicle segment as this segment is expected to dominate in US as well as in other countries.

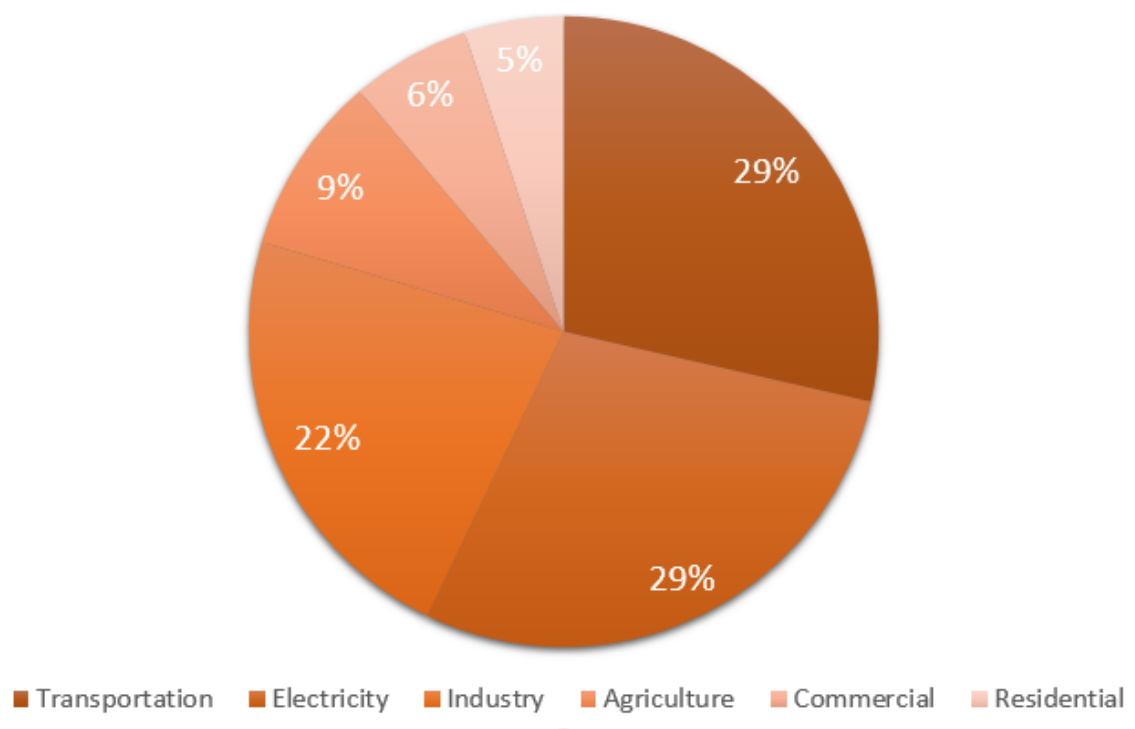

Figure 1.1: 2016 US GHG emissions by sector [1] 


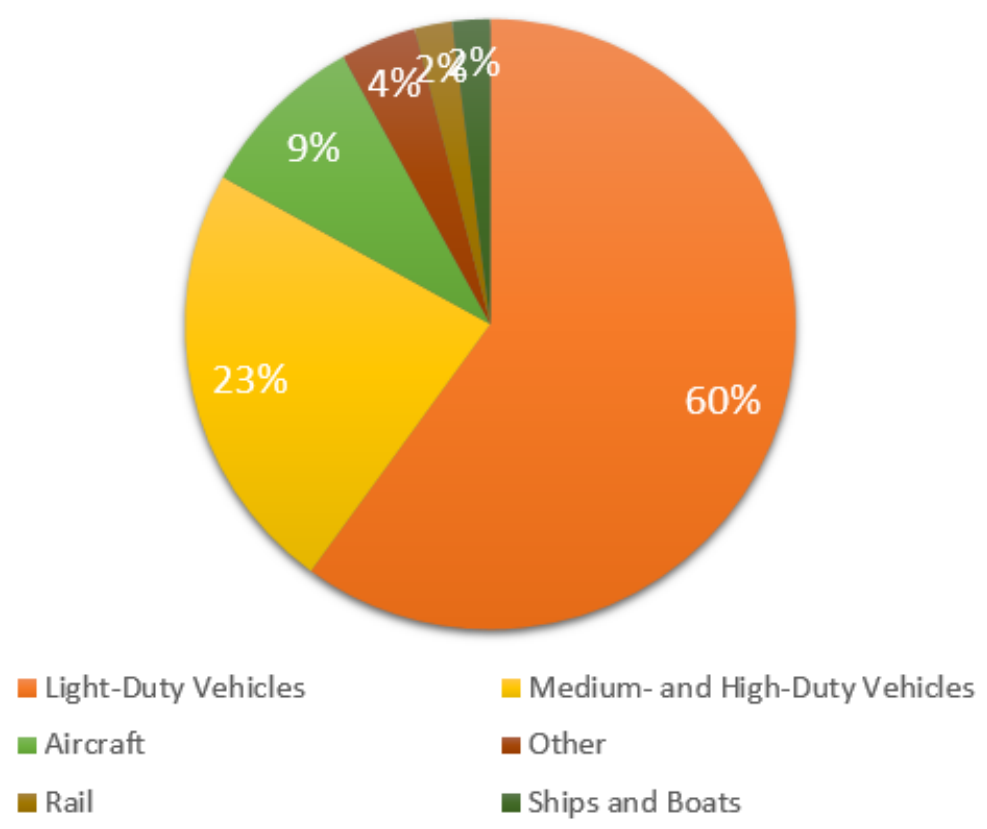

Figure 1.2: 2016 US GHG emissions in Automotive sector [1]

To cater to the increasing demands of reduced fuel consumption, Carbon Di-Oxide emissions from the light-duty vehicle class, industries have adopted various technologies. As seen in Figure 1.4, in 2013, the major focus was on improving the transmission technologies i.e. implementing 6 speed and higher transmissions etc. Now, as the CAFE targets become more stringent, the focus is on fuel injection technologies such as GDI, downsizing and turbocharging of the IC engines. Also micro and mild level of hybridization of the fleet to improve city fuel economy has been increased to a large extent in this time period. 


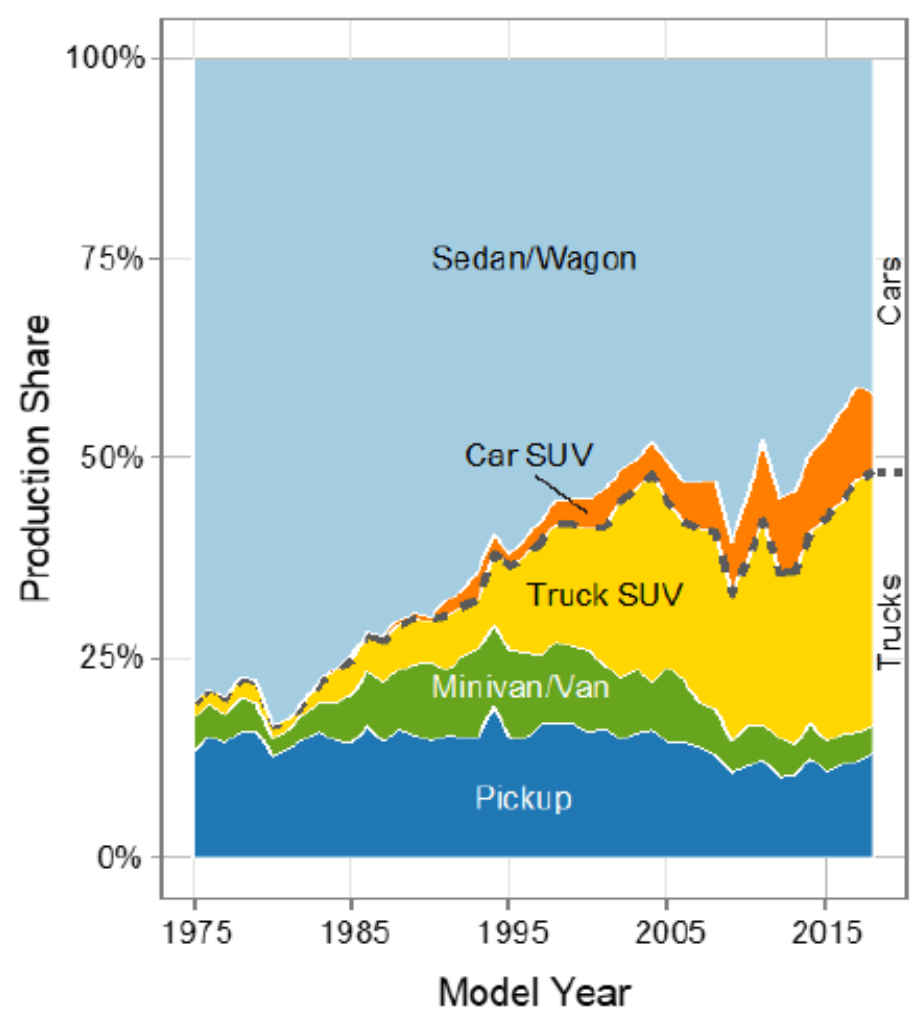

Figure 1.3: Production share by vehicle type from MY 1975 to MY 2017 [2]

\subsection{General Trends in HEV}

Each year we see new electric car companies striving to achieve commendable vehicle performance. The well established companies in the market are also turning towards electrification of their vehicle fleet as the EPA targets for CAFE becomes more stringent. As a result of this, it is predicted that the HEVs will penetrate up to $58 \%$ in the global market as shown in Figure 1.5. A significant amount of contribution will come from full and mild hybrids as consumers still expect that IC Engines are better 


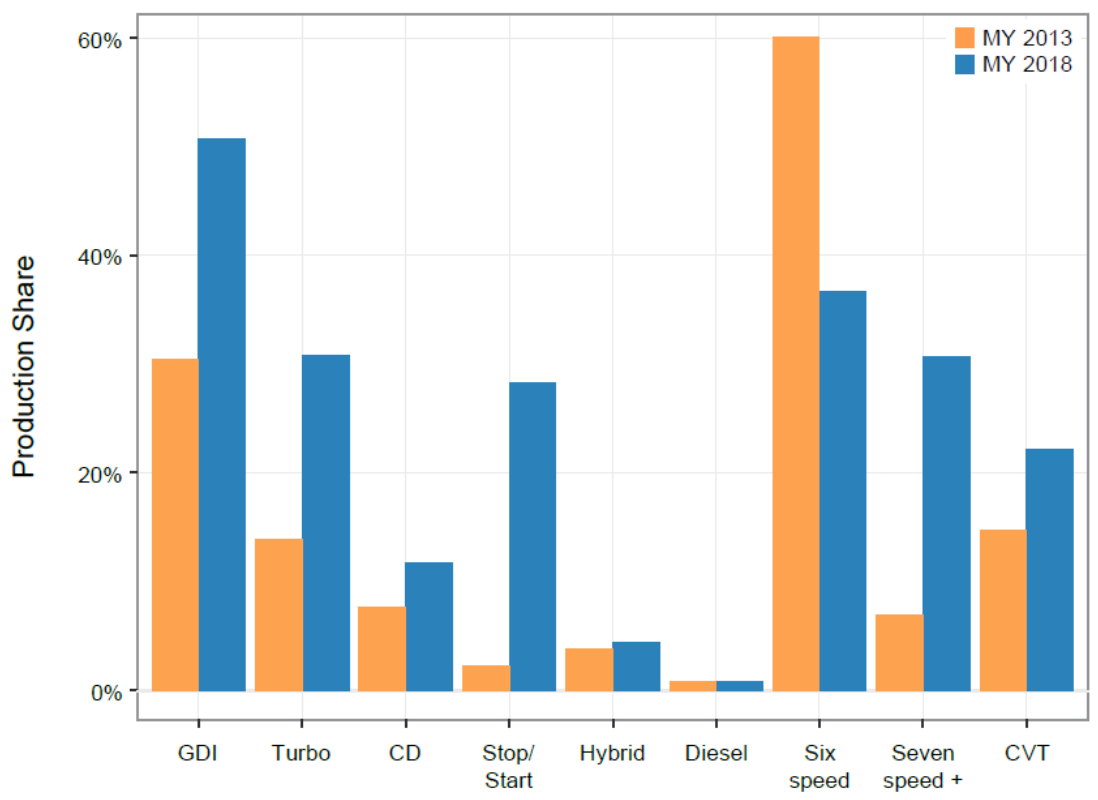

Figure 1.4: A comparison between technologies implemented in light-duty vehicles

than that of pure electric power because of fear of getting stuck after full usage of battery.

This rise in the number of electrified vehicles in the market can also be associated with the decreasing cost of ownership. Considering that consumers still want to have a range extender in their vehicle, the PHEV stands out from all other HEVs in the cost of ownership which is around $\$ 1500$ less than pure ICE powered vehicles (see Figure 1.6). Also, seeing consumer attraction towards PHEVs can be confirmed from the consumer satisfaction chart shown in Figure 1.7. A very high rating in terms of performance is given to the PEVs (Plug-in Electric Vehicles) due to the sheer 


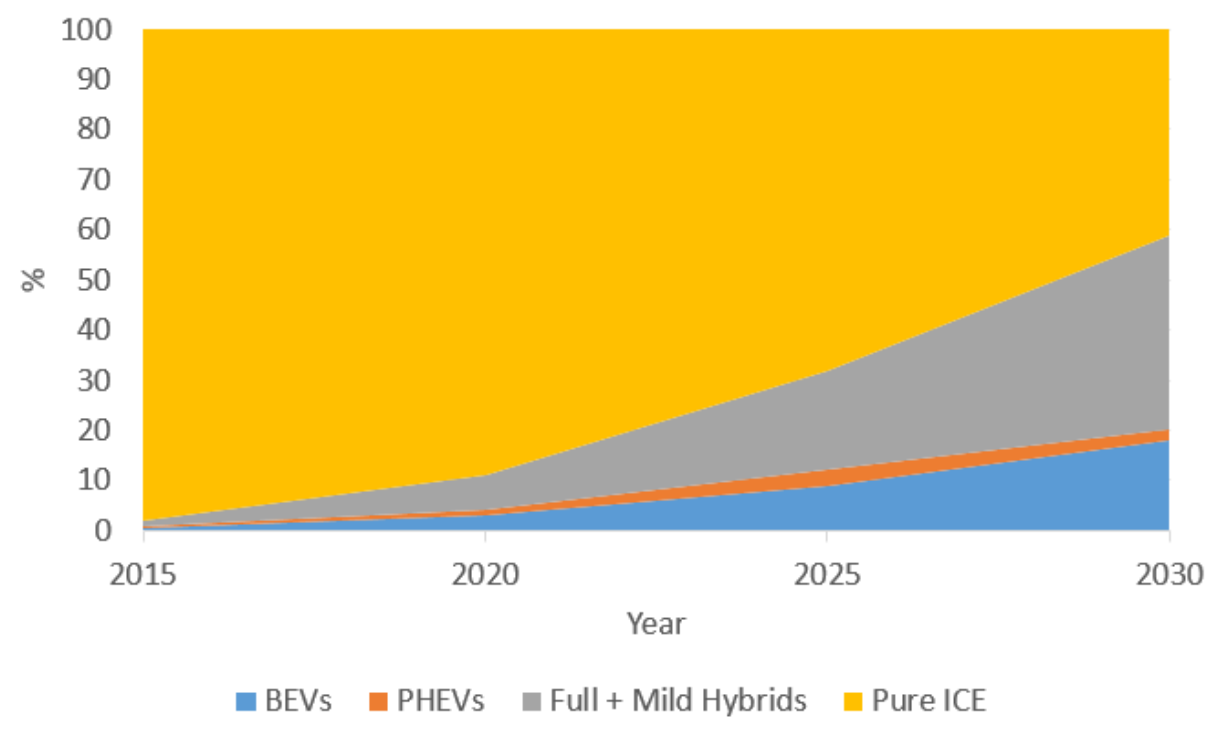

Figure 1.5: Global market penetration of HEVs in by 2030 [3]

acceleration might possessed by these vehicles, thanks to the high torque availability because of electric motors.

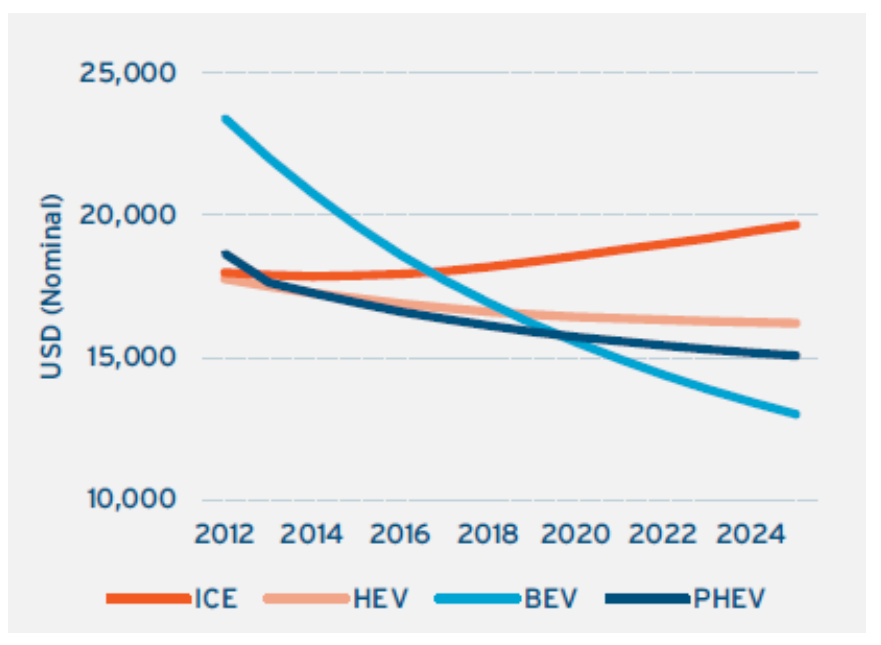

Figure 1.6: Comparison of cost of ownership [4]

Further, we can see a complete win of PEVs as they have been rated higher than ICE powered vehicles and HEVs in all segments of comparison. At the end, one important 
is the fuel economy advantage of HEVs over conventional powered vehicle. In Figure 1.8, even the average hybrid car is over $45 \%$ more efficient than a non-hybrid car and this number is increasing day by day. In all, the HEVs today are achieving pinnacles in each performance and consumer appeal all indicating a brighter future of HEVs in mobility with PEVs being popular among industry.

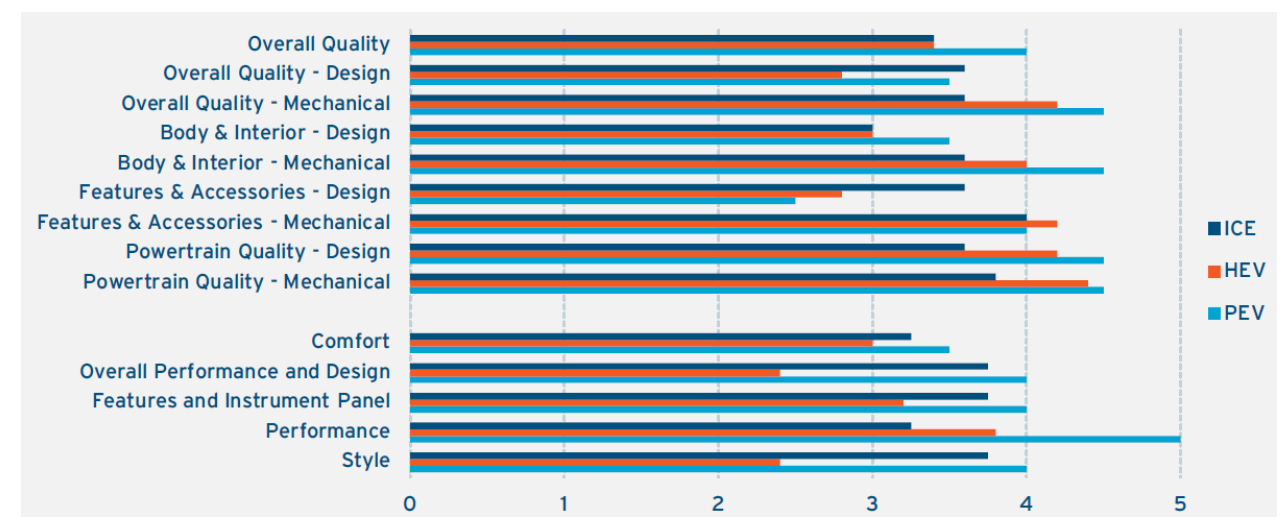

Figure 1.7: U.S. consumer satisfaction of vehicle ownership [4]

\subsection{The NEXTCAR project}

The work dedicated in this report is based on the ARPA-E's Project NEXTCAR, a short form for "NEXT-Generation Energy Technologies for Connected and Automated On-Road Vehicles". The project aims at optimizing vehicle dynamics and powertrain controls of individual vehicle using the ever increasing vehicle to vehicle and vehicle to infrastructure connectivity and vehicle automation. The current con- 


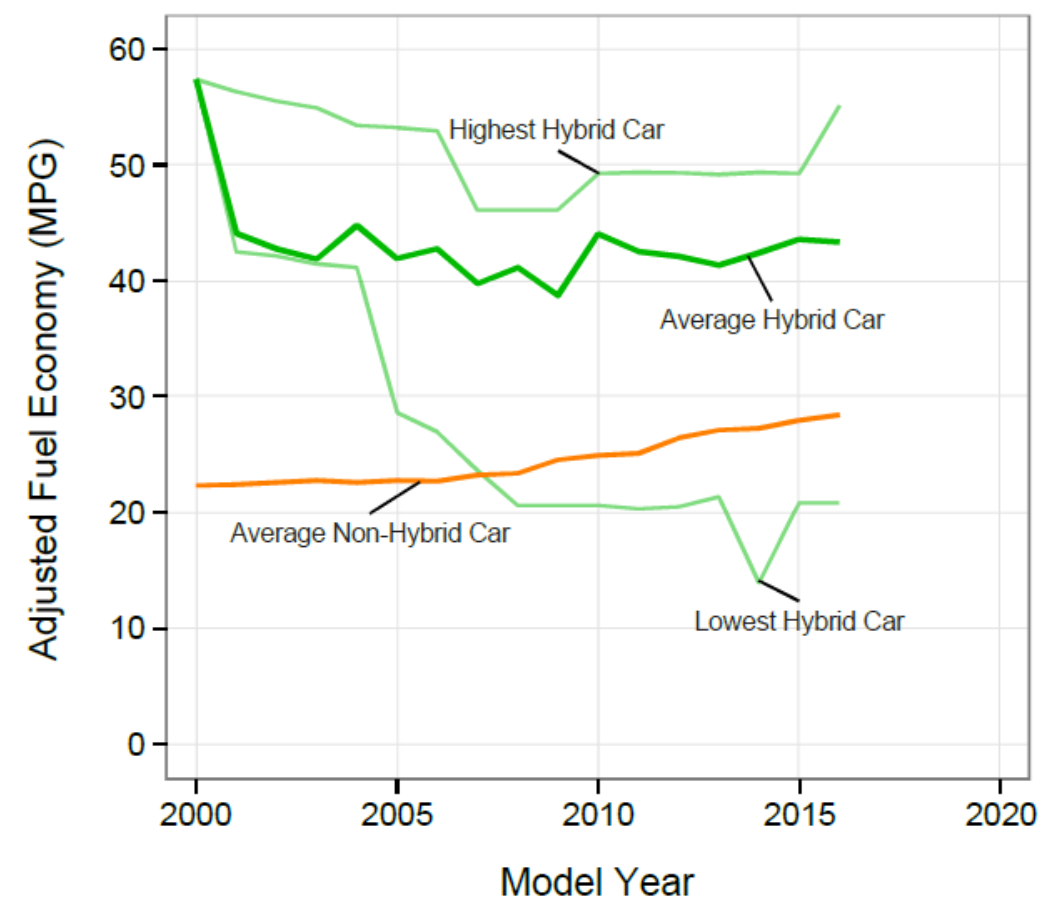

Figure 1.8: Adjusted fuel economy comparison for various light-duty vehicle type

nected \& automated vehicle systems mostly focus on driver safety and ease of driving. The technology has opened new ways to improve single vehicle and overall traffic efficiency by using same information to predict future driving conditions as close as possible to generate potential fuel savings.

Michigan Technological University, in association with General Motors, is aimed at successfully developing and deploying a model-based predictive control (MPC) on a powertrain of eight hybrid vehicles fleet, to achieve $20 \%$ decrease in the energy consumption along with increasing the EV drive range by $6 \%$. The vehicles will be 
automated and connected to each other and to a mobile computing platform, the MTU Mobile Lab. For this job, the hybrid vehicle in focus is 2017 Gen 2 Volt, an advanced and more efficient PHEV in market.

The successful completion of this project will also help in reducing vehicle carbon footprint which enables OEMs to attain stringent EPA norms. Further, this will also culminate in more greener mobility which a need of the day and also will decrease US dependency on oil imports.

\subsection{Objective of Technical Report}

In order to assess and optimize the Model Predictive Control (MPC) to achieve the set targets of reducing energy consumption, it is necessary to develop a high fidelity powertrain model along with its controller in order to control torque distribution between three power sources available based on the velocity target set by the MPC.

A high fidelity powertrain model without any control is achieved which was able to predict energy consumption within $5 \%$ of the in-vehicle and ANL experimental data. This model required the commanded engine and motor torques to determine vehicle velocity and energy consumption. This report aims at discussing development of a 
powertrain control which will be able to decide the vehicle driving mode and torque blending in order to achieve set vehicle velocity and estimating energy consumption; thus, taking one step towards increasing model independency by removing the need of external inputs to the model. This controller is exclusively developed for charge sustaining operation of the vehicle. The model then only will be in need of the velocity targets which are determined by the MPC. Also, an analysis of vehicle driving behavior on the vehicle energy consumption is conducted to investigate how much excess energy is used by a driver when doing flat-out acceleration whenever its required to increase speed.

The powertrain controller is developed in MATLAB/SIMULINK programming platform using the high fidelity parameters provided by Argonne National Laboratory (ANL) experimental data and the data provided by GM. Also, the model accuracy was further increased by including models for some components such as transmission spin loss, friction brake, road gradient using either dynamic equations or mapping. The control algorithms are developed based on the analysis of in-vehicle test data collected for a devised MTU drive cycle. In addition, various literature was referred to understand vehicle behavior and to develop control functions, dynamical equations and maps. The control model validation is done using the ANL experimental data and the on-road test data for MTU drive cycle. 


\subsection{Vehicle Specifications}

The work in this report is based on the PHEV Chevy Volt Gen II, a vehicle by General Motors' Chevrolet division. The vehicle came to market in October 2015.

Figure 1.9 shows Chevy Volt Gen II and Table 1.1 includes the vehicle specifications of its powertrain components.

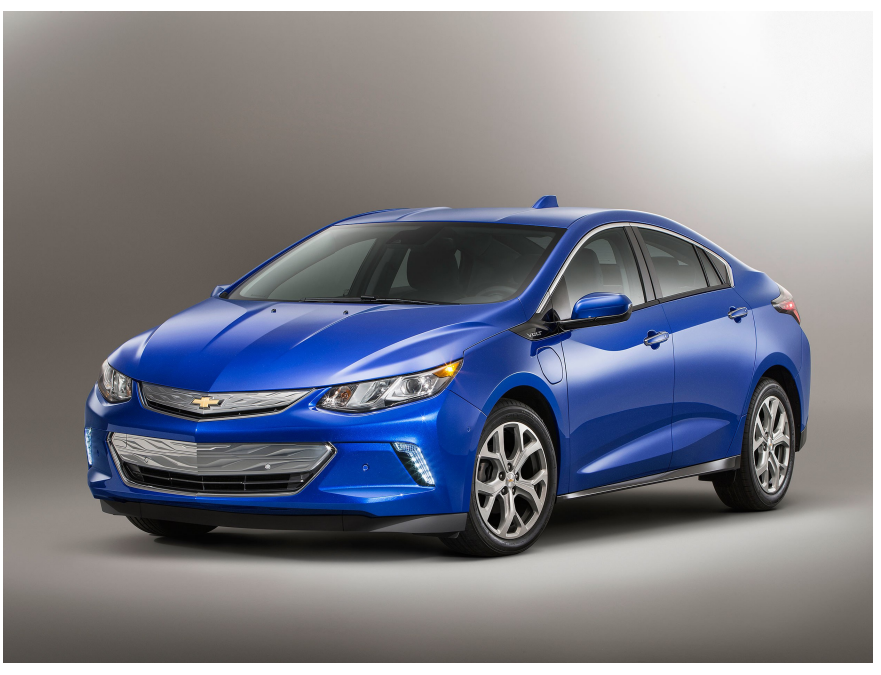

Figure 1.9: Chevy Volt Gen II [18] 
Table 1.1: Specifications of Chevy Volt Gen II [19]

\begin{tabular}{|c|c|}
\hline Parameters & Specification \\
\hline Model & Chevrolet Volt \\
\hline Driveline & Front wheel drive (FWD) \\
\hline EPA vehicle class & Compact car \\
\hline Battery chemistry & Lithium-ion \\
\hline Battery energy & $18.4 \mathrm{kWh}$ \\
\hline Engine type & 1.5L DOHC I-4 \\
\hline Engine output (kW/hp @ rpm) & 75/101@5600 \\
\hline MGA unit type & Distributed bar wound, Ferrite Magnet \\
\hline MGA power/torque (kW/Nm) & $48 \mathrm{~kW} / 118 \mathrm{Nm}$ \\
\hline MGB unit type & Distributed bar wound, NdFeb magnet \\
\hline MGB power/torque (kW/Nm) & $87 \mathrm{~kW} / 280 \mathrm{Nm}$ \\
\hline Performance (0-60 mph) & $8.4 \mathrm{sec}$ \\
\hline EV range (city) & 53 miles / $85 \mathrm{~km}$ \\
\hline Extended range & 420 miles / $675 \mathrm{~km}$ \\
\hline Wheelbase (in/mm) & $106.1 / 2694$ \\
\hline Vehicle length (in/mm) & $180.4 / 4582$ \\
\hline Vehicle width (in/mm) & $71.2 / 1809$ \\
\hline Vehicle height (in/mm) & $56.4 / 1432$ \\
\hline Curb weight (lb / kg) & $3543 / 1607$ \\
\hline
\end{tabular}




\subsection{Literature Review}

Automotive researchers have conducted a substantial amount of research on getting the logics for the torque distribution and drive selection for the Chevy Volt Gen II. Lee $\mathrm{H}$ et al. worked on analyzing vehicle-level control strategies for Gen II Volt under ambient temperature conditions at ANL. Figures 1.10 and 1.11 shows the axle torque and vehicle speed points for the vehicle running CS and CD modes respectively. This, in particular, signifies the vehicle operating regions for the entire CS mode operation which can be used as a starting point to detect vehicle drive mode $[5,6]$.

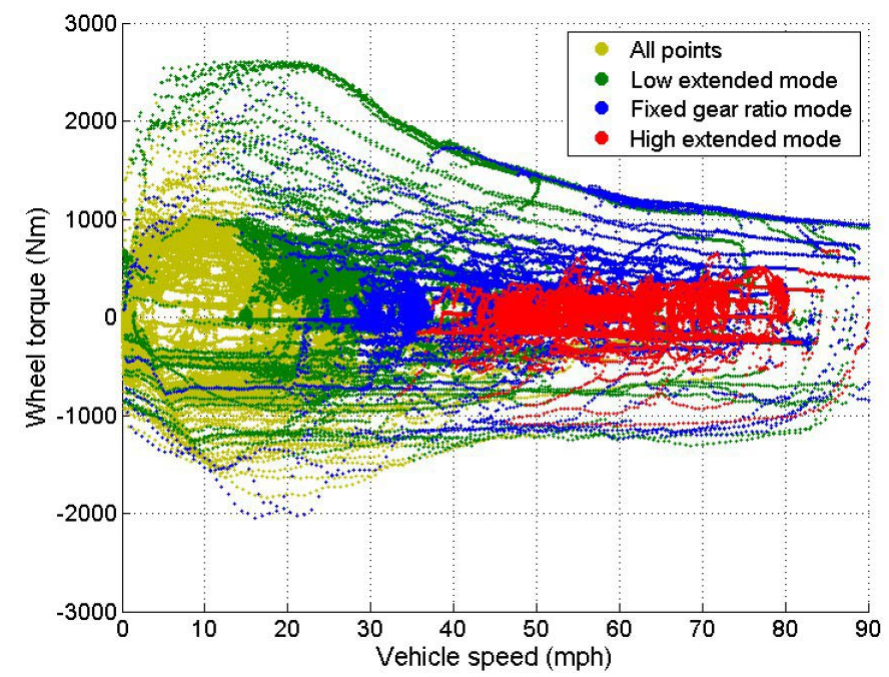

Figure 1.10: Axle torque and vehicle speed operating points for extended range modes [5] 


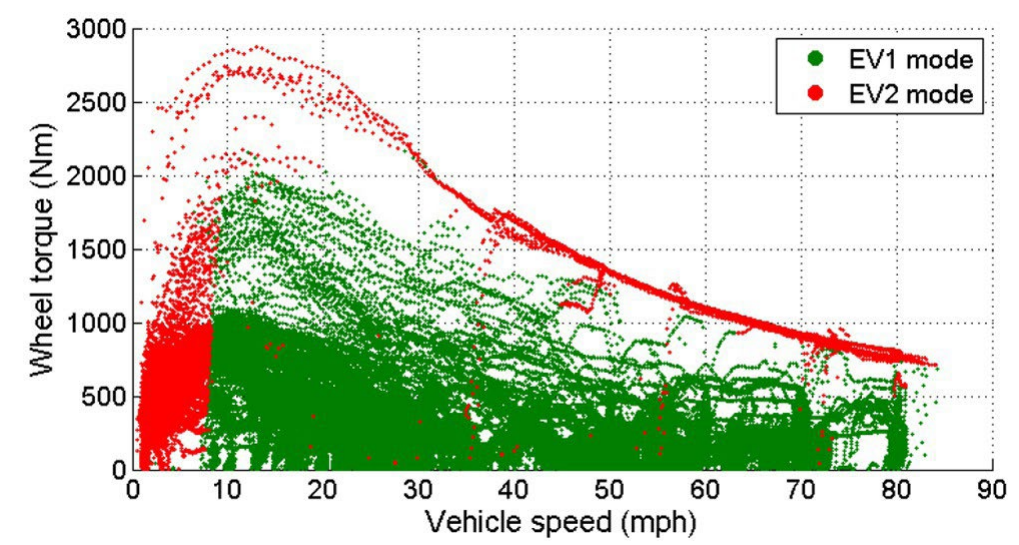

Figure 1.11: Axle torque and vehicle speed operating points for charge depletion modes [5]

Lee $\mathrm{H}$ et al. also identified some of the torque distribution strategies between two electric power units and engine operating points as shown in Figures 1.12 and 1.13. It was found that for most of the cases where $2 \mathrm{EV}$ mode is operational, the general torque distribution between MGA and MGB unit was found to be in the ratio of 9:1, concluding that $90 \%$ of the torque requests should be handled by MGB unit and the rest to be catered by MGA unit [5]. Also, it is important to note that the vehicle operating at higher speeds, does not stops the engine completely. It basically just cuts down the fuel and keeps the engine rotating with the help of MGA unit to quickly restart the engine if needed $[5,6]$. Only when the vehicle speed goes below $40 \mathrm{mph}$, then the engine is totally stopped. 


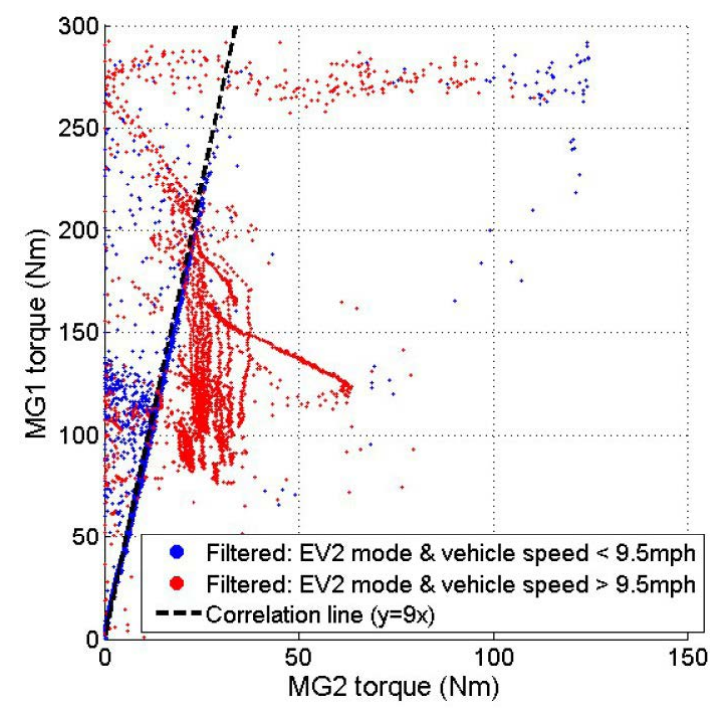

Figure 1.12: Torque distribution between MGA and MGB unit during CD driving

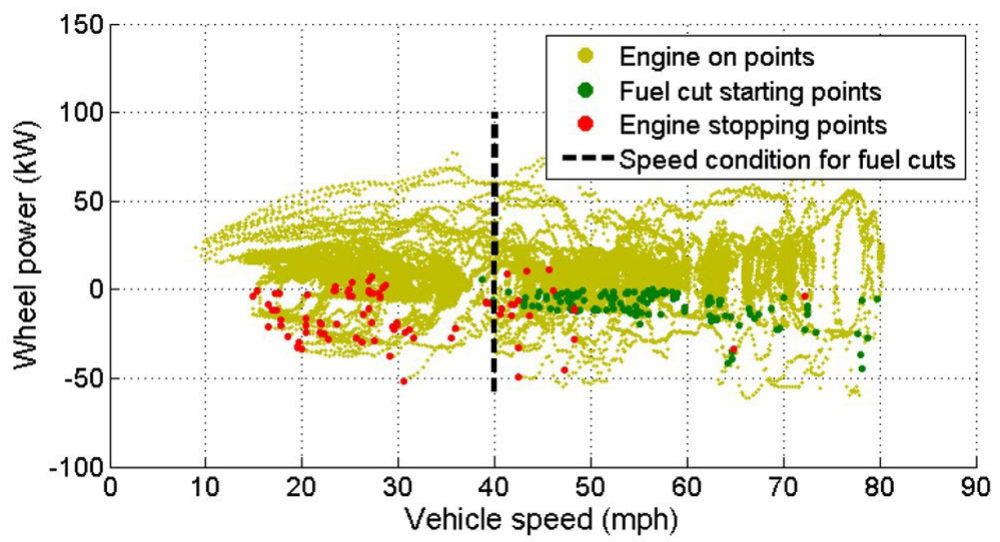

Figure 1.13: Engine fuel cut-off points during extended range modes [5]

In addition, the engine starting point for the vehicle changes actively based on the vehicle battery SOC. The minimum SOC at which the engine may come into operation is just above 17\% as shown in Figure 1.14. The engine starting points during CS driving varies linearly based on the vehicle SOC [6]. The torque distribution logic for 
extended range modes are also analyzed through the experimental data. The points below summarizes the general idea on how the vehicle distributes power demand in each of the range extended mode.

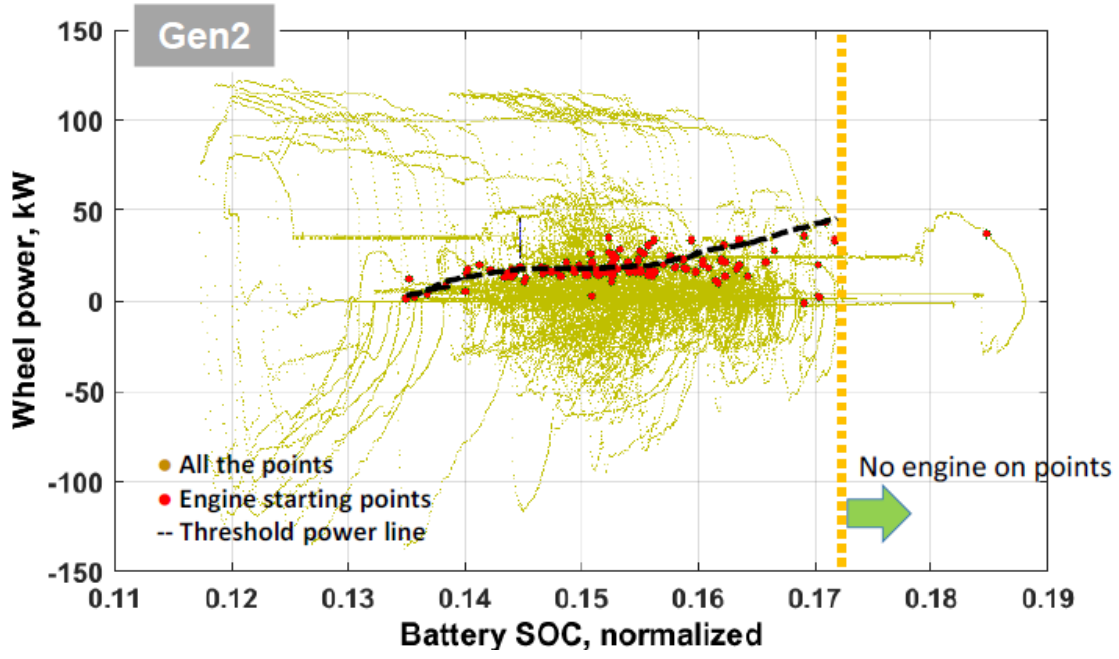

Figure 1.14: Engine starting points based on vehicle battery SOC [6]

- In Low Extended Range (LER) mode, in general, the engine is operated in the range of 25 to $35 \mathrm{~kW}$ irrespective of the wheel power demand in order to run the engine at very high efficiency. If the wheel power demand is less than 20 $\mathrm{kW}$, the engine is still maintained around $15 \mathrm{~kW}$. The excess energy required or available is taken care by the MGB unit either by supplying the excess energy or by recovering the energy by charging the battery [5].

- The fixed extended range mode mechanically connects the engine with the wheels, thus, making the engine speed to be dependent on the vehicle speed. During this drive mode, the engine maintains a constant torque between range 
of 90 to $110 \mathrm{~N}-\mathrm{m}$ based on various vehicle power demands [5, 6].

- The High Extended Range (HER) mode has a unique character wherein the engine speed and torque are controlled separately to get a wide range of engine operating points within a specific region where the engine efficiency is very high [5]. Since, there is no specific constraints on how the engine will operate and how the power distribution will work here, finding out very specific control logics for this mode was found to be very difficult.

Now, to model these control strategies, a platform has to be developed and programming method has to be selected. Since the previous powertrain model was fully developed in Simulink graphic based designing platform, the controller is also developed in the same environment. Now, the level at which the model needs to be developed is based on its application. For controller development, basically we have three levels of development, viz. Model in the loop (MIL), Software in the loop (SIL), and Hardware in the loop (HIL). Since, the controller developed here is actually reproducing vehicle performance right now without any new technology implementation, a MIL level of controller development is sufficient as the study sticks in the simulation endowment only. A model based design approach is implemented in developing control models in MIL and other models discussed below as the model based development allows much flexibility in rapid correction and validation model without retracing all the way from the start [7] [8] [9] [10]. 
Although, different models are found in literature to simulate and optimize HEVs, models to represent the SC of "production HEVs" for MIL and HIL applications are rarely discussed in literature. This report aims to address this gap by developing a model that simulates the main SC tasks of a production HEV electronic control unit (ECU) such as mode selection, torque distribution and driver model development. The SC model is demonstrated for Chevy Volt Gen II, but the same methodology can be utilized for other HEVs.

\subsection{Report Organization}

Figure 1.15 shows the overview of this report. In the next section we will discuss the experimental setup for data acquisition from the Chevy Volt Gen 2. After that, the modeling of the vehicle components, drive mode selection, and torque blending for the powertrain controller is discussed. The control model validation for various drive cycles will then be discussed in the section following the modeling. Finally, a discussion on the effects of driving behavior on energy consumption is provided which is followed by conclusion and future work. 


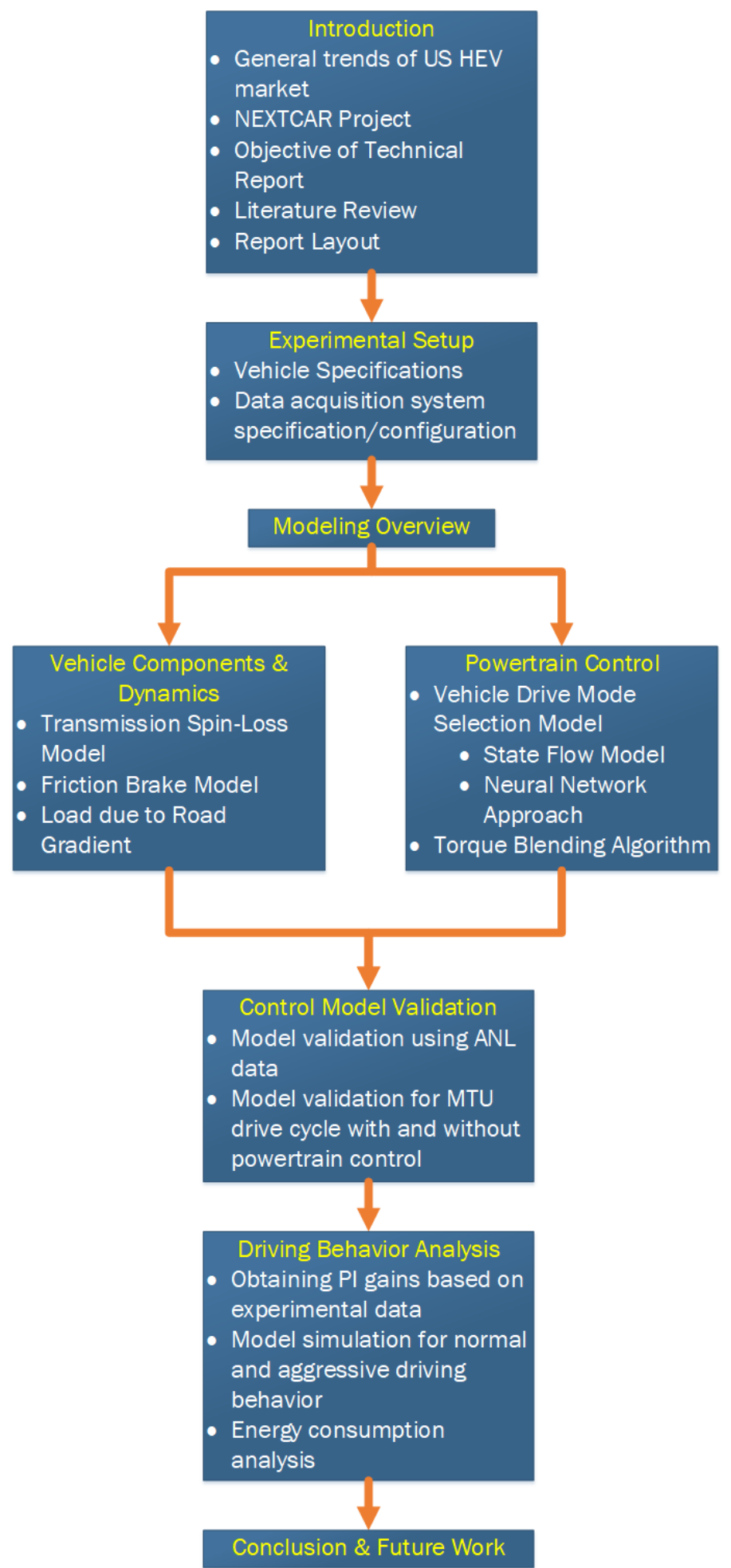

Figure 1.15: Organization of Report 


\section{Powertrain Component Modeling}

\subsection{Model Overview}

The overall model of the Chevy Volt Gen 2 is as shown in Figure 2.1 with all the powertrain components and vehicle dynamics. All these systems are modeled in MATLAB/SIMULINK platform. Modeling of the major components are done by MS student Yadav R [10]. This report will focus on development of HEV Supervisory controller design and component modeling necessary to make the model fully predictive.

Figure 2.2 shows the full predictive powertrain control layout with the controller and plant block in a feedback control loop. The target vehicle velocity is fed to the controller along with the actual or current vehicle speed, the current SOC of the battery. The HEV supervisory controller mainly consists of two major subsystems, the vehicle drive mode selection model and the torque blending model. The controller system calculates the torque request to the engine and MG B (Motor/Generator unit B), the speed request for MG A unit and the friction brake torque. Based on these inputs and the current road gradient, the plant model consisting models for powertrain components as discussed above calculates the vehicle speed, and the 


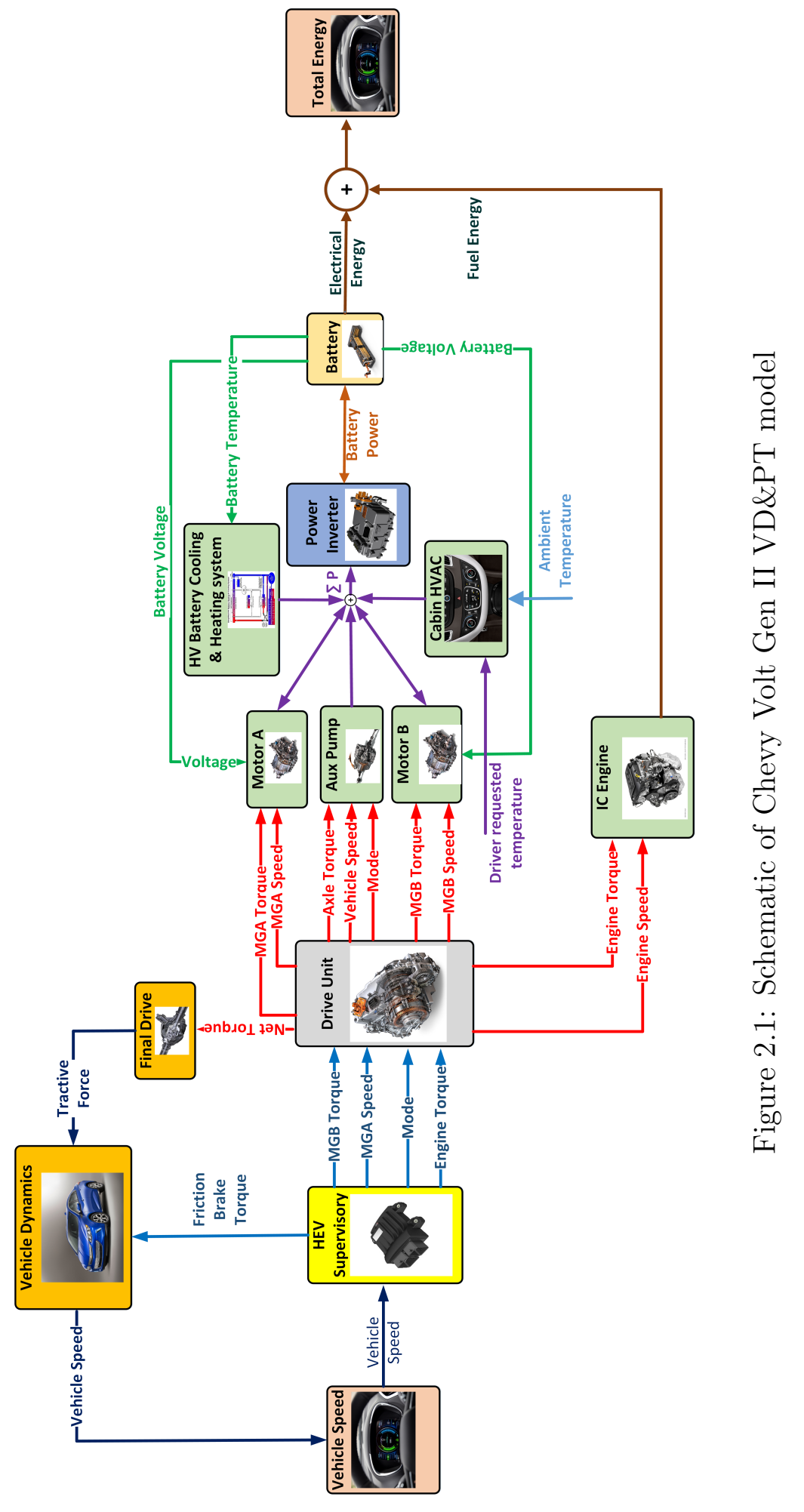


energy consumption,including both fuel and battery energy. This plant then gives out the net energy consumed, current battery SOC, vehicle velocity and engine speed which are then fed back to the controller with unity gain feedback. We focus on development of this controller subsystem.

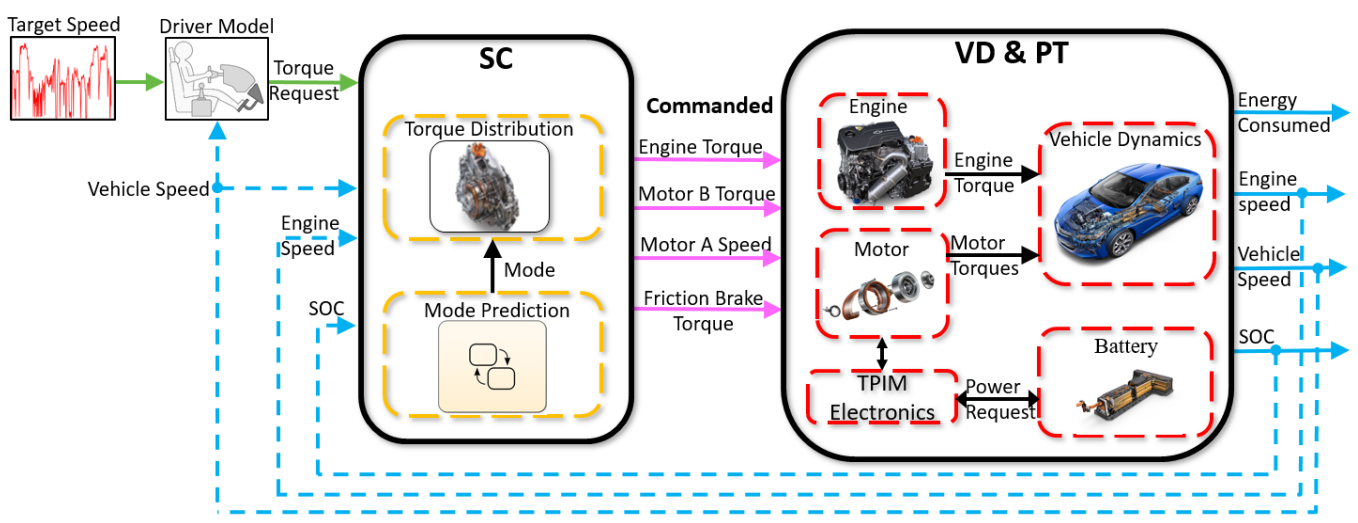

Figure 2.2: Fully predictive powertrain control layout

A more detailed layout of the HEV supervisory control is shown in Figure 2.3. As discussed earlier, the target speed and the actual speed of the vehicle gets compared in the PI control block which gives the required increase/decrease in the axle torque. This axle torque is then fed forward to the subsystems of the supervisory control as shown. There are three main subsystems ahead of PI control. The friction brake model, which calculates the friction brake torque required if the braking action demand more braking torque than the limit of regenerative braking available in the Chevy Volt Gen 2. This is controlled by the HEV supervisory controller.

In addition, there is vehicle drive mode selection model developed using SIMULINK 


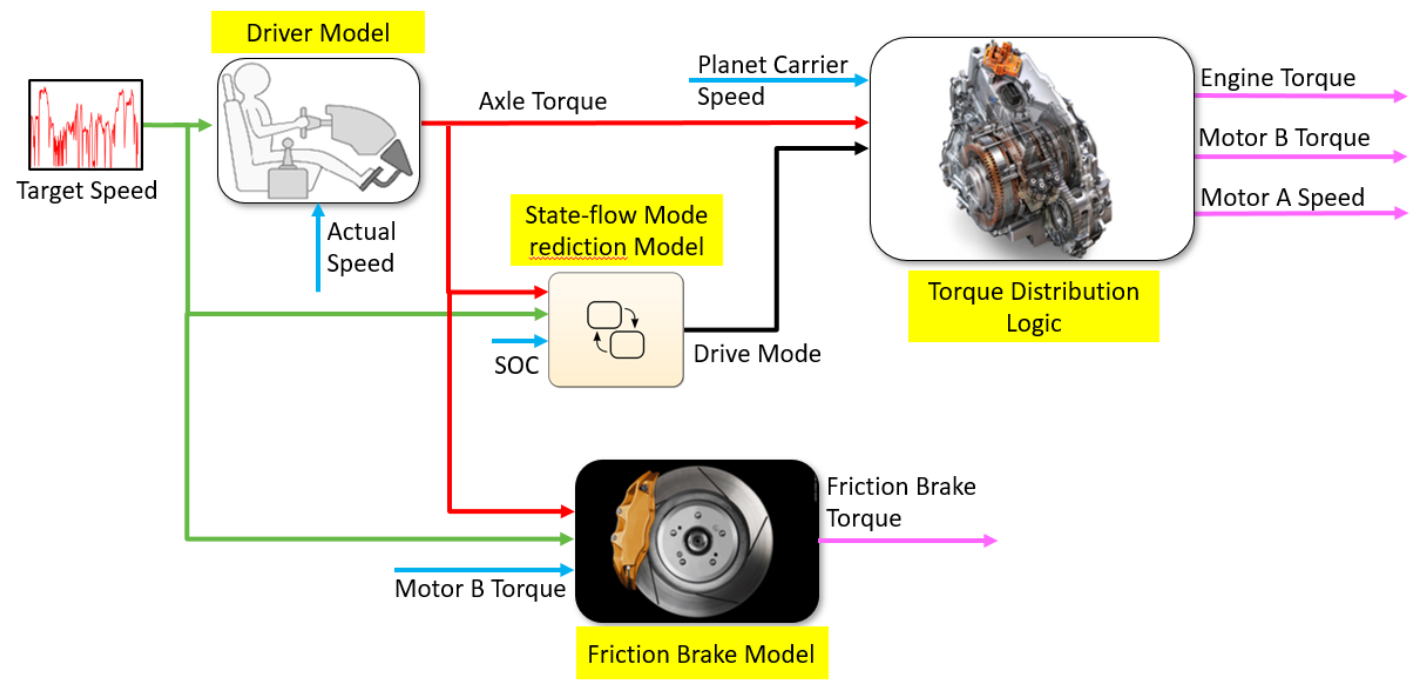

Figure 2.3: HEV supervisory control layout

State-flow (R. This subsystem takes in the axle torque request determined earlier, the target vehicle speed and the current vehicle battery SOC. A drive mode is determined and is then fed to the torque blending/distribution subsystem. Along with this, the requested axle torque, engine speed, the planet carrier speed of second planetary gear set are fed in the torque distribution subsystem where torque distribution based on the vehicle drive mode is decided and correspondingly, three outputs, engine torque, MGB torque, MGA speed are generated which are fed to the plant subsystem as shown in Figure 2.2. This subsystem is discussed in detail in the subsection below. 


\subsection{Load due to road gradient}

Previously, the model development process was conducted based on the ANL experimental test data where the ANL conducted these tests were conducted on a chassis dynamometer which does not introduce any road gradient effect. However, the tests conducted at Advanced Power Systems (APS) labs at Michigan Tech involved vehicle testing on actual road conditions rather than on a chassis dynamometer. To this end, it is imperative to include the effect of road gradient in the model in order to consider vehicle dynamics on hill/slope. Thus, a 1-D look-up table is developed which takes in the distance travelled by the vehicle and gives out the road gradient in radians.

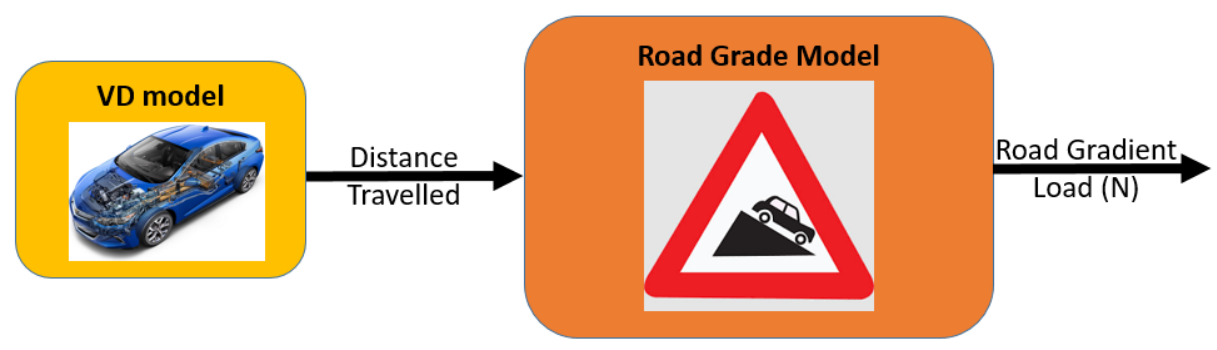

Figure 2.4: Road gradient load model

The road load due to gradient of the road is then calculated using the following equation:

$$
\operatorname{Load}_{\text {RoadGradient }}=m * g * \sin (\theta)
$$


where

$m=$ mass of the vehicle $(\mathrm{kg})$

$g=$ acceleration due to gravity $\left(\mathrm{m} / \mathrm{s}^{2}\right)$

$\theta=$ Road gradient in degrees

Now, the road grade model consists of a map created by the MTU experimental test data using the recorded latitude and longitude of the position of the vehicle along with the instantaneous distance travelled by the vehicle. The MTU drive cycle path is shown in 2.5. The road gradient profile for the MTU drive cycle is shown in Figure 2.6. This data is fed into the look-up table where we get the current road gradient based on the distance travelled by the vehicle. 


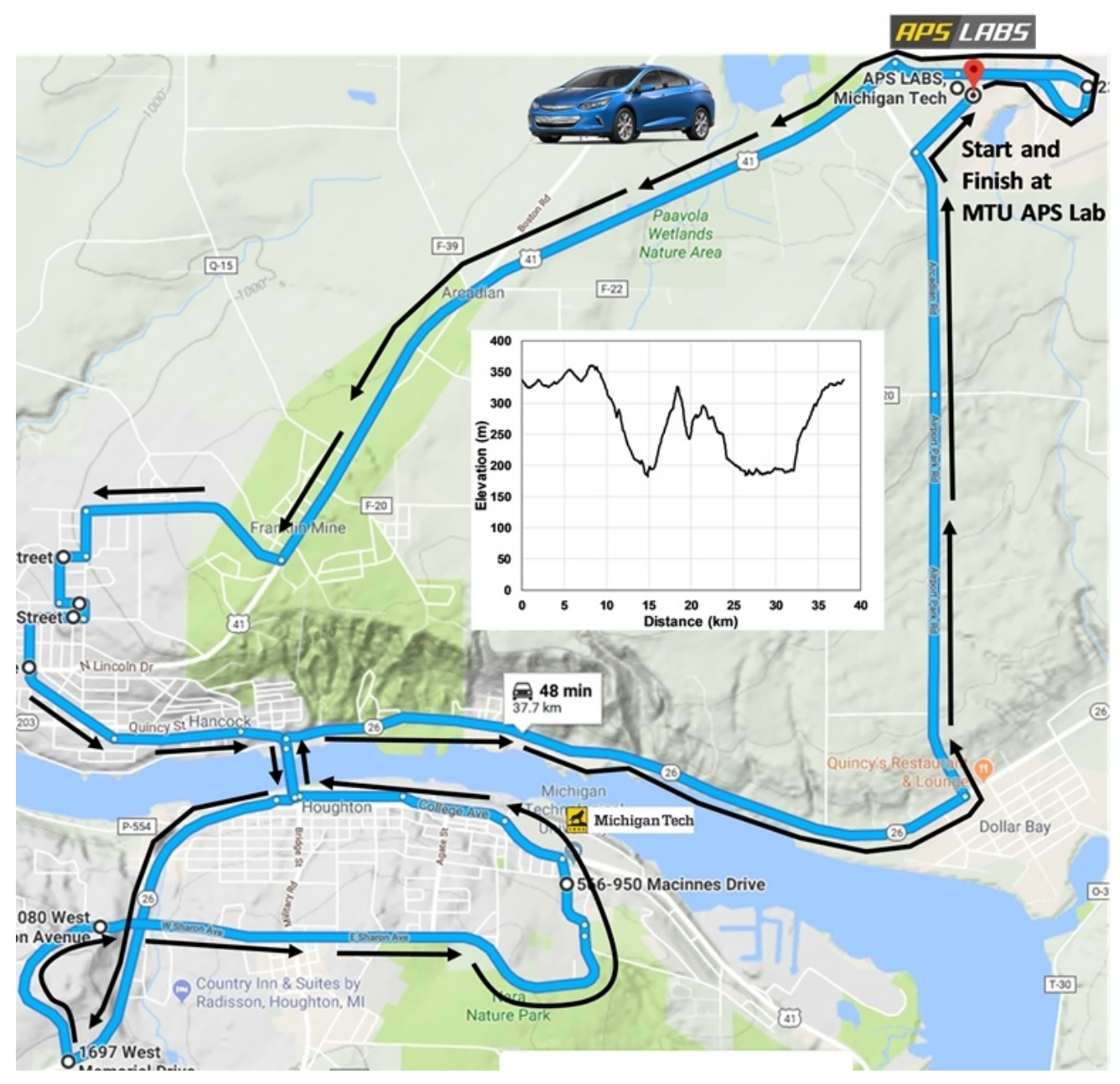

Figure 2.5: MTU drive cycle

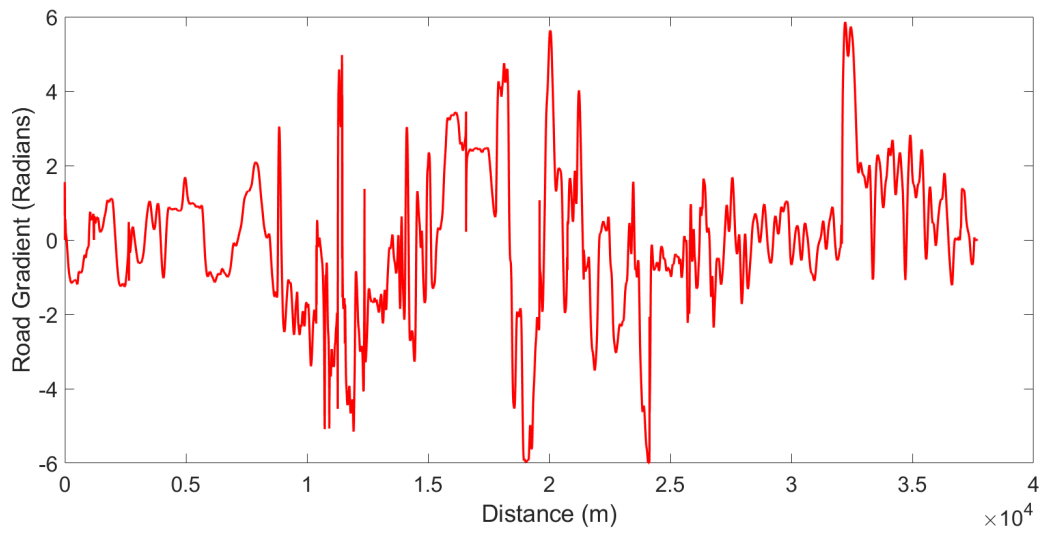

Figure 2.6: Road gradient profile for MTU drive cycle 


\subsection{Transmission spin loss model}

The transmission spin loss is induced due to resistance generated due to the presence of lubricating oil on gear and clutch faces. This can also include the energy loss due to the friction among various rotating parts in the transmission such as the bearing surfaces, gear mesh, seals and also due to churning of lubricating oil. Thus, to effectively calculate the total energy consumption, a 2-D look-up table is developed based on the data provided by GM on the Chevy Volt Gen II transmission.

The transmission spin loss, in general, is directly proportional to the rotational speed of the components of the transmission. Thus, the look-up table takes in the input and output speed in RPM of the transmission and determines the spin loss in $\mathrm{N}$ for the speeds (shown in Figure 2.7). This is then fed forward towards determination of the actual axle torque obtained.

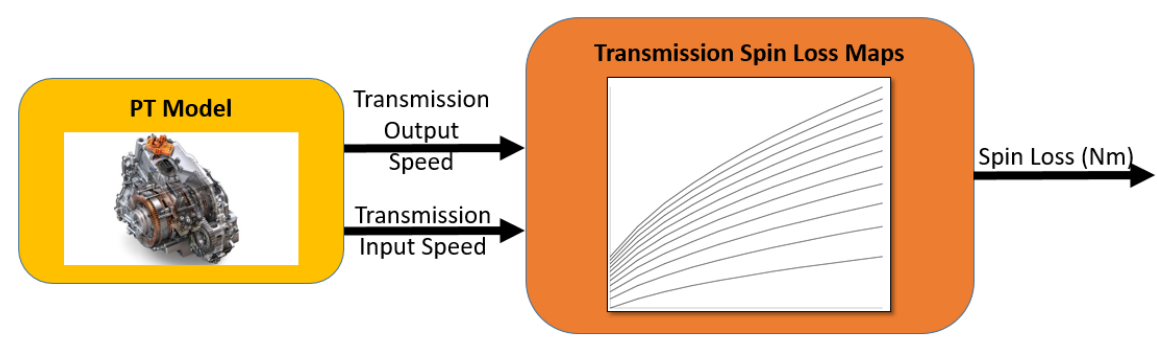

Figure 2.7: Transmission spin loss model 


\subsection{Friction Brake Model}

In PHEVs, due to the presence of electrical motors, during deceleration, the amount of energy that goes waste as heat can be recovered using the regenerative braking. But this system also has some limitations. One major limitation of regenerative braking is that it can not provide sufficient braking force in emergency situations i.e. when the rapid deceleration is demanded. In addition, it is limited by the energy storing capacity available at that moment and the motor output. Thus, in PHEVs, there is also the friction brakes as in conventional powered vehicle to supplement the regenerative braking. It is also designed to stop the vehicle by itself if the regenerative braking is not available.

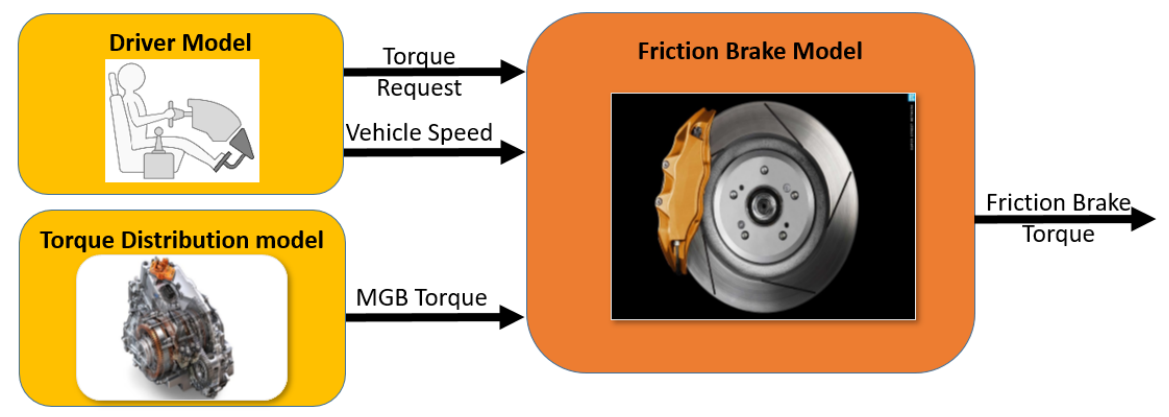

Figure 2.8: Friction brake model

The blending of the friction brakes and regenerative braking is decided by the powertrain controller. In Chevy Volt Gen 2, the MGB unit mostly caters to the regenerative braking operation. For the ease of modeling and to consider maximum efficiency of regenerative braking, it is considered that the MGB unit will provide the maximum 
possible braking and excess will be supplemented by the friction brakes. Figure 2.8 shows the model developed for estimating the required friction braking. It takes in the inputs, axle torque, vehicle speed from the driver model and the MGB torque from torque blending model and gives out friction brake torque based on following conditions

$$
\begin{gathered}
\text { if } v(k)-v(k-1)<0 \\
\text { friction brake torque }=\text { Axle Torque }-D R * M G B \text { Torque } \\
\text { else } \\
\text { friction brake torque }=0
\end{gathered}
$$

where

$v=$ vehicle speed

$k=$ index for time instants

$D R=$ Net drive ratio from MGB to the axle shafts 


\section{Powertrain Controller Modeling}

\subsection{Driver Model}

As the model is developed to work as a fully predictive model, computing total energy consumption and vehicle speed based on the target speed and road gradient, a driver model is needed to which will provide the required torque to accelerate or decelerate. The driver model thus, is affected by the target speed as well as a constant feedback of actual vehicle speed. By comparing the target speed and actual speed, the driver

decides to accelerate or decelerate the vehicle. Powell et. al. [16] developed a PI based driver model which generates vehicle acceleration or braking command based on the comparison of target and actual speed. There are various driver model developed based on the control inputs required as described in [17]. Since, the supervisory controller works on just one control input i.e. the torque request, the driver is required to perform a compensatory control task to match the actual speed to the target speed. Thus, this can be modelled using a simple PI control. This can also be considered as an implicit vehicle speed controller, with speed error associated with driver and PI capability to correct the speed error and thus to provide a necessary request of torque to the supervisory controller.

A particular set of PI gains can be correlated to a particular driving behavior, representing different levels of aggressive driving. A PI based driver model is developed as 
shown in Figure 3.1. The PI gains, the integral gain (Ki) and proportional gain (Kp) can be tuned to mimic driving behavior for different acceleration rates. This is discussed in Chapter 5. The target speed profile to be followed is fed to this model. The actual speed of the vehicle is then compared with target speed and the difference is fed to PI control. Thus, we get the axle torque request from the driver model which is fed to the drive mode selection model and the torque distribution algorithm to decide vehicle drive mode and the distribution of torque among three power sources.

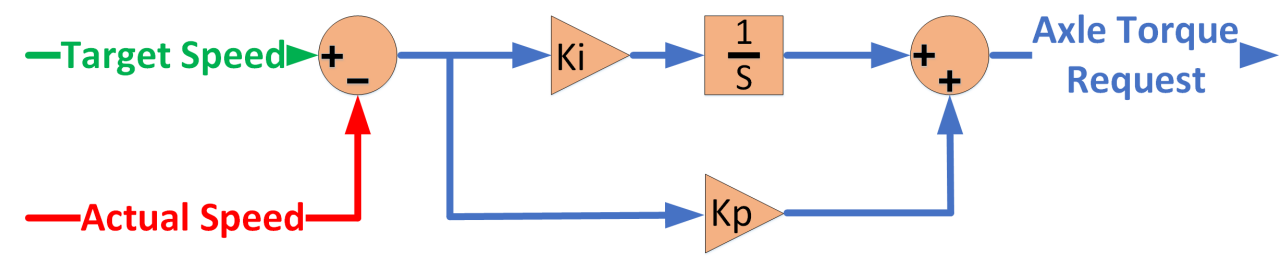

Figure 3.1: PI based driver model

\subsection{Vehicle drive modes}

This section discusses the modeling of the Chevy Volt's driving mode modeling. The first subsection gives a brief overview of how the vehicle drive modes works and the later sections are focused on the drive mode modeling. Figure 3.2 shows the volt's powertrain schematic. There are three power sources available to drive the vehicle. These three power sources are arranged together with the help of three clutches and two planetary gear sets as shown in Figure 3.2. The wheels are attached to the planet carrier of both planetary gear set 1 and 2 (named as PS1 and PS2). The ring of PS2 is 
connected to the sun of PS1 through a clutch 1. There is also clutch (named as clutch 2) to fix this ring gear to switch between different modes. A one way clutch is used to control the engine engagement during extended range operation. The motor units are connected to the Li-ion battery pack through Transmission Power Inverter Module (TPIM). Based on which clutches are engaged, different drive modes are activated.

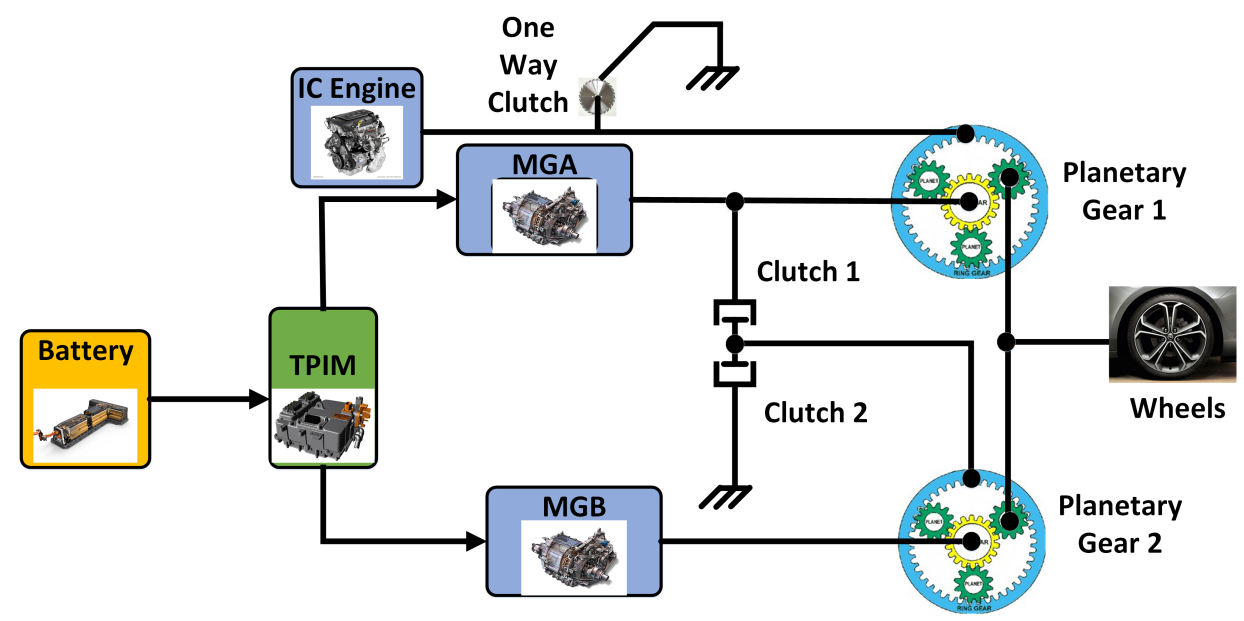

Figure 3.2: Chevy Volt Gen II vehicle powertrain layout

Figure 3.3 shows the one motor EV mode where in the MGB unit both propels and regenerates braking energy. Figure 3.4 shows the two motor EV mode where both MGA and MGB units work together to propel the vehicle when torque demands are high. Regenerative braking is done by MGB unit. Figure 3.5 shows the low extended range mode where the engine comes into the picture. Based on conditions, the ICE power is both used for propelling the vehicle and also to charge the batteries through MGA unit. MGB unit supplies excess power required and also does the regenerative braking. Figure 3.6 shows the fixed extended range mode power flow for 
the components. Here, the engine gets mechanically connected to the wheels and all the power of engine is sent to the wheels. The high extended range mode uses all the three power sources to propel the vehicle as shown in Figure 3.7 with a compound powersplit operation of engine power.

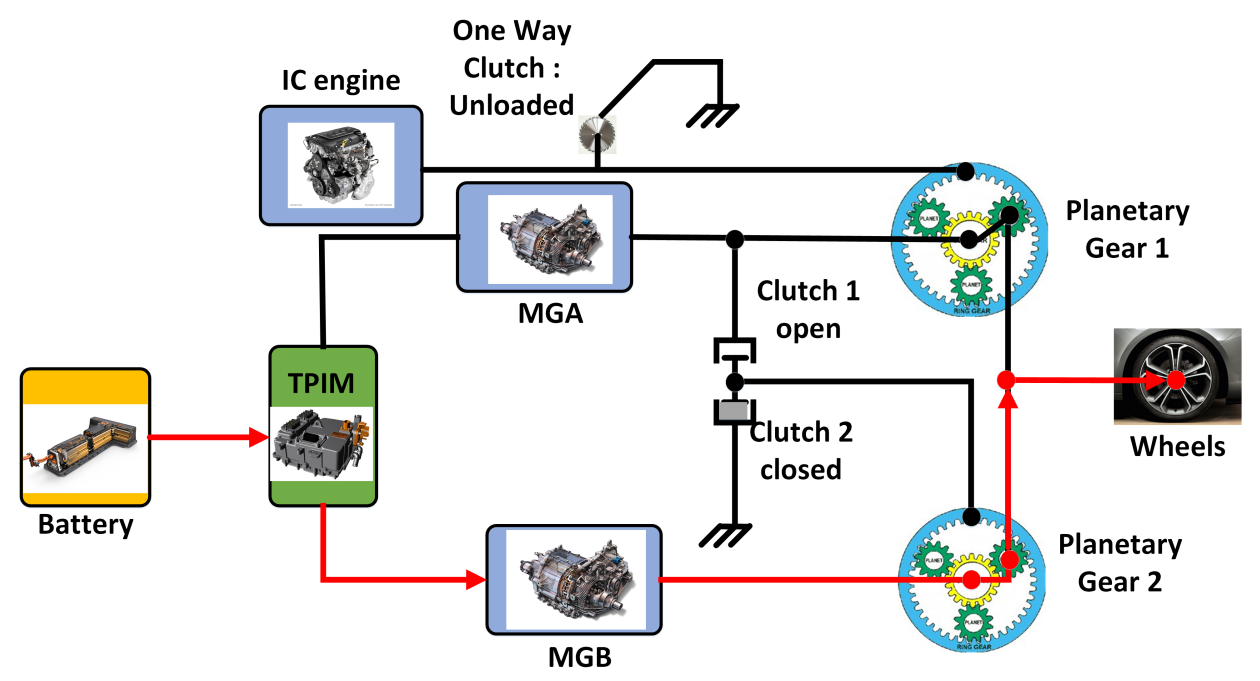

Figure 3.3: Chevy Volt Gen II - One Motor EV (1EV)

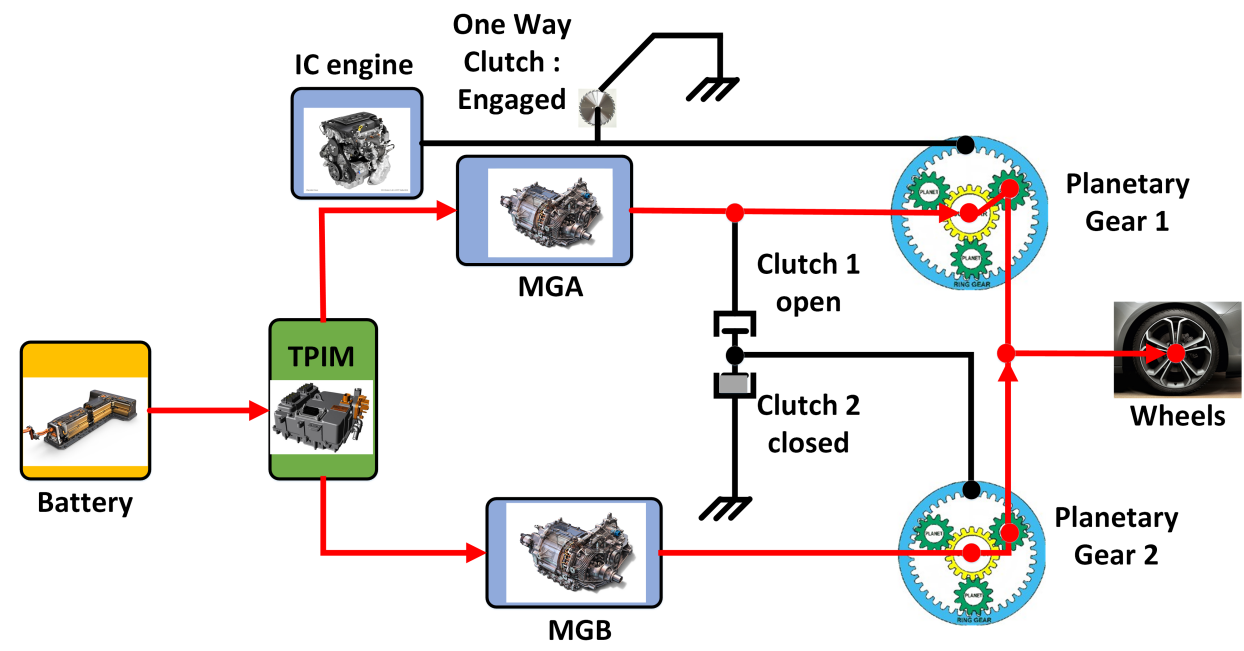

Figure 3.4: Chevy Volt Gen II - Two Motor EV (2EV) 


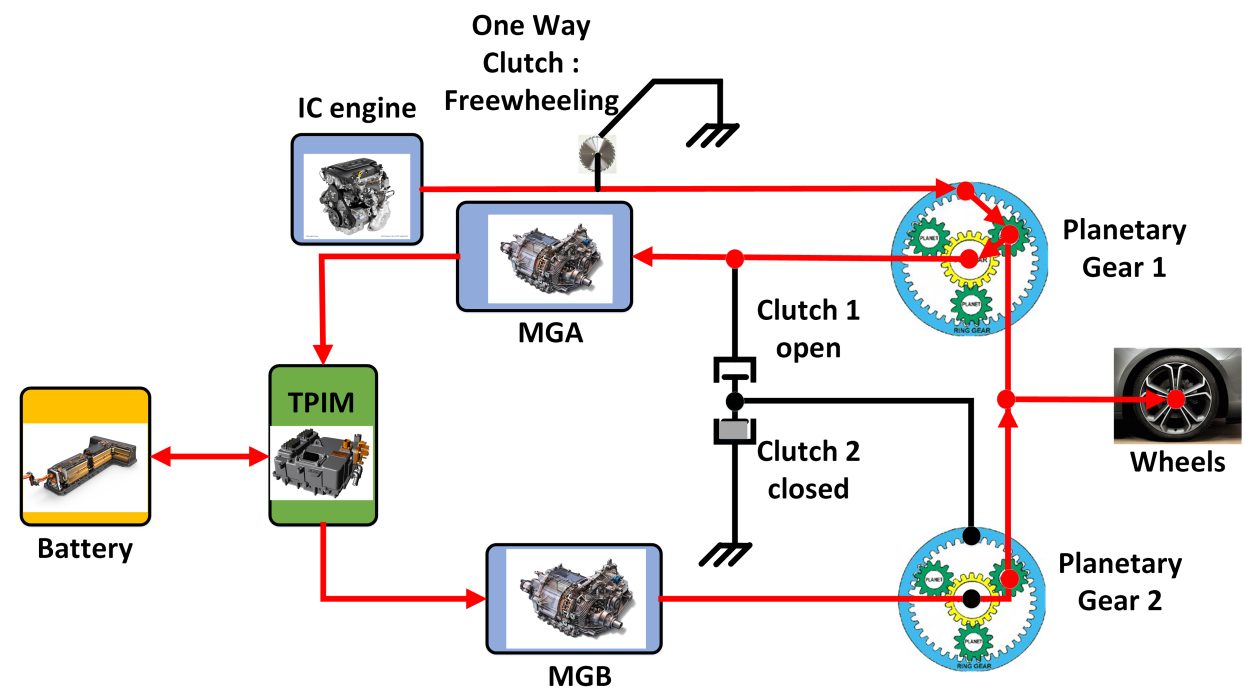

Figure 3.5: Chevy Volt Gen II - Low Extended Range (LER)

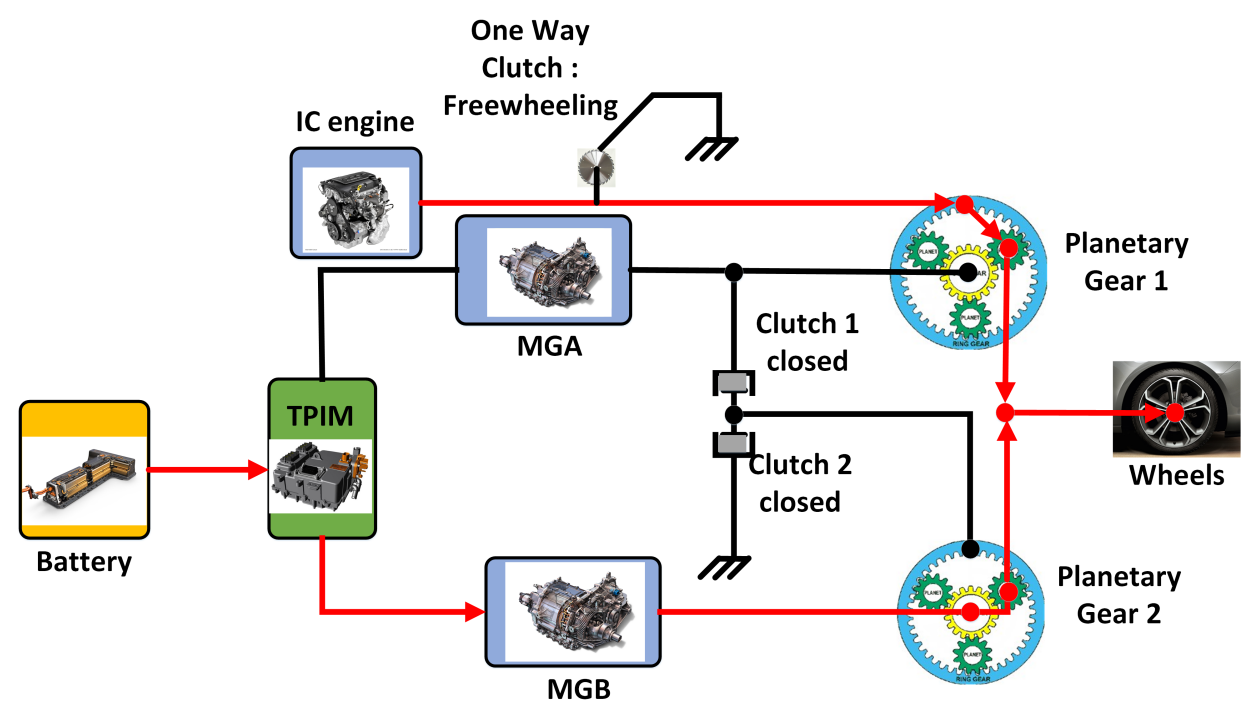

Figure 3.6: Chevy Volt Gen II - Fixed Extended Range (FER) 


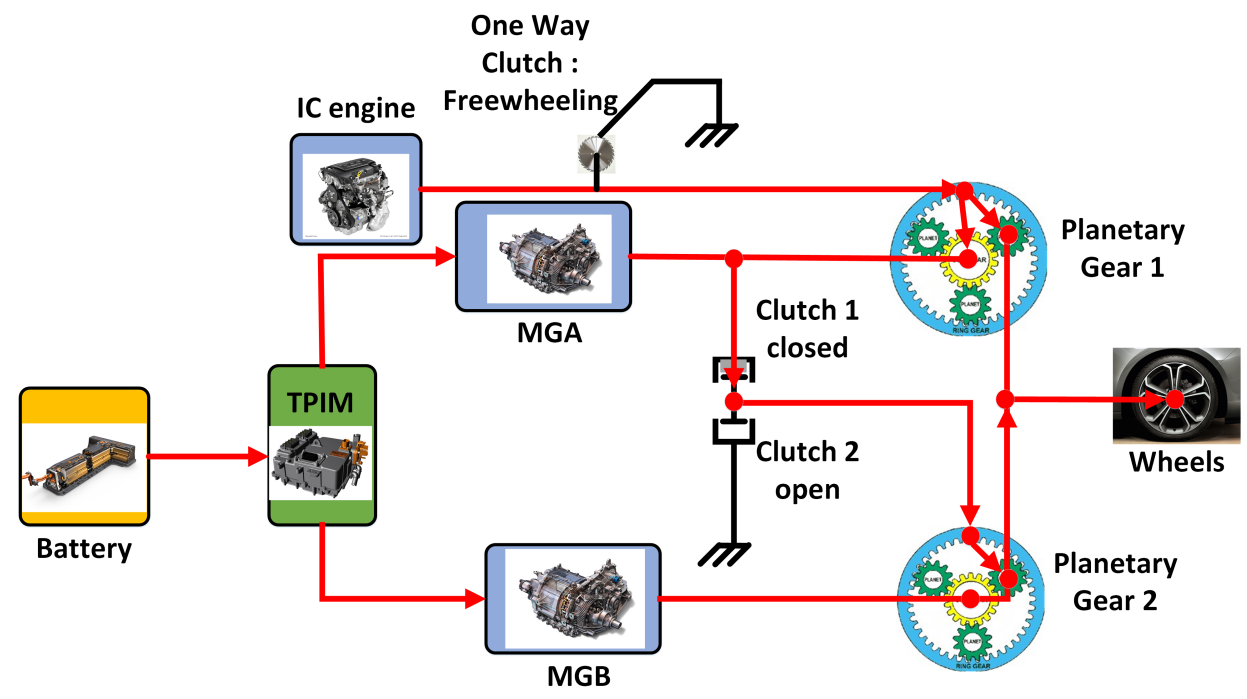

Figure 3.7: Chevy Volt Gen II - High Extended Range (HER)

\subsection{State-flow approach for drive modes modeling}

As discussed before, the Chevy Volt has a total of five driving modes, two EV modes and three range extender modes. Since, the powertrain controller is developed for charge sustaining (CS) case, focus is mostly on the range extender modes.

Two ways of modeling drive modes were considered, one with function fitting Neural Network and another with state-flow modeling with SIMULINK. The state-flow model developed is based on the 2-D map created using the ANL experimental data.

Figure 3.8 shows the vehicle speed and axle torque points based on the driving modes for three US driving schedule namely, UDDS, US06 and HWFET drive cycles, which almost covers vehicle city and highway cruising operations. It is clear that there are 


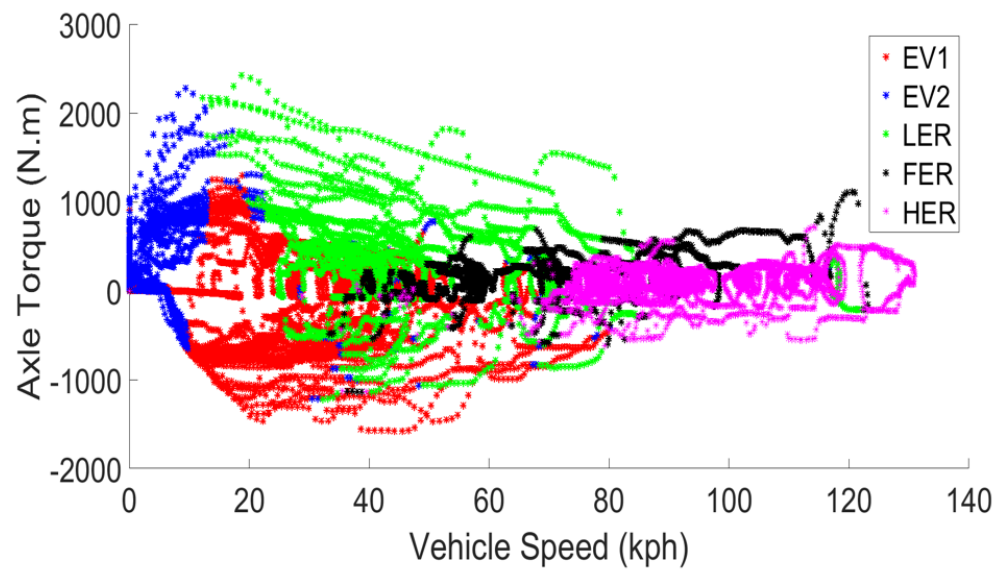

Figure 3.8: Vehicle operating points based on drive mode

specific regions in which the vehicle operates. Taking this as initial point of detecting the vehicle driving mode, these regions were extracted and a map is created which provides vehicle drive mode based on the vehicle speed and the axle torque requested as shown in Figure 3.9.

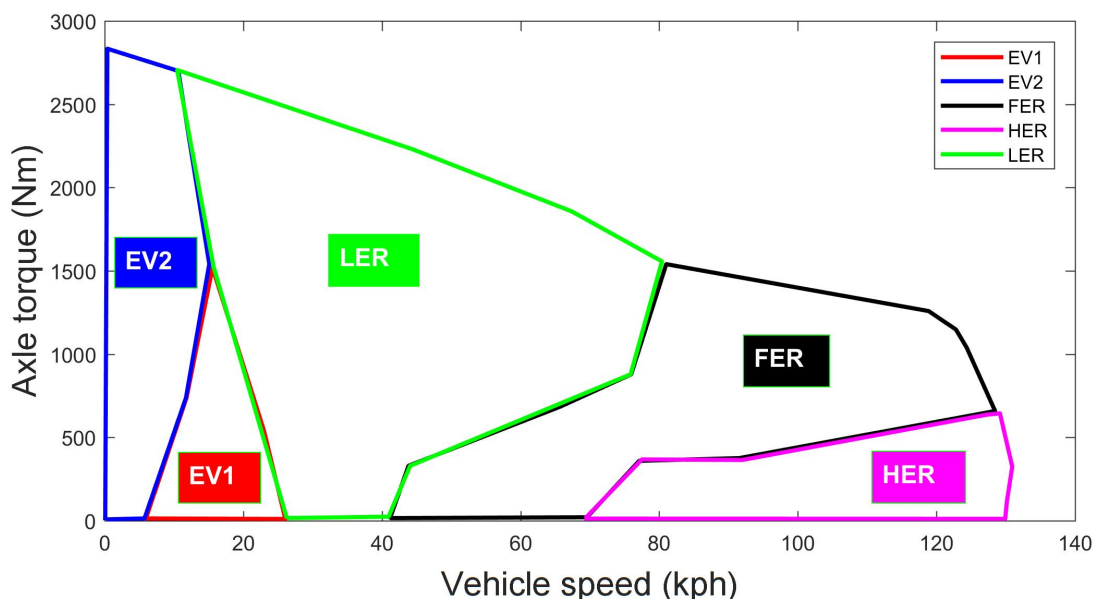

Figure 3.9: Regions extracted from the vehicle operating point for each driving mode 
Now, as Figure 3.8 shows that these regions are not completely separated from each other. The points of one driving mode being present in the region of another suggest that there should be a hysteresis between mode transition. This means that when the vehicle goes from, say, LER mode to FER mode, there should be a time period where this change happens and during which the vehicle still operates in the previous mode i.e. LER. This also explains the inertia of the clutches and hydraulic system that operates them. Thus, it is important to accommodate this hysteresis in order to properly model the driving modes. Based on this, states were decided, five driving modes and six transition states between these five states which incorporate the time hysteresis.

Figure 3.10 shows the vehicle drive mode selection flow chart during acceleration. As stated earlier, there are transition states where a particular drive mode runs a little longer before changing to the next mode. The method of introducing hysteresis is also kept in place for vehicle deceleration since it is undesirable to suddenly change the modes as it may happen that driver will accelerate again. In Figures 3.10 and 3.11, the purple blocks are the vehicle drive modes, green parallelogram block is the vehicle speed and axle torque input to the algorithm, red blocks are the decision parameters, and finally, the dark green blocks represents the state transition blocks. The two algorithms are shown separately for ease of understanding but actually these algorithms work simultaneously in the model. 


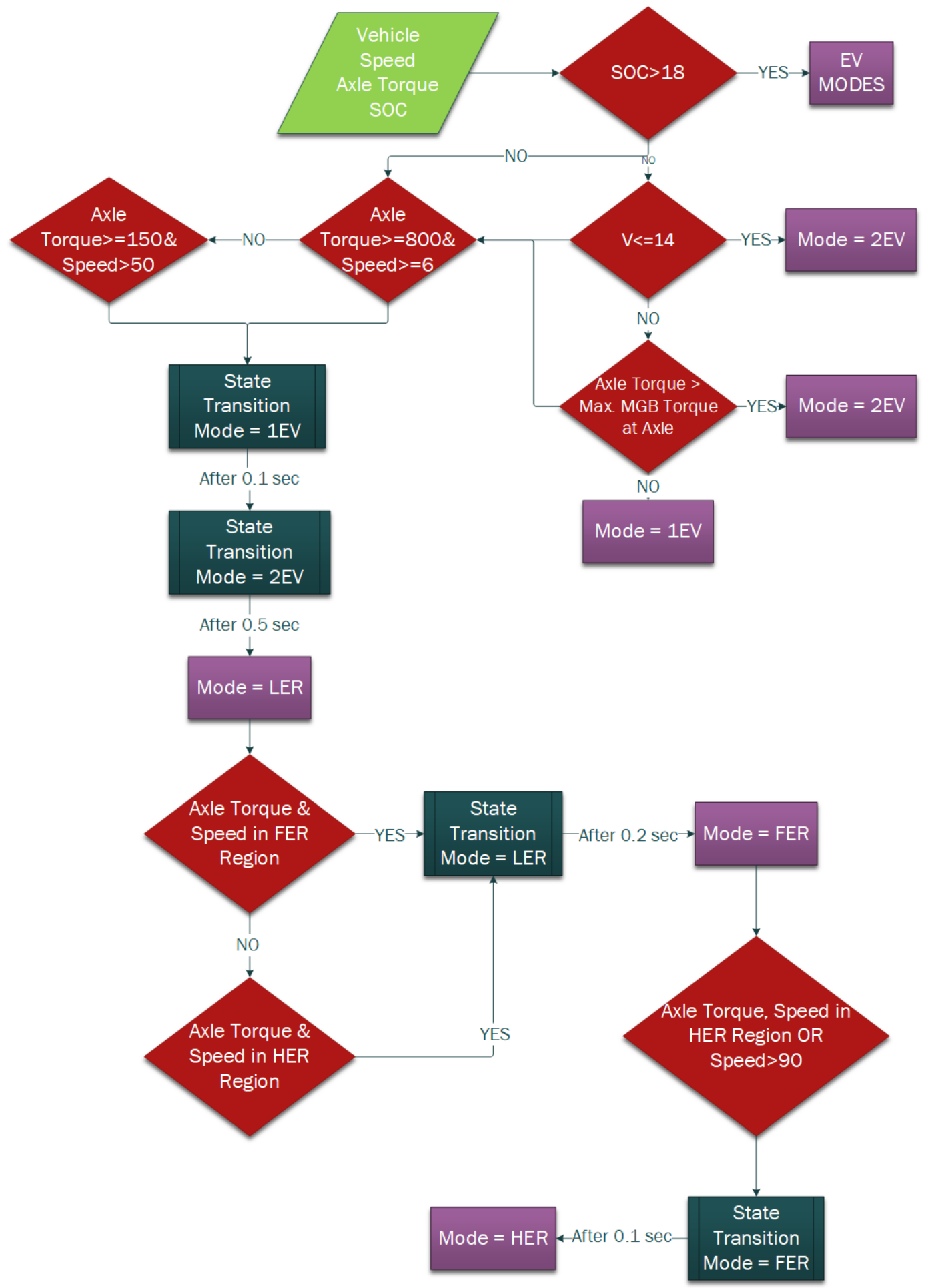

Figure 3.10: State-flow chart for drive mode selection during vehicle acceleration 


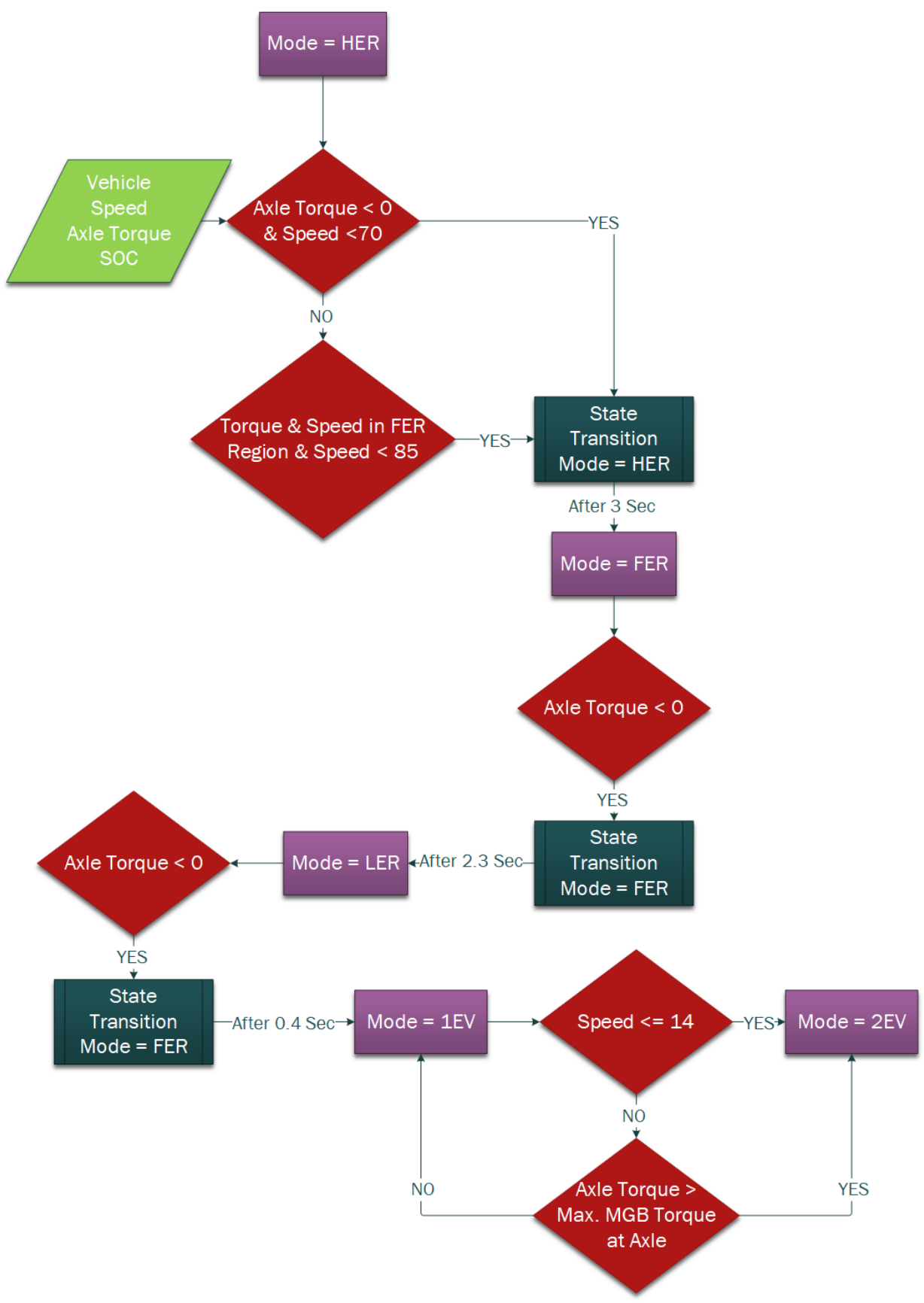

Figure 3.11: State-flow chart for drive mode selection during vehicle deceleration 
Let's first consider the vehicle drive mode selection during acceleration as shown in Figure 3.10. The inputs are the vehicle speed, axle torque and the battery SOC. In general, it was found that the vehicle stays in charge depletion (CD) operation until the SOC dips below $18 \%$. Now, once the SOC is below $18 \%$, the charge sustaining (CS) operation of the vehicle starts.

- It was found in the tests conducted by ANL that the vehicle always start in CD mode irrespective of the battery SOC. So, first the vehicle speed is checked and if the vehicle speed is below $14 \mathrm{kph}, 2 \mathrm{EV}$ mode will be selected.

- Along with increase in speed axle torque is checked whether driver demand is high or not. If the driver demand is high, the $2 \mathrm{EV}$ mode is dropped and vehicle drive modes gets to first range extender mode i.e. LER through a state transition modes as shown. This is in conformance with what the researchers at ANL found.

- Now, the regions we discussed comes into picture to select the other range extender modes. During the vehicle operation in LER mode, the algorithm continuously checked if the vehicle operating points enter the FER and HER modes along with their duration of operating in these regions. This is very important in order to avoid drive mode chattering which may lead to unrealistic model.

- Once the above condition is satisfied again the state transition mode is activated 
in which vehicle continues to run as in LER mode until the clutch states has changed and we get FER mode at first irrespective of which region the vehicle started operating in (FER or HER).

- Even when vehicle is operating in FER now, the vehicle operating point is still being checked. If the initial trigger of the change in drive mode was due to HER region or the vehicle speed has reached above $90 \mathrm{kph}$, the vehicle quickly leaves the FER mode and moves into HER mode again through a state transition as shown in Figure 3.10.

Now, the Figure 3.11 discusses the algorithm during vehicle deceleration. This works relatively similar to the algorithm during acceleration.

- Consider that the vehicle is cruising on highway and is in HER mode, the algorithm simply checks here for negative axle torque or the braking torque as well as if the vehicle speed has dropped below $70 \mathrm{kph}$. This is again to avoid vehicle mode chattering. Along with this, it also checks if the vehicle operating points are in FER mode or not. Once any of the above conditions is triggered, the vehicle goes into state transition and then after a moment attains FER drive mode.

- If the vehicle goes on decelerating, the drive modes goes on changing from FER till EV modes with the state transitions in between to account for time hysteresis as shown in Figure 3.11. 
Table 3.1: Mode transition hysteresis for the vehicle drive mode shift

\begin{tabular}{|c|c|c|c|}
\hline Mode Transition & Time (s) & Mode Transition & Time (s) \\
\hline 1EV-2EV & 0.3 & 2EV-1EV & 0.2 \\
\hline 2EV-LER & 0.6 & LER-2EV & 2.2 \\
\hline LER-FER & 0.2 & FER-LER & 2.3 \\
\hline FER-HER & 0.1 & HER-FER & 2 \\
\hline
\end{tabular}

The mode transition hysteresis times for all possible mode shifts are shown in Table 3.1. The values are obtained after analyzing experimental data.

\subsection{Artificial Neural Network (ANN) design for drive modes prediction}

Another way of modeling the vehicle drive modes in predictive way is by using the artificial neural network. Figure 3.12 shows the architecture used to identify the drive modes based on six inputs. There are more inputs to this neural network than to the state-flow model. Along with Axle torque, vehicle speed and battery SOC, the model uses the vehicle acceleration, battery power and the mode that was in simulation during previous time step.

It is comprised of four fully connected layers, with input and output layers and two hidden layers. The neural network was trained on ANL test cycle data, $70 \%$ of the 
data was used for training, $15 \%$ for validation and the remaining $15 \%$ for testing.

Figures 3.13 and 3.14 show the performance of the ANN during training in terms of confusion charts.

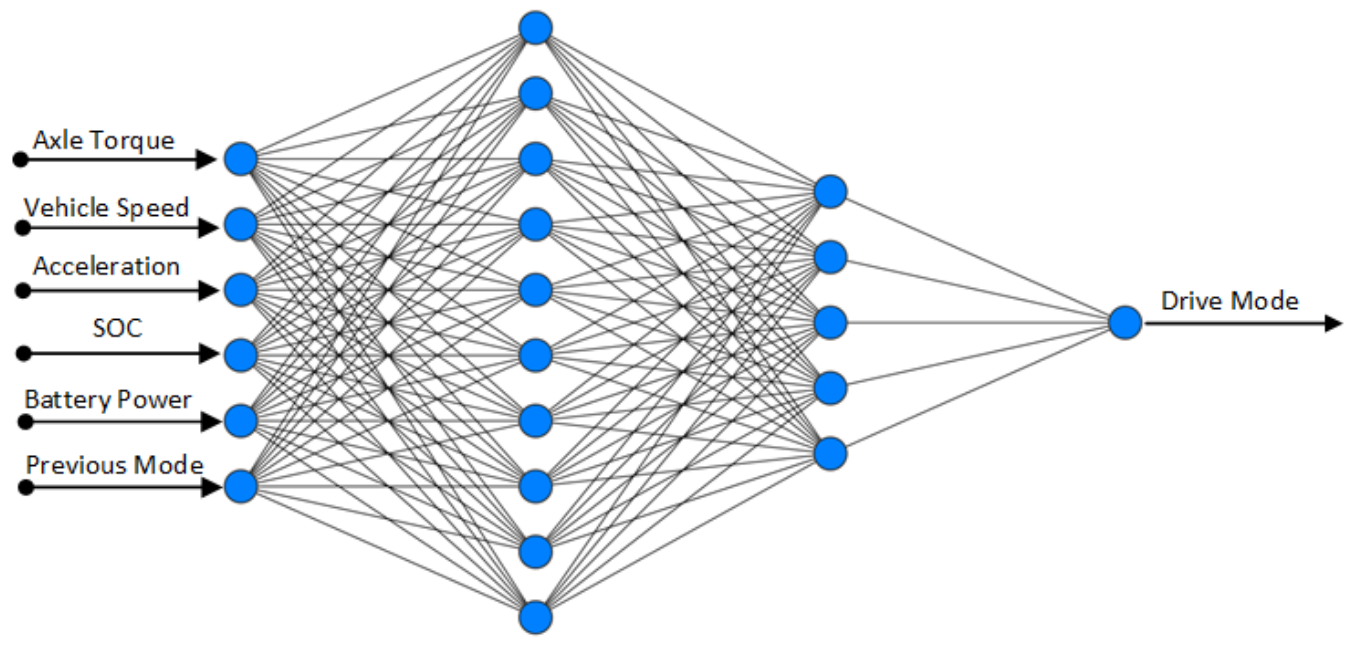

Figure 3.12: ANN model for predicting vehicle drive mode

\begin{tabular}{|c|c|c|c|c|c|c|}
\hline \multicolumn{2}{|c|}{$\begin{array}{c}\text { Training Accuracy } \\
99.3 \%\end{array}$} & \multicolumn{6}{|c|}{ True Class } \\
\hline \multirow{4}{*}{$\begin{array}{c}\text { Predicted } \\
\text { Class }\end{array}$} & & $1 E V$ & $2 E V$ & LER & FER & HER \\
\cline { 2 - 7 } & $1 \mathrm{EV}$ & 10386 & 31 & 1 & 0 & 0 \\
\cline { 2 - 7 } & $2 \mathrm{EV}$ & 34 & 1157 & 19 & 0 & 0 \\
\cline { 2 - 8 } & LER & 4 & 8 & 2114 & 12 & 4 \\
\cline { 2 - 7 } & FER & 5 & 8 & 16 & 2694 & 8 \\
\cline { 2 - 8 } & HER & 0 & 0 & 0 & 2 & 5585 \\
\hline
\end{tabular}

Figure 3.13: Confusion matrix for validation data

A net accuracy of $99.3 \%$ was obtained during the training process as shown in Figures 3.13 and 3.14. Though, this neural network was very much effective in accurately predicting the vehicle drive modes, it was not incorporated in the final HEV supervisory control model due to following reasons: 


\begin{tabular}{|c|c|c|c|c|c|c|}
\hline $\begin{array}{c}\text { Validation Accuracy } \\
99.3 \%\end{array}$ & \multicolumn{5}{|c|}{ True Class } \\
\hline \multirow{4}{*}{$\begin{array}{c}\text { Predicted } \\
\text { Class }\end{array}$} & & $1 E V$ & $2 E V$ & LER & FER & HER \\
\cline { 2 - 8 } & 1EV & 10445 & 22 & 0 & 0 & 0 \\
\cline { 2 - 8 } & 2EV & 43 & 1154 & 10 & 1 & 1 \\
\cline { 2 - 8 } & LER & 5 & 16 & 2143 & 19 & 0 \\
\cline { 2 - 8 } & FER & 3 & 6 & 16 & 2726 & 7 \\
\cline { 2 - 8 } & HER & 0 & 0 & 0 & 0 & 5471 \\
\hline
\end{tabular}

Figure 3.14: Confusion matrix for test data

- It was expected that the drive mode selection model should only use three inputs namely, the axle torque, vehicle speed and the battery SOC. When the model was restricted to these inputs, the prediction accuracy drastically decreased with increased mode chattering.

- In addition, the ANN model with reduced number of inputs required to have the time hysteresis which is an essential term to remove mode chattering. It was found that it is very difficult to accommodate the time hysteresis within the designed ANN.

- Therefore, the results in this report are based on the state-flow approach (section 3.4) to predict vehicle drive mode. 


\subsection{Charge sustaining (CS) torque distribution model}

As shown in Figure 2.3, once the vehicle drive mode is decided, the next thing to control is the torque blending among the three power sources. Now, the Volt's HEV supervisory controller contains hundreds and thousands of look-up tables and logic to control the torque blending. Identifying each of these relations using the available experimental data is out of scope of this report. A great amount of effort is taken to mimic the vehicle performance in terms of net energy consumption with the use of just enough control logics required to achieve it. Also, due to the unique powersplit configuration of the Volt's powertrain, it is also difficult to get speed and torque relationships among three power sources since all of them may not necessarily be in constant mechanical constraint. Using the available literature on the Chevy Volt gen II and test data conducted at MTU APSRC and at ANL, various torque blending relationships are identified.

A PI controller is used to achieve the target vehicle speed. Figures 3.15 and 3.16 show the torque blending flowcharts during vehicle acceleration and deceleration respectively. The control logic is described for each situation. The vehicle drive mode is already selected and the logic is based on the mode in which the vehicle is currently running.

- The inputs to this system are vehicle speed, drive mode, axle torque request, SOC, power demand, planet carrier speed of the second planetary gear-set, 
maximum MGB torque available at axle and engine speed.

- If the vehicle is in $1 \mathrm{EV}$ mode, only MGB unit supports the power demand. both engine and MGA unit are not in use.

- If the vehicle is in $2 \mathrm{EV}$ mode, the torque distribution between two motors depends on the vehicle speed. If the speed is low i.e. around $30 \mathrm{kph}$ or less, the torque is distributed based on ratio of 90:10, i.e. $90 \%$ of the torque demand is catered by MGB unit and the rest by the MGA unit.

- If the speed is higher then the torque distribution is based on the maximum MGB torque availability and the again, the rest is supplied by MGA unit. There is no constant torque distribution ratio in this case.

- For the vehicle in LER mode, the first range extender mode, the torque distribution is based on the actual vehicle power demand. In addition, the engine power changes based on the SOC of the battery. The engine power demand is always kept in efficient BSFC. A 1D look-up table taking engine speed as inputs gives out the efficient power demand for the engine based on the BSFC data is calculated. The power demand is basically divided into three categories, viz. demand less than $20 \mathrm{~kW}$, between 20 and $35 \mathrm{~kW}$, greater than $35 \mathrm{~kW}$. Based on this, the engine power demand changes and the rest of the demand or excess energy is supplied or captured by MGB unit. MGA unit in this is mostly required to control the engine speed. 
- Mode FER, as discussed earlier, mechanically connects the engine to the axle. The experimental data showed that in the FER mode, the vehicle maintained a constant engine torque around $110 \mathrm{Nm}$. Thus, engine torque is maintained at this torque and the rest of the demand or the excess energy is catered by MGB unit. MGA Unit is not in use during this drive mode.

- In drive mode HER, the logic first checks the torque demand. If the torque demand is high, the vehicle takes more power from the engine and the rest/excess energy is controlled by MGB unit, while MGA unit here also helps in charging the battery based on the energy availability. Since a good amount of algorithms here are possible based on SOC, torque demand etc, a simplest and mostly observed case is used here which takes the SOC bounds to be less or greater than $14 \%$. 


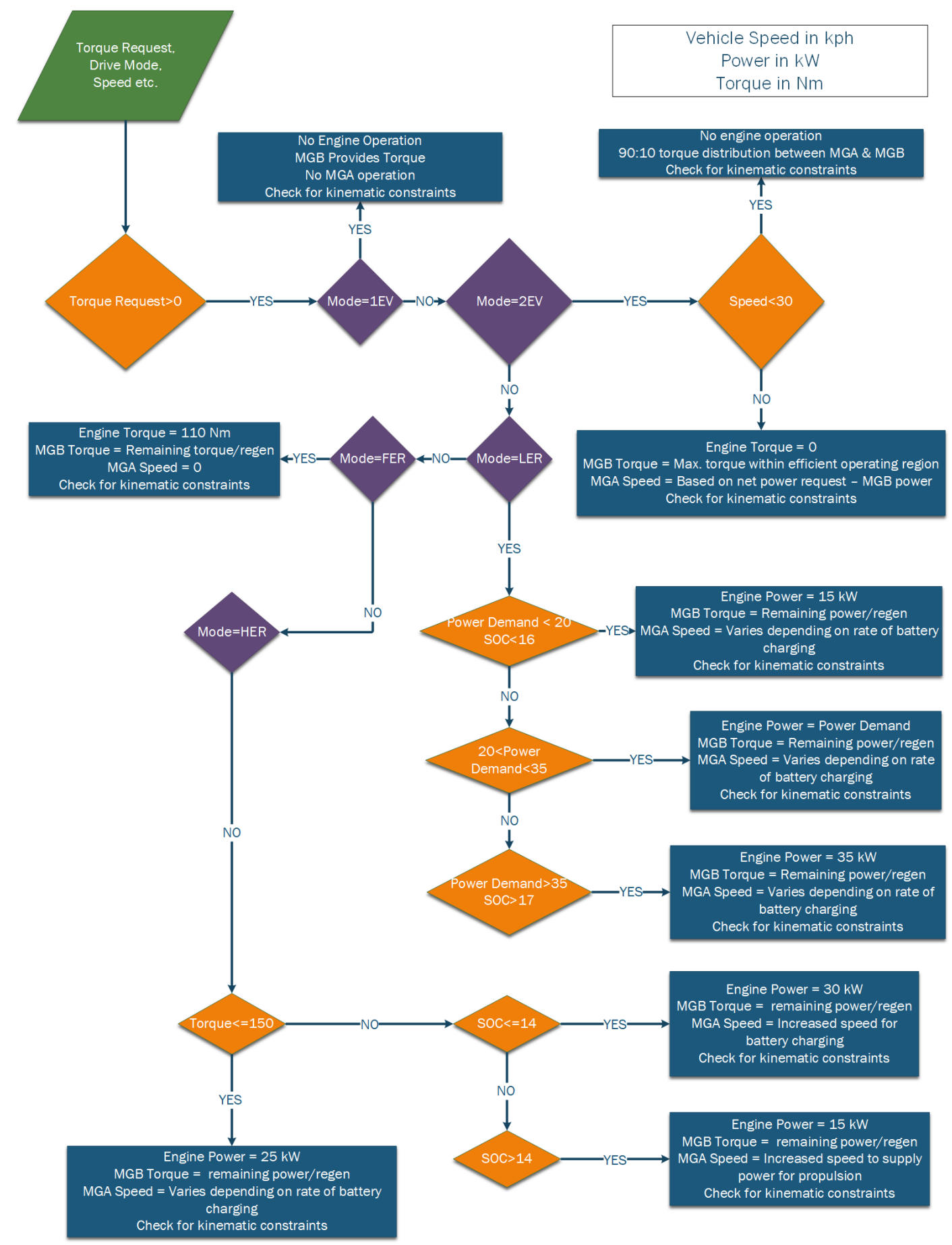

Figure 3.15: Flow chart for torque blending logic during vehicle acceleration 
The logic behind vehicle deceleration is comparatively simple since our main focus is to regenerate as much of battery energy as possible. Figure 3.16 shows the logic for torque distribution during vehicle deceleration.

- The inputs to the system are same. If the vehicle is in $1 \mathrm{EV}$ or $2 \mathrm{EV}$ mode, the MGB unit regenerates the braking energy mostly.

- Now, it is important that the engine on/off should be controlled in the most efficient manner because the start/stop can cause a good amount of fuel energy loss which occurs as the engine start-up penalty, catalyst light-off and engine coolant penalty, etc. Thus, in range extender modes, if the vehicle speed is higher i.e. greater than $40 \mathrm{kph}$, it is best to keep the engine running and not to cut the fuel even if the vehicle is decelerating because it may happen that driver will demand the power again and not completely stopping the vehicle.

- Therefore, based on which mode is operating, either the engine power or engine torque is maintained which is used as energy for charging battery along with the regeneration.

- If the vehicle speed is lower than $40 \mathrm{kph}$ during deceleration, the engine is totally turned off by cutting the fuel supply, but the MGA unit controls its speed to keep the engine rotating idle for to save fuel energy if the vehicle requires the engine back in action. 


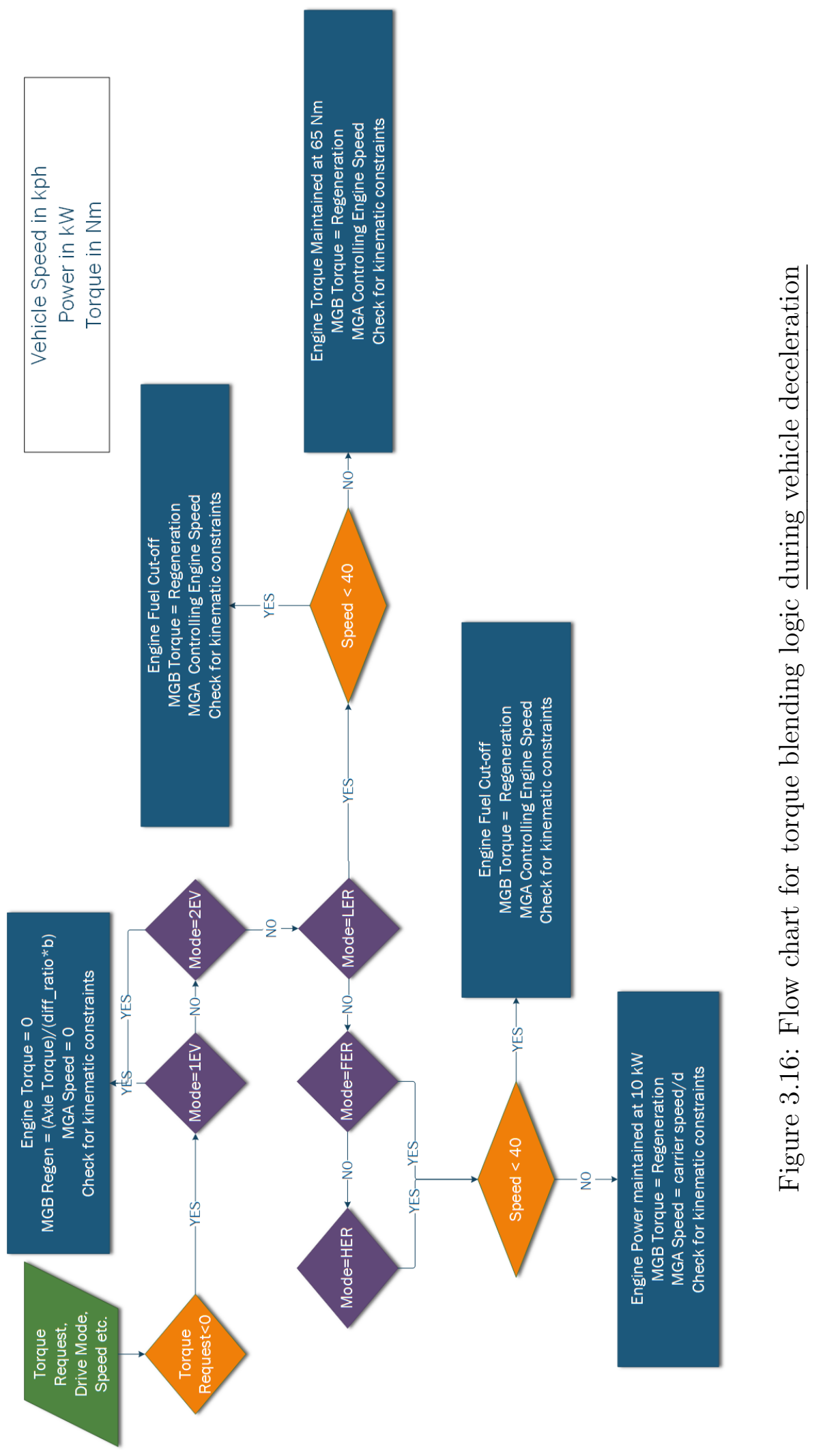




\section{Model Validation}

This section discusses the model validation for standard drive cycles as well as the MTU drive cycle. The model is validated based on the total energy consumption comparison with the simulation and the experimental test data from ANL and data collected by MTU NEXTCAR team. The target of the simulation i.e. the HEV powertrain controller to get the total energy consumption within $5 \%$ that of experimental data. This is required to attain high fidelity for simulation model.

\subsection{Standard FTP Drive cycles}

Figures 4.1, 4.2 and 4.3 show total powertrain model validation including the HEV supervisory controller for standard FTP drive cycles. The controller was able to track the target velocity profile very closely with maximum average error in velocity being under one kph. Now, since CS mode uses all the three available power sources simultaneously, it is a difficult task to analyze and detect all the control logics used by the vehicle. Thus, target here was to get as close to the vehicle performance as possible in terms of total energy consumption. The errors for UDDS \& HWFET drive cycles is much lower as compared to the error for US06 cycle. The major difference here is the HER mode operation of vehicle. The HER mode is a highway cruising mode which utilizes all the power sources which works in very different way and contains higher number of logics which are difficult to identically reproduce. 


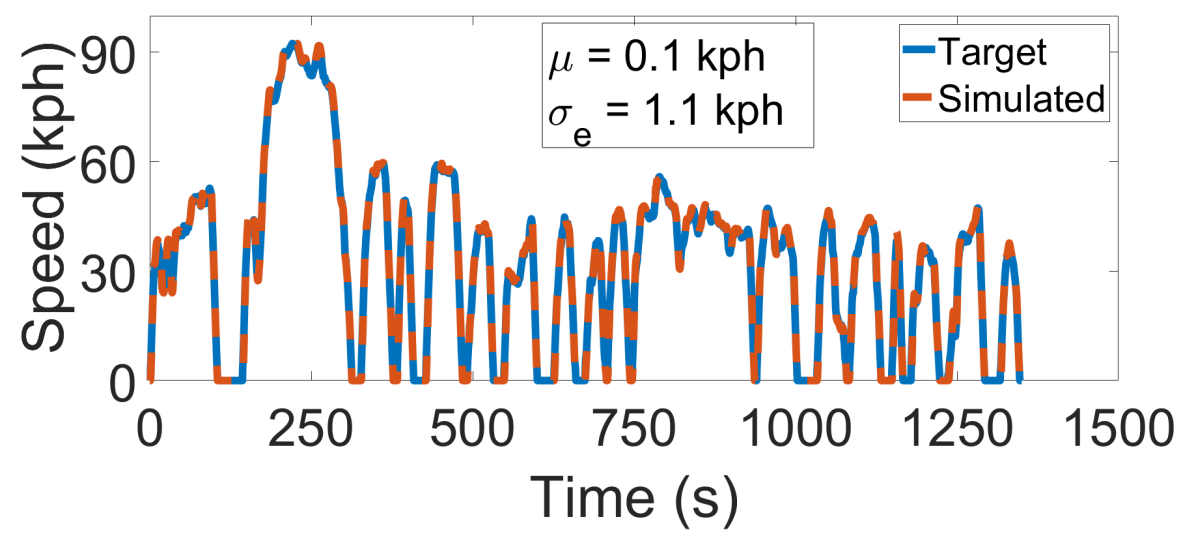

(a) Validation of vehicle speed

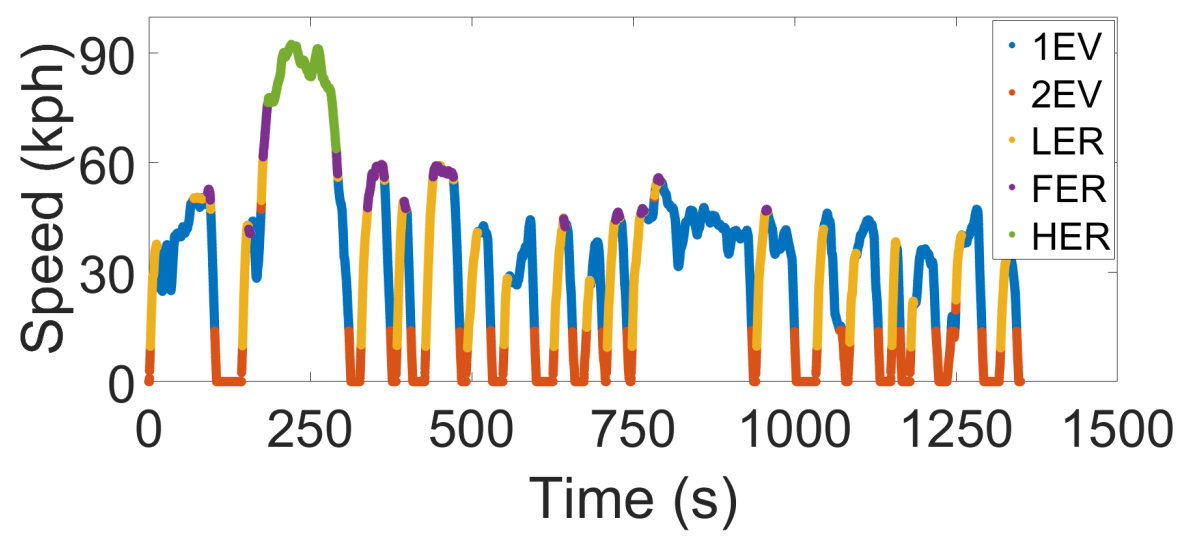

(b) Vehicle drive modes during simulation

Figure 4.1: Validation of control model for UDDS CS drive cycle using ANL Data ( $\epsilon=$ average error, $\sigma_{e}=$ standard deviation of error). See Appendix A (Filename: 61607020.mat) for details of experimental data 


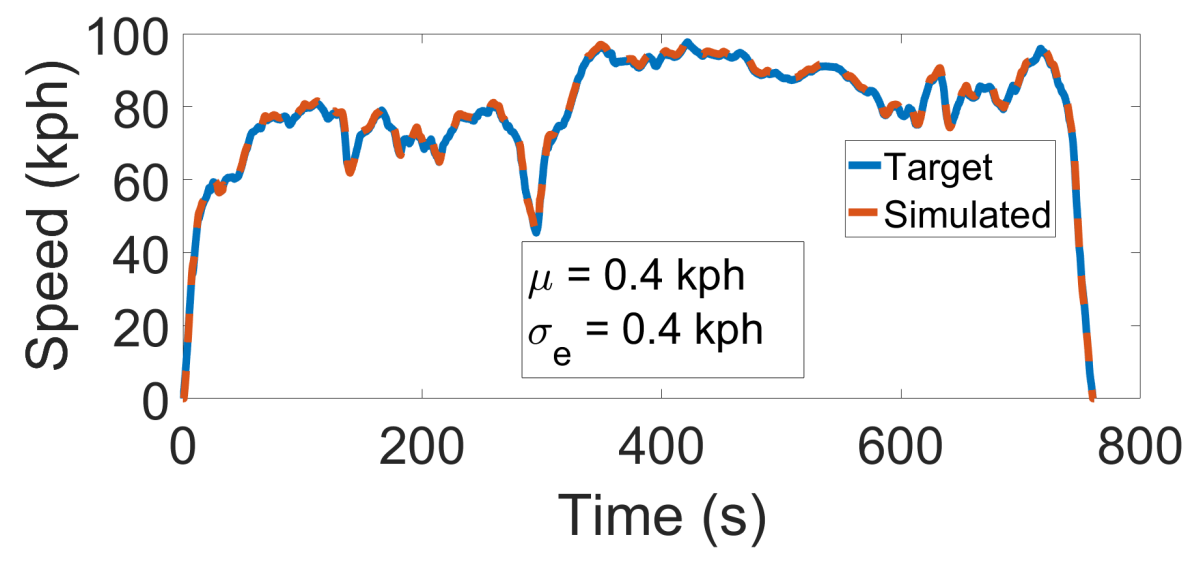

(a) Validation of vehicle speed

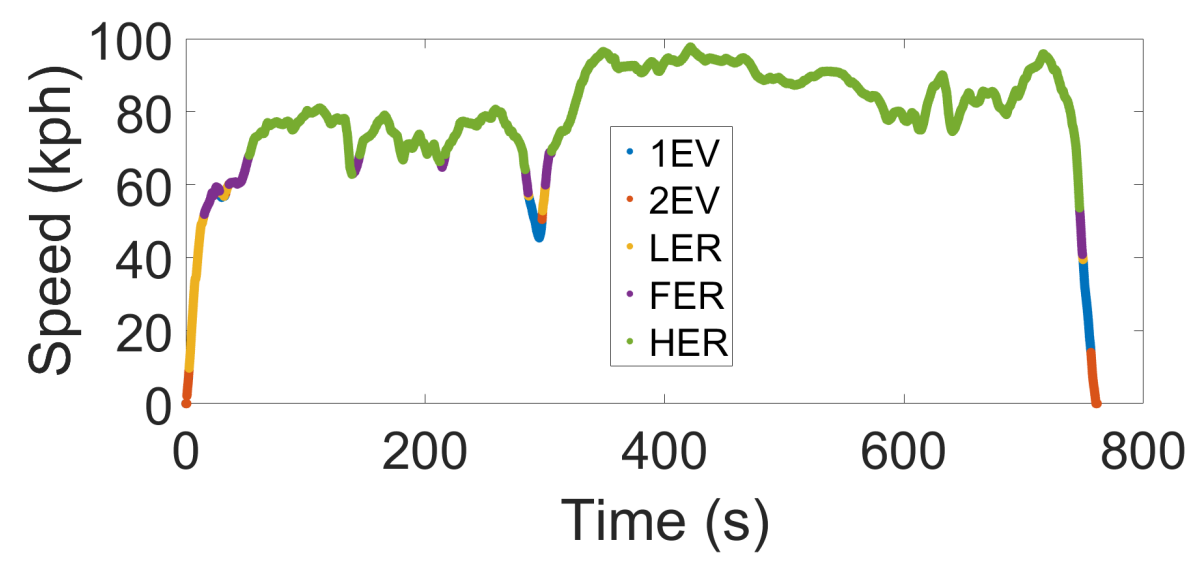

(b) Vehicle drive modes during simulation

Figure 4.2: Validation of control model for HWFET CS drive cycle using ANL Data ( $\epsilon=$ average error, $\sigma_{e}=$ standard deviation of error). See Appendix A (Filename: 61607018.mat) for details of experimental data 


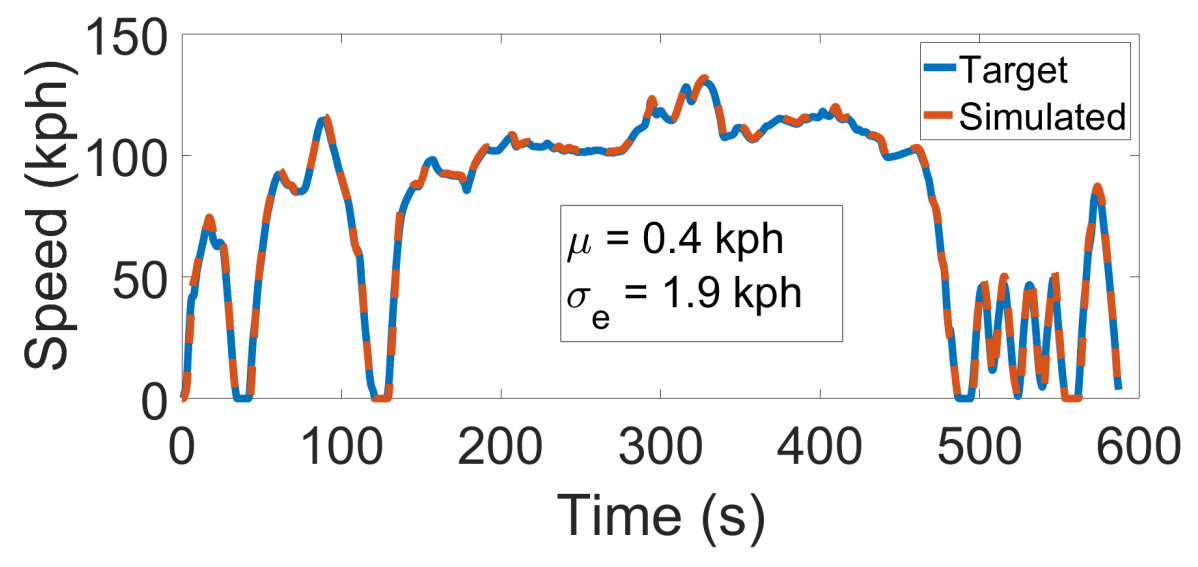

(a) Validation of vehicle speed

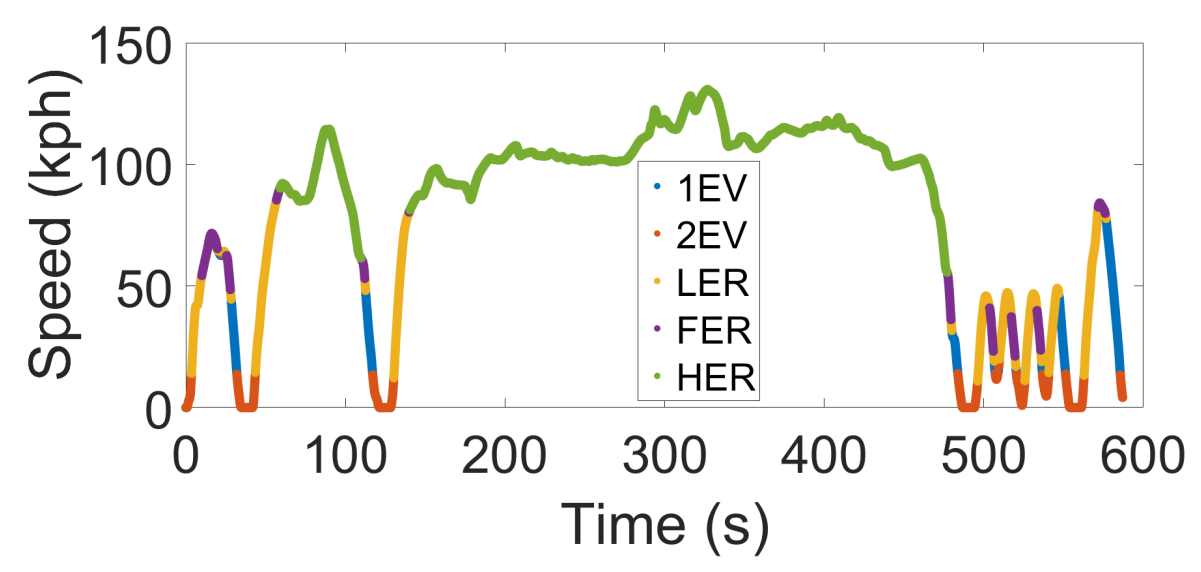

(b) Vehicle drive modes during simulation

Figure 4.3: Validation of control model for US06 CS drive cycle using ANL Data ( $\epsilon$ $=$ average error, $\sigma_{e}=$ standard deviation of error). See Appendix A (Filename: 61607008.mat) for details of experimental data 
Table 4.1: Vehicle fuel and electrical energy consumption comparison of model with ANL experimental data

\begin{tabular}{|c|c|c|c|c|c|}
\hline & \multicolumn{2}{|c|}{ Model Simulation } & \multicolumn{2}{c|}{ Experimental Data } & \\
\hline Drive Cycle & Fuel (MJ) & Electrical (MJ) & Fuel (MJ) & Electrical (MJ) & Error (\%) \\
\hline UDDS & 17.34 & 0.83 & 17.82 & 0.15 & 1.11 \\
HWFET & 21.71 & 0.85 & 22.93 & -0.66 & 1.30 \\
US06 & 19.71 & 1.87 & 22.87 & -0.29 & 4.42 \\
\hline
\end{tabular}

Table 4.1 shows the fuel and electrical energy consumption for the model simulation and for the ANL experimental data for these cycles. The maximum error in energy consumption is about $4.5 \%$ which is within the project NEXTCAR $5 \%$ target.

\subsection{MTU drive cycle}

For the NEXTCAR project, a drive cycle was created which is used as standard drive cycle to assess the vehicle performance. The drive cycle depicts the driving conditions around Houghton and Hancock, MI area. 


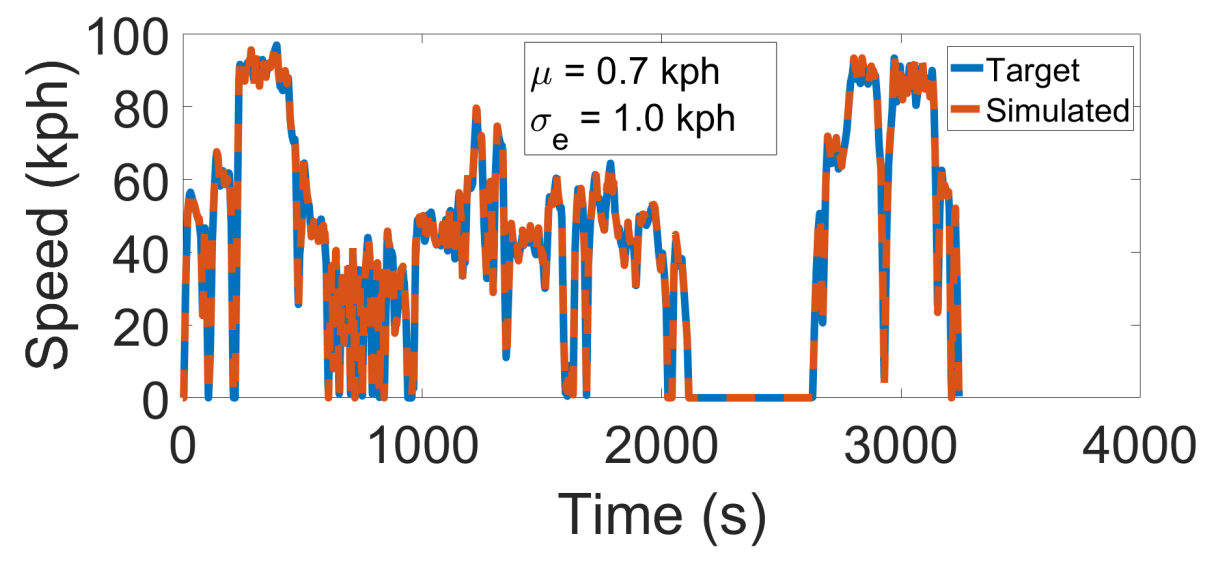

(a) Validation of vehicle speed

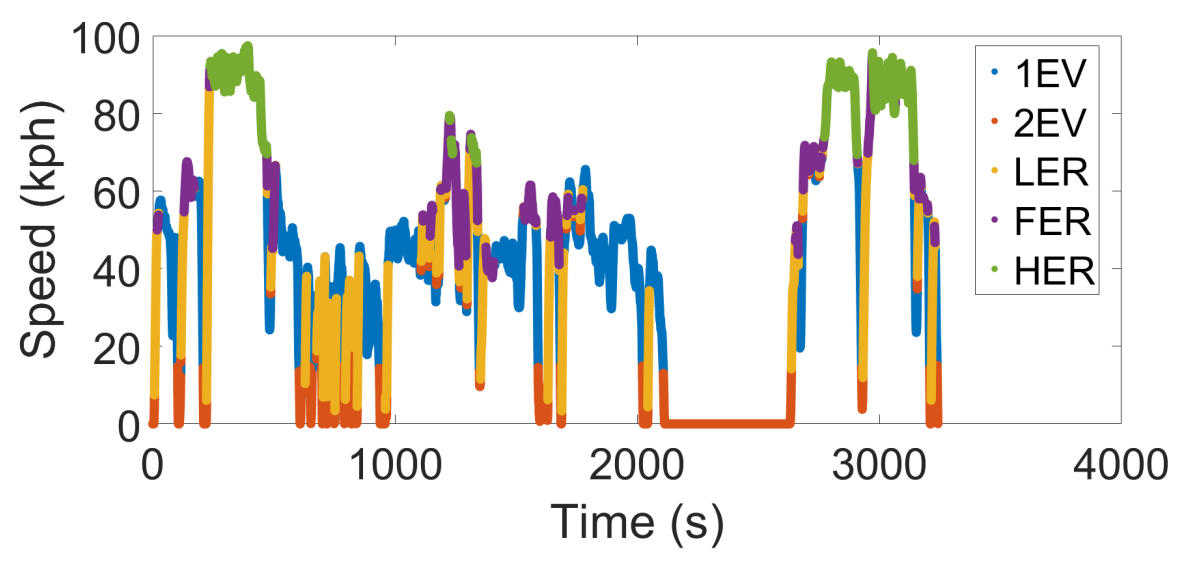

(b) Vehicle drive modes during simulation

Figure 4.4: Validation of control model for MTU drive cycle in Normal-CS (Initial $\underline{\mathrm{SOC}=15 \%})$ mode using MTU APSRC Data $\left(\epsilon=\right.$ average error, $\sigma_{e}=$ standard deviation of error). See Appendix A (Filename: MTU DC 052218 0430pm Beta Normal Undergrad CS.mat) for details of experimental data 


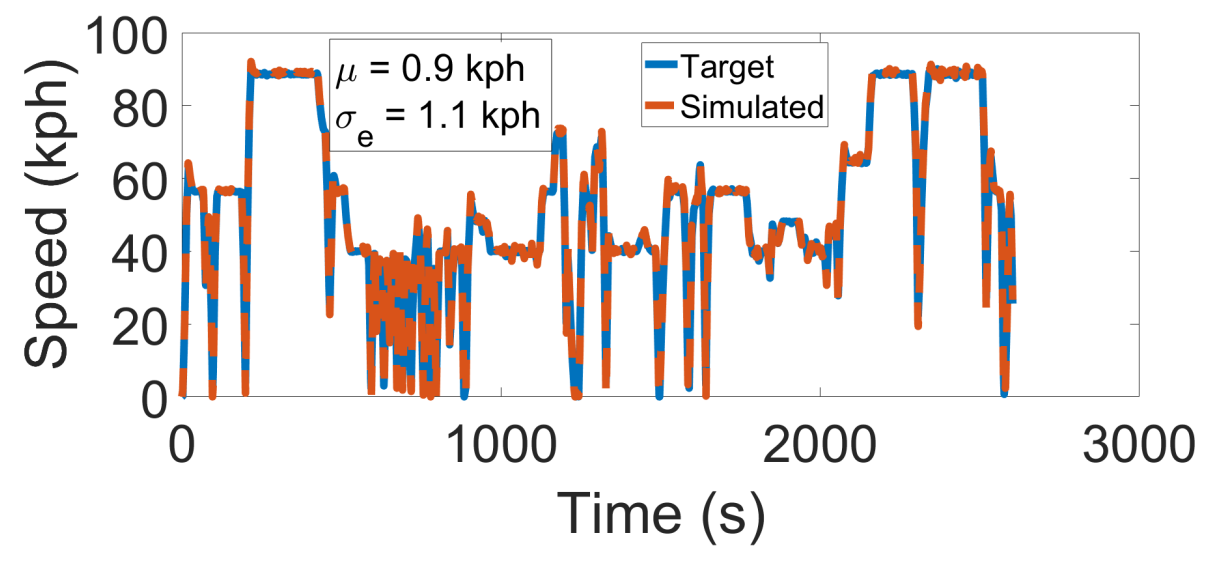

(a) Validation of vehicle speed

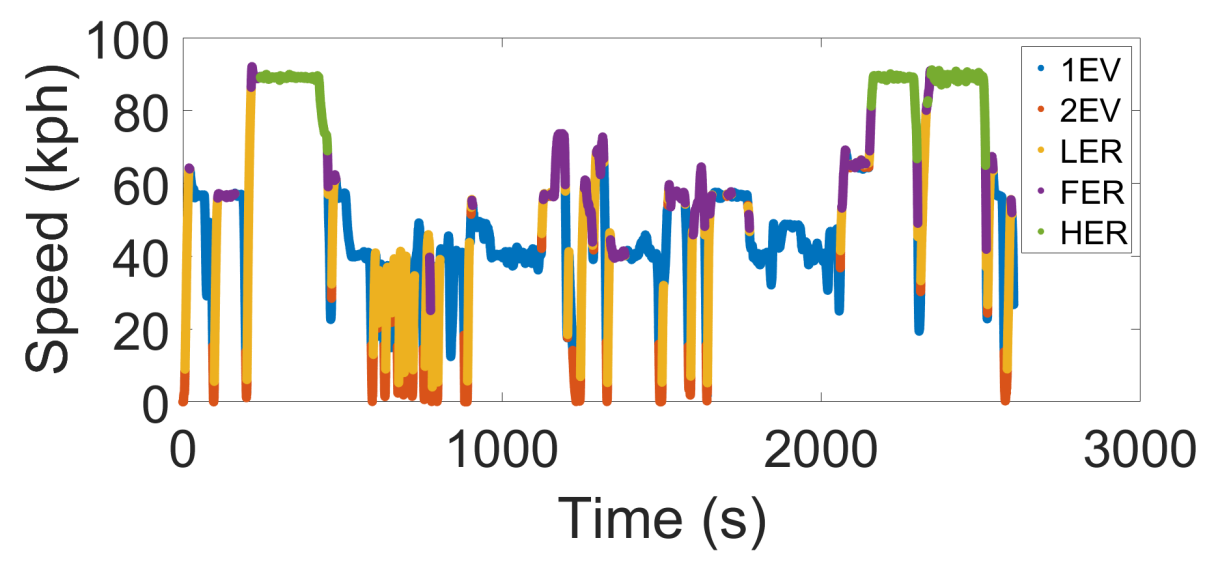

(b) Vehicle drive modes during simulation

Figure 4.5: Validation of control model for MTU drive cycle in Hold-CS (Initial

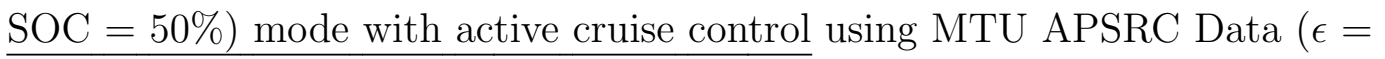
average error, $\sigma_{e}=$ standard deviation of error). See Appendix A (Filename: MTU DC 060110181400 ALPHA 50 CS 2person.mat) for details of experimental data 


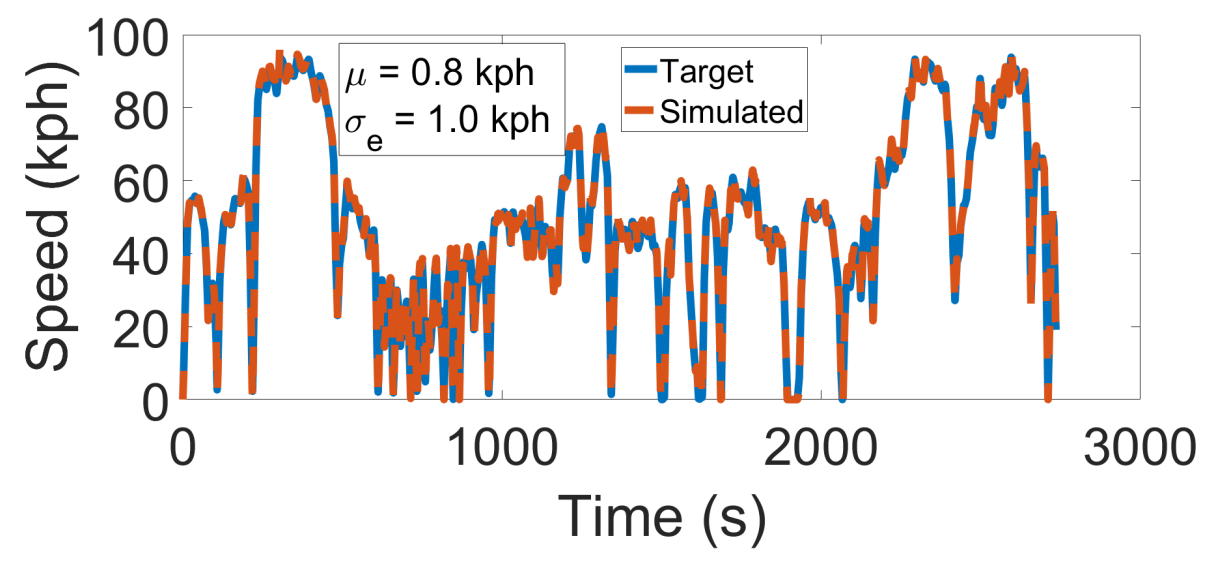

(a) Validation of vehicle speed

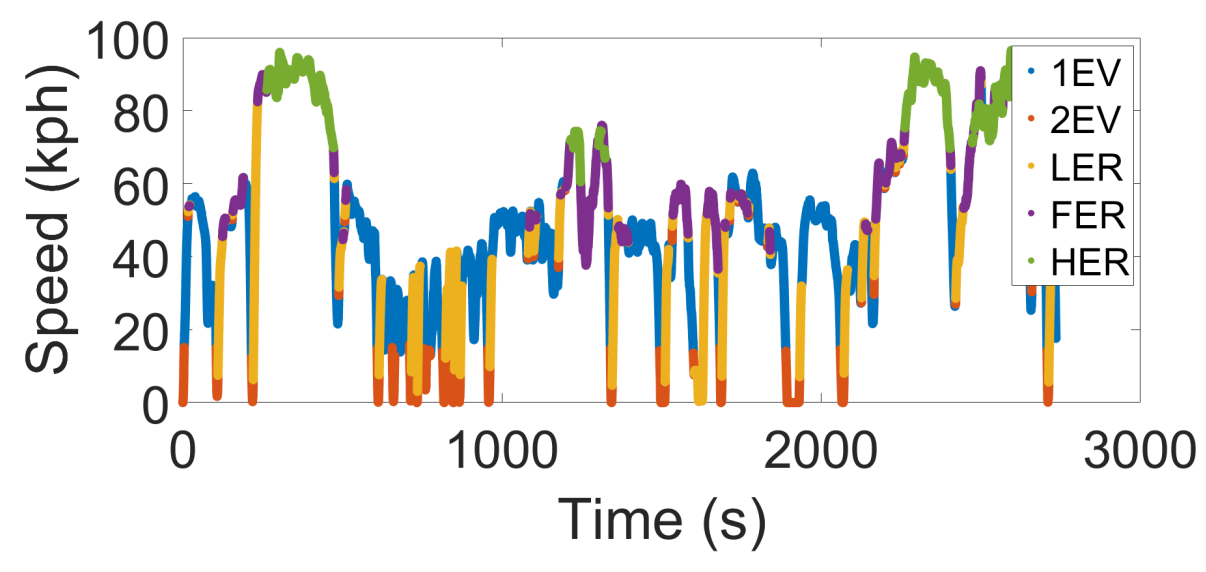

(b) Vehicle drive modes during simulation

Figure 4.6: Validation of control model for MTU drive cycle in Hold-CS (Initial $\underline{\mathrm{SOC}}=50 \%)$ mode without active cruise control using MTU APSRC Data $(\epsilon=$ average error, $\sigma_{e}=$ standard deviation of error). See Appendix A (Filename: MTU DC 0531180115 Undergraduate CS 0115pm 0520 2persons.mat) for details of experimental data 
Figures 4.4 and 4.6 show the control model simulation for MTU drive cycles using the experimental data from MTU APSRC tests. The controller was able to achieve the target vehicle speed with average error of $0.85 \mathrm{kph}$. The error introduced in this control is due to the inherent response delay in the PI control in MATLAB. Also, this condition gets worse when the vehicle speed increases in very short period of time, which can be considered at flat-out vehicle acceleration. There can be other associated factors as well. The simulation step time set in the simulation environment also affects in the response of the control model. The solver used by the simulation affects the computational efficiency and therefore the control response.

Figure 4.4 show the simulation running in the Normal-CS mode of vehicle operation. The Normal-CS mode is in action when the vehicle has depleted over $80 \%$ of battery SOC and thus, need to conserve the battery energy by using the range extender modes. The test data under consideration has taken in from a predefined route specifically defined for this project around Houghton \& Hancock city, Michigan. Thus, these cycles shows different traffic conditions faced during vehicle testing. Figure 4.4 shows the vehicle stuck and stationary for around 10 minutes.

Figure 4.5 shows the vehicle driving in Hold-CS mode of operation along with active cruise control. A Hold-CS mode is manually activated if driver wishes so, the objective being to retain battery energy and use engine energy instead. This mode, does not stop the use of electric motors but instead it uses them along with the IC engine 
Table 4.2: Vehicle fuel \& electrical energy consumption comparison of model with MTU APSRC experimental data

\begin{tabular}{|c|c|c|c|c|c|c|}
\hline \multicolumn{2}{|c|}{ MTU DC } & \multicolumn{2}{|c|}{ Model Simulation } & \multicolumn{2}{|c|}{ Experimental Data } & \\
\hline Type & Initial & Fuel & Electrical & Fuel & Electrical & Error \\
& SOC (\%) & $(\mathrm{MJ})$ & $(\mathrm{MJ})$ & $(\mathrm{MJ})$ & $(\mathrm{MJ})$ & $(\%)$ \\
\hline & 15 & 65.83 & -1.37 & 66.61 & -0.71 & 2.18 \\
& 15 & 66.13 & -2.55 & 65.07 & -0.95 & 0.84 \\
Normal & 15.5 & 67.33 & -1.35 & 67.69 & -0.45 & 1.87 \\
& 16 & 64.03 & -0.99 & 65.02 & -0.03 & 3.00 \\
\hline \multirow{2}{*}{$\begin{array}{c}\text { Hold } \\
\text { CS }\end{array}$} & 50 & 62.55 & -1.59 & 62.32 & 0.03 & 2.13 \\
\hline
\end{tabular}

to maintain and/or charge battery SOC. Figure 4.6 shows the vehicle drive cycle in Hold-CS mode but without cruise control. More MTU drive cycle validations are presented in Appendix B.

Table 4.2 shows the vehicle energy consumption for all the MTU drive cycles described above. The net error in predicting vehicle energy is less than $5 \%$ in all cases, with the maximum observed at around $3 \%$. 


\section{Simulation of driving behavior}

The behavior of the driver contributes largely towards the vehicle fuel consumption. Werner K. [12] found that the vehicle fuel consumption can be reduced by up to $17 \%$ for highway driving and $26 \%$ for city driving for the 108 drivers approach he used for analyzing results, if they drive like the efficient drivers. It can also be considered as removing 20 out of 100 vehicles out of a traffic. Thitipatanapong R. et. al. also found a similar result and found that the difference between fuel consumed by an efficient driver and a worse driver can be up to $30 \%$ depending on whether they are driving in city or on highway [13].

The tests conducted by Werner K. [12] also showed that the drivers tend to drive at a speed higher than the efficient speed on highway and at a speed lower than the efficient speed in city. This means that even though the driver is not driving aggressively, it can result into loss of economic drive. This observation was also validated from the report published by National Renewable Energy Laboratory [14]. They observed the general fact that high average acceleration does result in higher fuel consumption. On the other hand, they found that the vehicles in city driving with lower average acceleration as well as lower average speeds below 20 mph showed similar increase in fuel consumption.

Thus, it is important in the connected and automated vehicles, to investigate the 


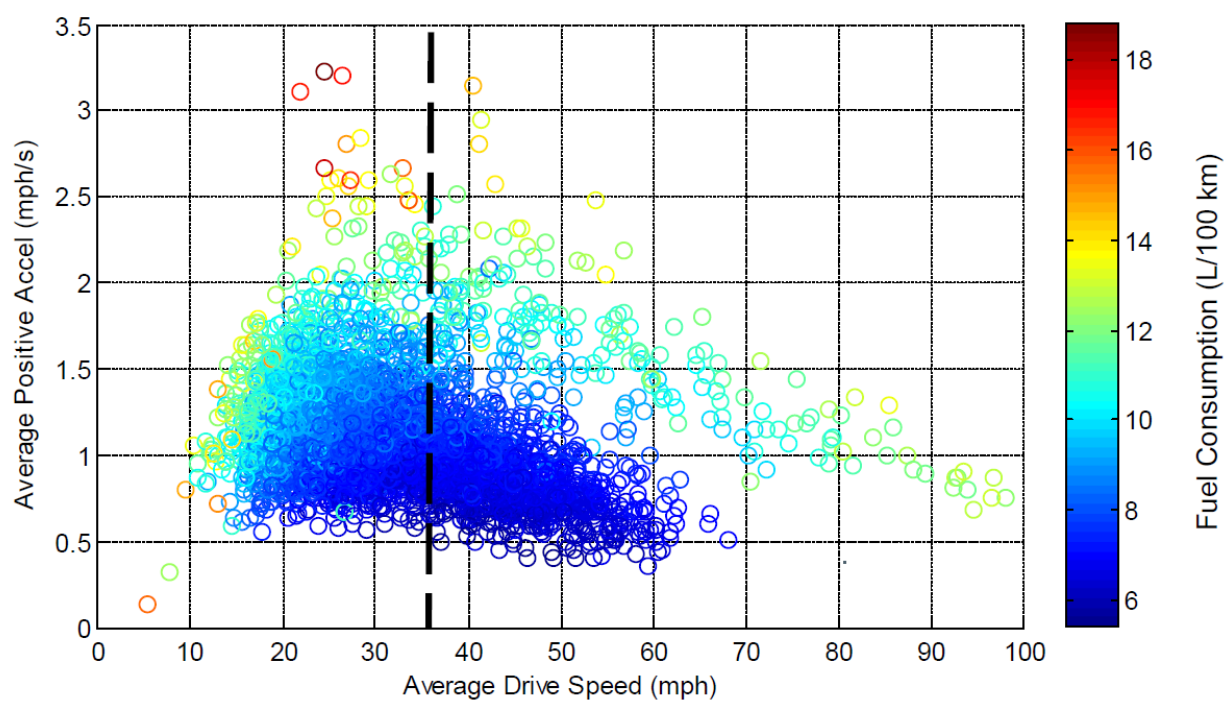

Figure 5.1: Scatter plot of combined city and highway fuel consumption for 4000 real world trips $[14]$

effect of driving behavior towards achieving low energy consumption which is a prime objective of the NEXTCAR project. In this section, energy consumption for two drivers is analyzed based on their driving styles observed through an experimental study. An attempt is made to simulate the driving behavior based on tuning of PI control gains used in the driver model described in Section 3.1. An experiment was conducted wherein the two individuals drive the vehicle aggressively, differentiating from each other on the basis of the acceleration rates. The driving behavior, in this context, is defined as the rate of acceleration for the vehicle to go from say, 10 to 50 mph. The more aggressive driver, denoted by driver B performed flat out acceleration demand for increasing its speed. Figure 5.2 shows the given step input of the speed target which is tracked by the drivers. 


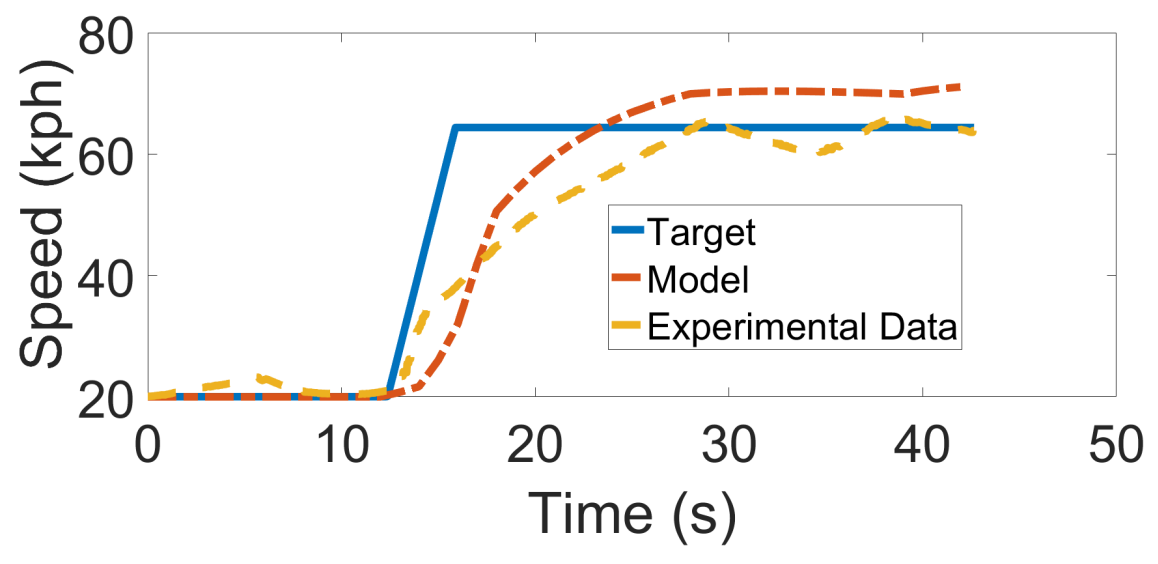

(a) Driver A

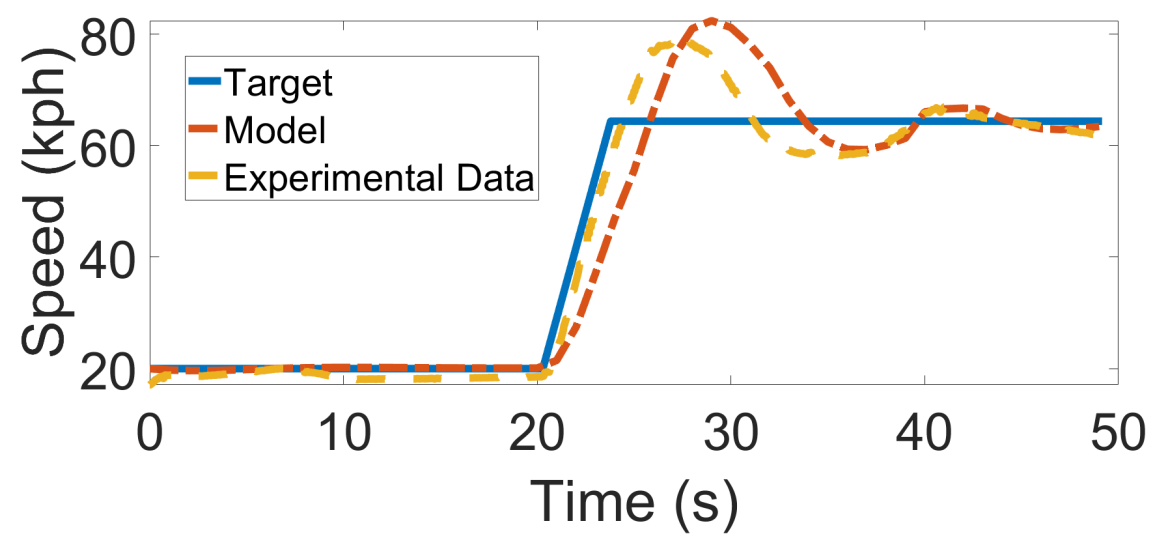

(b) Driver B

Figure 5.2: Driver model response for tuned PI gains to represent drivers behavior during tip-in acceleration events (a) Driver A, (b) Driver B. See Appendix A (Filename: Normal10to40.mat and Aggr10to40.mat) for details of experimental data 
Table 5.1: PI gains for different driving behaviors

\begin{tabular}{|c|c|c|}
\hline Control Parameter & Driver A & Driver B \\
\hline Proportional Gain & 30 & 60 \\
\hline Integral Gain & 1 & 30 \\
\hline
\end{tabular}

The tuning of the PI gains were done in such a way that the simulation acceleration rate is similar to that of the experimental data. Based on the tuning, the PI gains obtained for driver A and driver B are as shown in Table 5.1.

Now, to assess the energy consumed by each driver, a generic drive cycle is created which corresponds to the driving conditions around Houghton and Hancock, MI area. The change in speeds corresponds to the speed limits in this area. McLauglin, S. et. al. [15] found that 90 percentile of people has a response time of just over 2 seconds. This information was used to develop the generic drive cycle. The model response for this generic drive cycle with driver $\mathrm{A}$ and driver B driving the car through this drive cycle is shown in Figure 5.3 and the energy consumption is summarized in Table 5.2. 
(a) Driver A

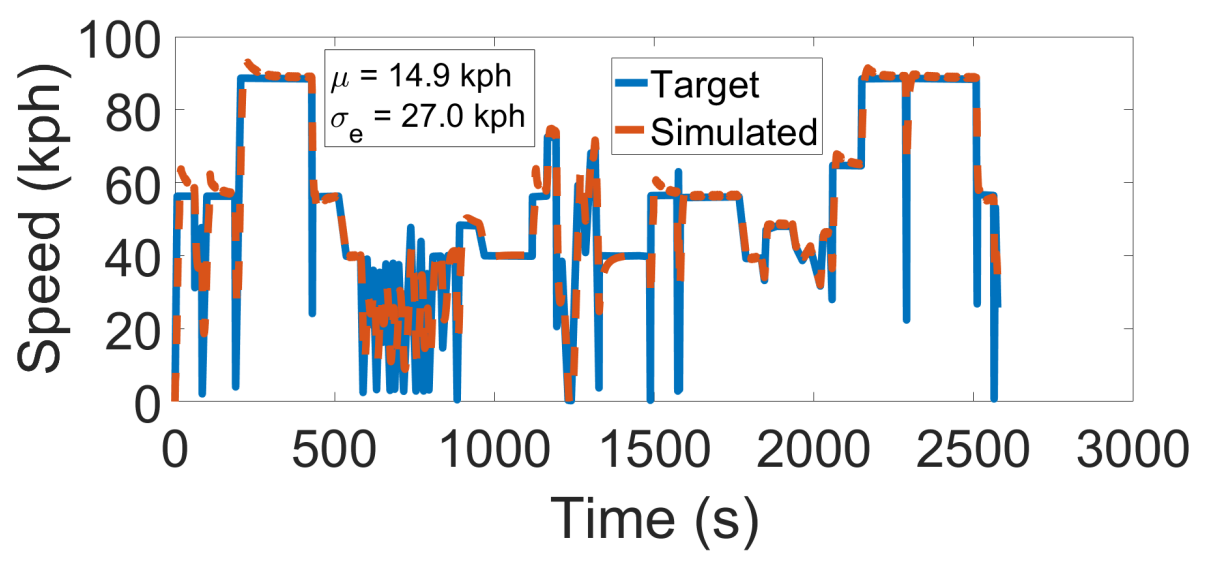

(b) Driver B

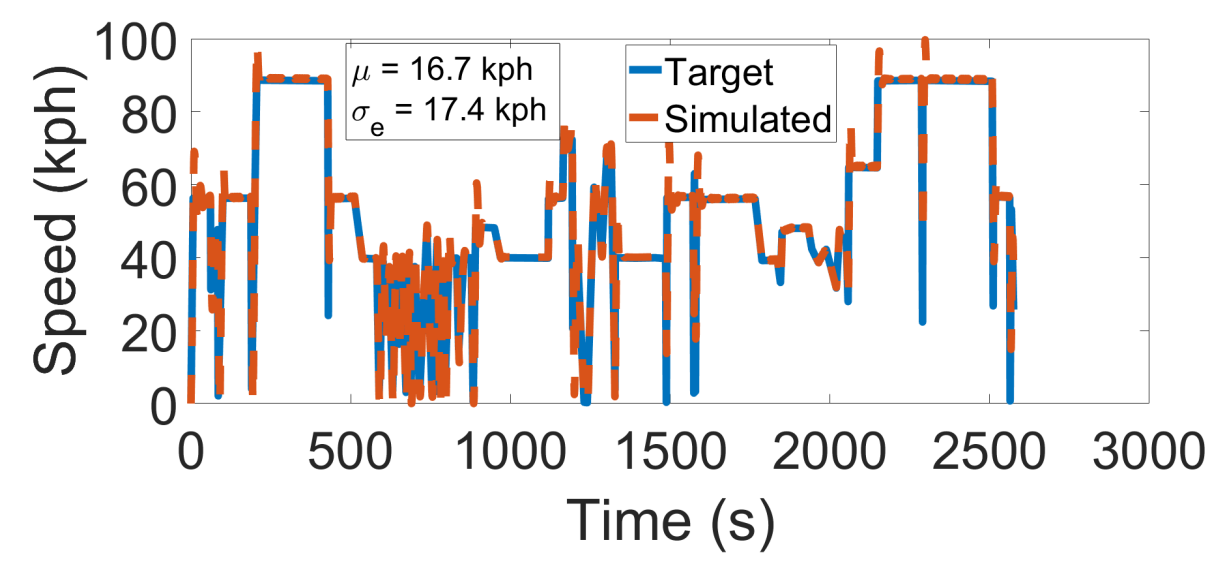

Figure 5.3: Driver model response for tuned PI gains to represent different driving behaviors (a) Driver A, (b) Driver B ( $\epsilon=$ average error, $\sigma_{e}=$ standard deviation of error). See Appendix A (Filename: New ACC MTU AGGR DRIVE.mat) for details of experimental data 
Table 5.2: Energy consumption comparison for Drivers A and B

\begin{tabular}{|c|c|c|c|c|}
\hline \multirow{2}{*}{ Driver } & \multicolumn{2}{|c|}{ Model Simulation } & \\
\cline { 2 - 4 } & Fuel & Electrical & Total & Energy Difference \\
& $(\mathrm{MJ})$ & $(\mathrm{MJ})$ & $(\mathrm{MJ})$ & $(\%)$ \\
\hline A & 58.20 & -0.04 & 58.16 & - \\
\hline B & 59.23 & 3.24 & 62.48 & +7.42 \\
\hline
\end{tabular}

It was found that the driver B causes the vehicle energy consumption for the studied drive cycle to be more than $7 \%$ higher than that of driver A. This waste in total energy increases if the driving pattern persists for even longer drive cycle times. In addition, the major difference in energy was observed in the electrical energy consumed by the drivers. The more aggressive driver $B$, accelerates at a much higher rate than that of the driver A; Thus, a good amount of energy is extracted from the motor units to support this high power demand. 


\section{Conclusion and Future Works}

\subsection{Conclusion}

A supervisory controller model for Chevy Volt Gen II is developed in MATLAB/SIMULINK using the experimental data from ANL and tests conducted at MTU APSRC along with the parameters and maps provided by GM. Also, necessary components of vehicle powertrain and dynamics are included to further increase the model fidelity. The overall model validation is done using the test data available from ANL and on-road test data from APSRC. The key output of this report work are as follows:

- A fully predictive Chevy Volt Gen II powertrain model was developed to predict energy consumption within $5 \%$ of the experimental data.

- All the subsystems were integrated together with the whole powertrain model previously developed and were validated for standard FTP drive cycles from ANL experimental data for Charge Sustaining mode of operation. The model was also validated for MTU drive cycle for Normal-CS \& Hold-CS mode of operation for different real time traffic conditions. The model energy consumption was within $5 \%$ for all the cases.

- The model can be integrated with the MPC developed to optimize the vehicle operation and to analyze the vehicle energy consumption improvement which 
is the objective of the NEXTCAR project.

- A map based transmission spin loss model was incorporated into the model to accurately find the actual torque necessary to drive the vehicle.

- A road gradient 1-D map based look-up table was developed specifically for MTU drive cycle to account for the forces due to changes in road gradient.

- Model developed by Yadav R. [10] used external inputs such as motor, engine and friction torques to run the model to analyze energy consumption. To increase model independency and to make the model fully predictive based on only the vehicle velocity profile and road gradient, a supervisory controller model is developed.

- A PI control based driver model was developed to produce net torque request based on the target and actual vehicle speeds.

- A State flow and Neural network based model were developed to select vehicle drive modes. Later the state flow model was incorporated in the model as the Neural network model was not able to accommodate the associated time hysteresis with each drive mode and the restraints on the inputs to use to identify the modes.

- A rule-based torque blending model based on the vehicle drive mode was developed based on the analysis of the ANL \& MTU APSRC experimental data. 
- A rule-based friction brake model was developed taking into account the amount of regeneration possible by MGB unit and supplying required excess braking force.

- The PI gains in the driver model can be tuned to represent and to simulate a particular driving behavior. The energy consumed by driving vehicle more aggressively was compared with less aggressive driving. It was observed that the more aggressive driving resulted in $6 \%$ increase in total energy consumption, where the significant difference was observed in the electrical energy consumed.

\subsection{Future Works}

- A more extensive study can be conducted by collecting experimental data for a broad range of operating conditions to analyze and find more torque blending logic to improve accuracy of the designed supervisory controller.

- Other structures of artificial neural network (ANN) modeling approach for selecting vehicle drive mode can be further investigated in order to make the model accurate based on limited number of inputs such as only vehicle speed, axle torque and SOC and inclusion of time hysteresis for each drive mode.

- The friction brake model can be more accurate by incorporating logics based on various braking situations as the regenerative braking is not always favoured. 
- Electrical losses associated with mode transition, battery temperature should be incorporated in the model to enhance model the fidelity.

- The model currently takes into account the road gradient which is specific to a particular drive track. A longitude and latitude (GPS data) based road grade can be incorporated to generalize model usage for any driving roads.

- The effect of driving attitude on fleet energy consumption during connected platooning can be studied. A more detailed driver model, using connected vehicle platooning data can be developed to incorporate driving behaviors such as distance maintained behind the lead car, overtaking maneuvers, etc.

- New control strategies for supervisory controller can be developed to mitigate the effect of aggressive driving of driver by using minimum amount of energy without compromising the performance requested. 


\section{References}

[1] United States Environmental Protection Agency, "Green Vehicle Guide", https://www.epa.gov/greenvehicles, accessed on March 10, 2019.

[2] United States Environmental Protection Agency, 2019, "The 2018 EPA Automotive Trends Report: GHG, Fuel Economy and Technology since 1975", EPA-420R-19-002 March 2019.

[3] Kaneva N., Brinkman R., J. P. Morgan Global Research, 2018, "Driving into Future 2025: Future of Electric Vehicles", https://www.jpmorgan.com/global/research/electric-vehicles, Accessed on March $10,2019$.

[4] Electrification Coalition, 2013, "State of the Plug-in Electric Vehicle Market, EV Market Outlook", https://www.electrificationcoalition.org/StateEVMarket, Accessed on March 10, 2019.

[5] Jeong, J., Choi, S., Kim, N., Lee, H. et al., "Model Validation of the Chevrolet Volt 2016," SAE Technical Paper 2018-01-0420, 2018, doi:10.4271/2018-01-0420.

[6] Kim, N., Choi, S., Jeong, J., Vijayagopal, R., Stutenberg, K., Rousseau, A., 2018, "Vehicle Level Control Analysis for Voltec Powertrain", World Electric Vehicle Journal, MDPI, 9(2), 29. 
[7] Renault, Centre Technique de Lardy, France, "Model-Based Powertrain Control: Many Uses, No Abuse",IFP International Conference, Vol. 62 (2007), No.4, pp. 427-435.

[8] Khan I., Madhukar M., Narula M., Sahoo T., ARAI, "Model Based Design of xEV Powertrain Controls", SAE Technical Paper, 2012-28-0023

[9] Kim, N., Rousseau, A., Lee, D., Busch, H., "Thermal Model Development and Validation for 2010 Toyota Prius". SAE Technical Paper 2014-01-1784, doi:10.4271/2014-01-1784, 2014

[10] Yadav, R., "Modeling and analysis of energy consumption in Chevrolet Volt Gen II Hybrid electric vehicle", Master's Thesis, Michigan Technological University, 2018.

[11] Surresh, K., "Modelling and Analysis of Chevy Volt Gen II Hybrid Vehicle in Electric Mode", Master's Technical Report, Michigan Technological University, 2018.

[12] Werner, K., 2013, "Driver Behavior and Fuel Efficiency", Undergraduate Honors Thesis, University of Michigan.

[13] Thitipatanapong, R., Luangnarutai, T., 2011, "Effects of A Vehicle's Driver Behavior to The Fuel Economy", The "th International Conference on Automotive Engineering (ICAE-7), Bangkok, Thailand. 
[14] National Renewable Energy Laboratory (NREL), 2011, "Final Report on the Fuel Saving Effectiveness of Various Driver Feedback Approaches", Milestone Report No. NREL/MP-5400-50836.

[15] McLauglin, S., Hankey, J., Dingus, T., "A method for evaluating collision avoidance systems using naturalistic driving data", Accident Analysis \& Prevention, Volume 40, Issue 1, 2008, Pages 8-16, ISSN 0001-4575.

[16] Powell, B., Bailey, K., Cikanek, S., "Dynamic modeling and control of hybrid electric vehicle powertrain systems," in IEEE Control Systems Magazine, vol. 18, no. 5, pp. 17-33, Oct. 1998. doi: 10.1109/37.722250

[17] Day, T., Metz, L., "The Simulation of Driver Inputs Using a Vehicle Driver Model," SAE Technical Paper 2000-01-1313, 2000, https://doi.org/10.4271/200001-1313.

[18] https://www.wired.com/2015/09/chevys-new-volt-way-better-maybe-not-goodenough/

[19] "Chevrolet Product Information". media. chevrolet. com , 2015. 


\section{APPENDIX}

\section{A Summary of Program \& Data Files}

\section{A.1 Chapter 1}

Table A.1: Figure Files

\begin{tabular}{cc}
\hline File Name & File Description \\
\hline US emissions by sector.png & 1.1 \\
EPA transport GHG split.png & 1.2 \\
Production share.png & 1.3 \\
Tech prod share ldv.png & 1.4 \\
Global EV forecast.png & 1.5 \\
Cost ownership.png & 1.6 \\
\hline
\end{tabular}


Table A.2: Figure Files

\begin{tabular}{cc}
\hline File Name & File Description \\
\hline Consumer satisfaction.png & 1.7 \\
Fuel economy comparison.png & 1.8 \\
CS case points in paper.png & 1.9 \\
Ref CD Case points.png & 1.10 \\
Ref CD torque dist.png & 1.11 \\
Ref fuel cutoff points.png & 1.12 \\
Ref engine onoff pts on soc.png & 1.13 \\
\hline
\end{tabular}

Table A.3: Visio Files

\begin{tabular}{cc}
\hline File Name & File Description \\
\hline Report Organization updated.vsdx & 1.15 \\
\hline
\end{tabular}




\section{A.2 Chapter 2}

Table A.4: Figure Files

\begin{tabular}{cc}
\hline File Name & File Description \\
\hline HEV control plus plant.png & 2.2 \\
Supervisory control layout.png & 2.3 \\
road grade model.png & 2.4 \\
mtu drive on maps.jpg & 2.5 \\
Road grade map data.png & 2.6 \\
transmission spin loss model.png & 2.7 \\
Fric brake block diagram.png & 2.8
\end{tabular}

Table A.5: Visio Files

File Name File Description

Whole Model.vsdx

2.1 


\section{A.3 Chapter 3}

Table A.6: Figure Files

\begin{tabular}{cc}
\hline File Name & File Description \\
\hline drive mode map anl data.fig & 3.8 \\
drive mode map.png & 3.9 \\
Test conf matrix.png & 3.13 \\
Valid conf matrix.png & 3.14 \\
\hline
\end{tabular}


Table A.7: Visio Files

\begin{tabular}{cc}
\hline File Name & File Description \\
\hline driver model.vsdx & 3.1 \\
transmission mode 1.vsdx & 3.2 \\
transmission mode 2.vsdx & 3.3 \\
transmission mode 3.vsdx & 3.4 \\
transmission mode 4.vsdx & 3.5 \\
transmission mode 5.vsdx & 3.6 \\
Stateflow modes flowchart.vsdx & 3.7 \\
Torque Blending Flowchart decel.vsdx & 3.10 \\
Ttateflow modes flowchart deceleration.vsdx & 3.11 \\
NN architecture.vsdx & 3.12 \\
\hline Blending Flowchart.vsdx & 3.15 \\
\hline
\end{tabular}




\section{A.4 Chapter 4}

Table A.8: MATLAB Figure Files

\begin{tabular}{cc}
\hline File Name & File Description \\
vehVel UDDS.fig & $4.1 \mathrm{a}$ \\
Stateflow modes UDDS.fig & $4.1 \mathrm{~b}$ \\
vehVel HWFET.fig & $4.2 \mathrm{a}$ \\
Stateflow modes HWFET.fig & $4.2 \mathrm{~b}$ \\
vehVel US06.fig & $4.3 \mathrm{a}$ \\
Stateflow modes US06.fig & $4.3 \mathrm{~b}$ \\
\hline
\end{tabular}


Table A.9: MATLAB Figure Files

\begin{tabular}{|c|c|}
\hline File Name & File Description \\
\hline vehVel test2.fig & $4.4 \mathrm{a}$ \\
\hline SimulatedModes test2.fig & $4.4 \mathrm{~b}$ \\
\hline vehVel test3.fig & B.1a \\
\hline SimulatedModes test3.fig & B.1b \\
\hline vehVel test4.fig & B.2a \\
\hline SimulatedModes test4.fig & B. $2 \mathrm{~b}$ \\
\hline vehVel test7.fig & B.3a \\
\hline Modes test7.fig & B.3b \\
\hline vehVel test6.fig & B. $4 \mathrm{a}$ \\
\hline Modes test6.fig & B. $4 \mathrm{~b}$ \\
\hline vehVel test1.fig & $4.5 \mathrm{a}$ \\
\hline Modes test1.fig & $4.5 \mathrm{~b}$ \\
\hline vehVel test5.fig & $4.6 \mathrm{a}$ \\
\hline Modes test5.fig & $4.6 \mathrm{~b}$ \\
\hline
\end{tabular}


Table A.10: MATLAB/Simulink Files

\begin{tabular}{cc}
\hline File Name & File Description \\
\hline model run file for mtu drive cycle.m & Initialization m-file \\
extractOperatingPoints.m & m-file for extracting inputs \\
from saved ANL/MTU data in folders \\
modeSort JCT 060517.m & m-file for extracting drive modes \\
model.slx & from ANL/MTU data in folders \\
Chevy Volt Powertrain Model \\
validationAnalysisPlots 071217.m
\end{tabular}

Table A.11: Vehicle Data Files

File Name

EV2.mat

FER new.mat

HER new.mat

LER mode.mat

\section{File Description}

$2 \mathrm{EV}$ torque vs speed operating region

FER torque vs speed operating region

HER torque vs speed operating region

LER torque vs speed operating region

DataToLoad JCT 071417.mat Volt engine \& motor data 
Table A.12: Data Files

\begin{tabular}{|c|c|c|}
\hline File Name & Test File & Condition \\
\hline \multirow[t]{2}{*}{ Figure 4.1} & Load mat file 61607020. mat and & UDDS CS \\
\hline & run model.slx & \\
\hline \multirow[t]{2}{*}{ Figure 4.2} & Load mat file 61607018.mat and & HWFET CS \\
\hline & run model.slx & \\
\hline \multirow[t]{2}{*}{ Figure 4.3} & Load mat file 61607008.mat and & US06 CS \\
\hline & run model.slx & \\
\hline \multirow[t]{4}{*}{ Figure 4.4} & Load mat file MTU DC & MTU CS, initial \\
\hline & 0522180430pm Beta Normal & $\mathrm{SOC}=15 \%$ \\
\hline & Undergrad CS.mat and run & Long Stop at \\
\hline & model.slx & bridge \\
\hline \multirow[t]{4}{*}{ Figure 4.5} & Load mat file MTU DC & MTU CS, initial \\
\hline & 060110181400 ALPHA 50 CS & $\mathrm{SOC}=50 \%$ \\
\hline & 2person.mat and run model.slx & Active Cruise \\
\hline & & Control \\
\hline \multirow[t]{5}{*}{ Figure 4.6} & Load mat file MTU DC 053118 & MTU CS, initial \\
\hline & 0115 Undergraduate CS 0115pm & $\mathrm{SOC}=50 \%$ \\
\hline & 05202persons.mat and run & NO Cruise Con- \\
\hline & model.slx & trol, Normal \\
\hline & & Drive \\
\hline
\end{tabular}




\section{A.5 Chapter 5}

Table A.13: Figure Files

\begin{tabular}{cc}
\hline File Name & File Description \\
\hline fuel consumption speed vs accel.png & 5.1 \\
\hline Table A.14: MATLAB Figure Files \\
\hline File Name & File Description \\
\hline vehVel driver A experiment.fig & $5.2 \mathrm{a}$ \\
vehVel driver B experiment.fig & $5.2 \mathrm{~b}$ \\
vehVel driver A sim.fig & $5.3 \mathrm{a}$ \\
vehVel driver B sim.fig & $5.3 \mathrm{~b}$ \\
\hline
\end{tabular}


Table A.15: Data Files

\begin{tabular}{|c|c|c|}
\hline File Name & Test File & Condition \\
\hline \multirow[t]{3}{*}{$5.2 \mathrm{a}$} & Load mat file Nor- & Simulation to \\
\hline & mal10to40.mat, tune PI gains & extract driver $\mathrm{A}$ \\
\hline & $\mathrm{P}=30, \mathrm{I}=1$ and run model.slx & gains \\
\hline \multirow[t]{3}{*}{$5.2 \mathrm{~b}$} & Load mat file Aggr10to40.mat, & Simulation to \\
\hline & tune $\mathrm{PI}$ gains $\mathrm{P}=60, \mathrm{I}=30$ & extract driver $\mathrm{B}$ \\
\hline & and run model.slx & gains \\
\hline \multirow[t]{4}{*}{$5.3 \mathrm{a}$} & Load mat file New ACC MTU & MTU CS, Sim- \\
\hline & AGGR DRIVE.mat, tune PI & ulating driver $\mathrm{A}$ \\
\hline & gains $\mathrm{P}=10, \mathrm{I}=1$ and run & behavior \\
\hline & model.slx & \\
\hline \multirow[t]{4}{*}{$5.3 \mathrm{~b}$} & Load mat file New ACC MTU & MTU CS, Sim- \\
\hline & AGGR DRIVE.mat, tune PI & ulating driver $\mathrm{B}$ \\
\hline & gains $\mathrm{P}=60, \mathrm{I}=30$ and run & behavior \\
\hline & model.slx & \\
\hline
\end{tabular}




\section{B MTU drive cycle validations}

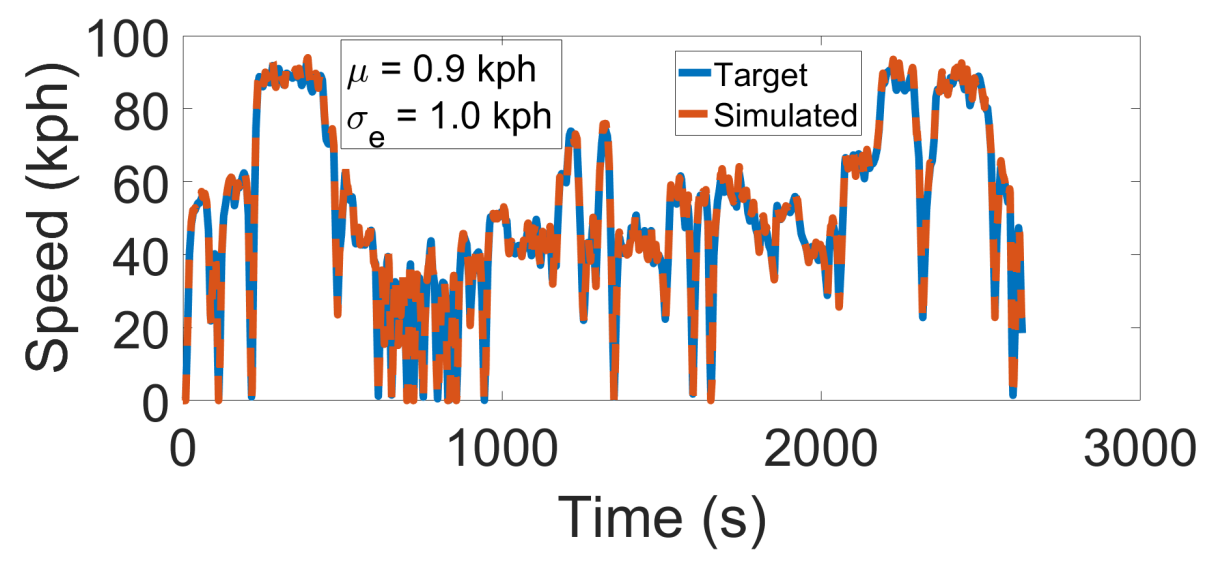

(a) Validation of vehicle speed

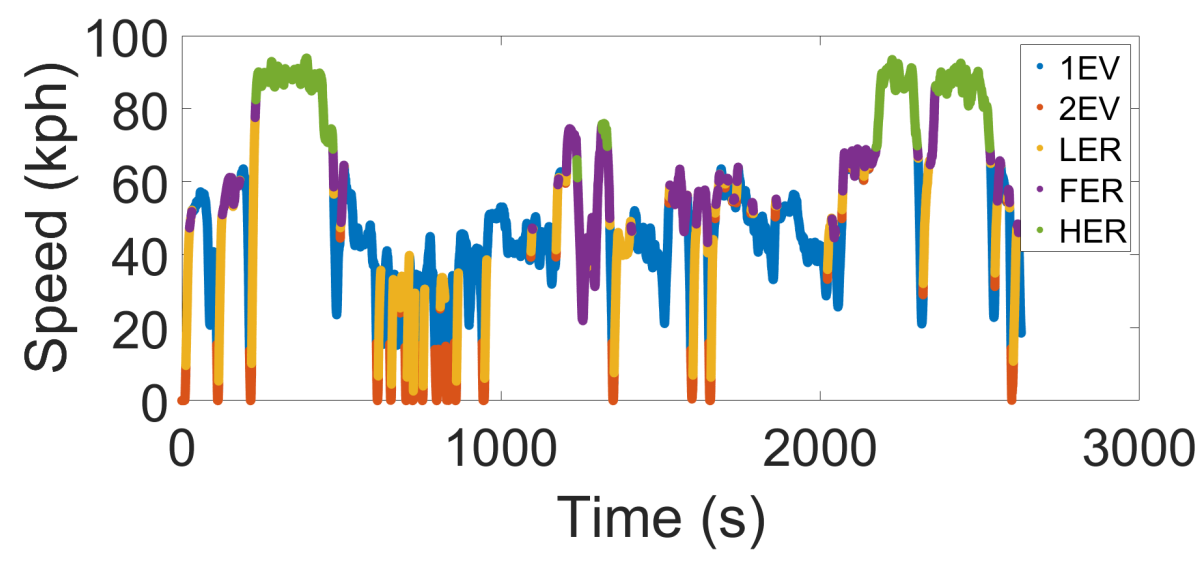

(b) Vehicle drive modes during simulation

Figure B.1: Validation of control model for MTU drive cycle in Normal-CS (Initial $\mathrm{SOC}=15 \%)$ mode using MTU APSRC Data $\left(\epsilon=\right.$ average error, $\sigma_{e}=$ standard deviation of error) Details in Appendix A (Filename: MTU DC $0523181142 \mathrm{am}$ Normal CS 2person.mat) 


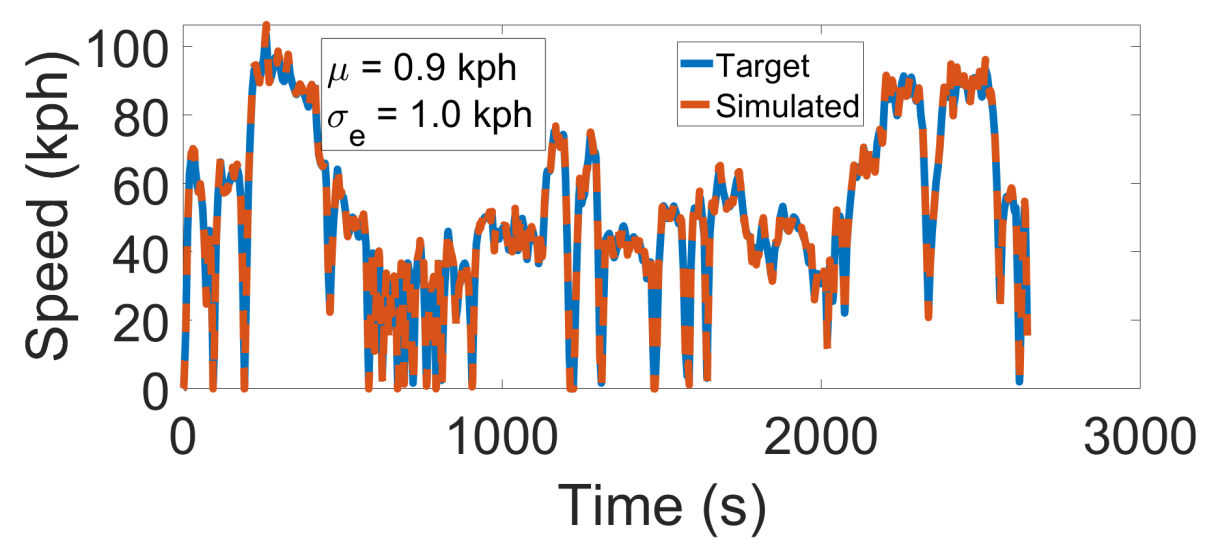

(a) Validation of vehicle speed

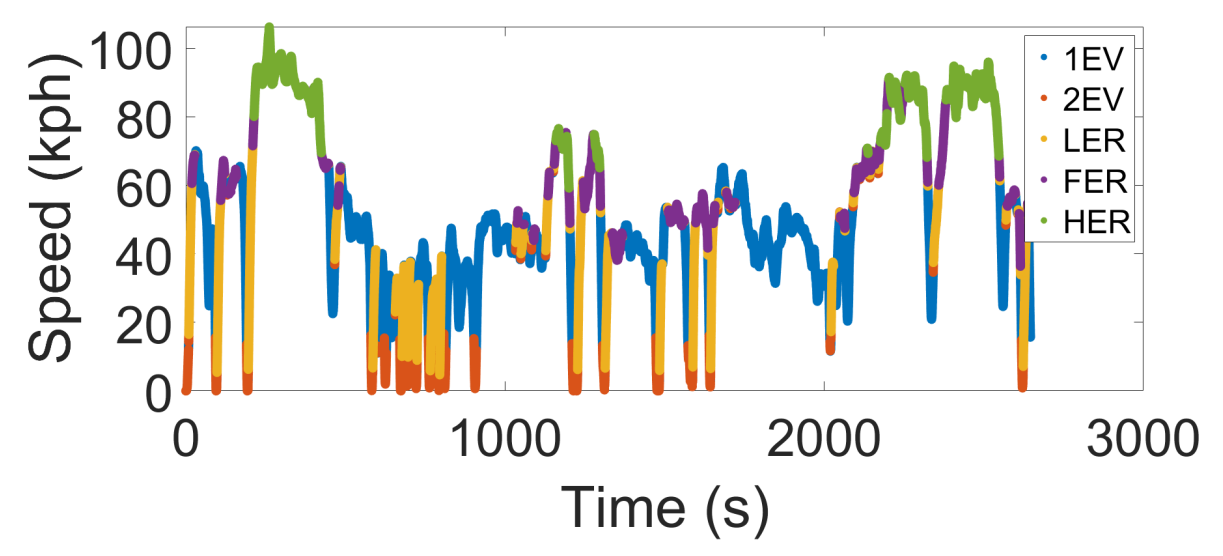

(b) Vehicle drive modes during simulation

Figure B.2: Validation of control model for MTU drive cycle in Normal-CS (Initial $\mathrm{SOC}=15.5 \%)$ mode with active cruise control using MTU APSRC Data $(\epsilon=$ average error, $\sigma_{e}=$ standard deviation of error) Details in Appendix A (Filename: MTU DC 0529180357 Undergraduate 015 DC CS 1Person.mat) 


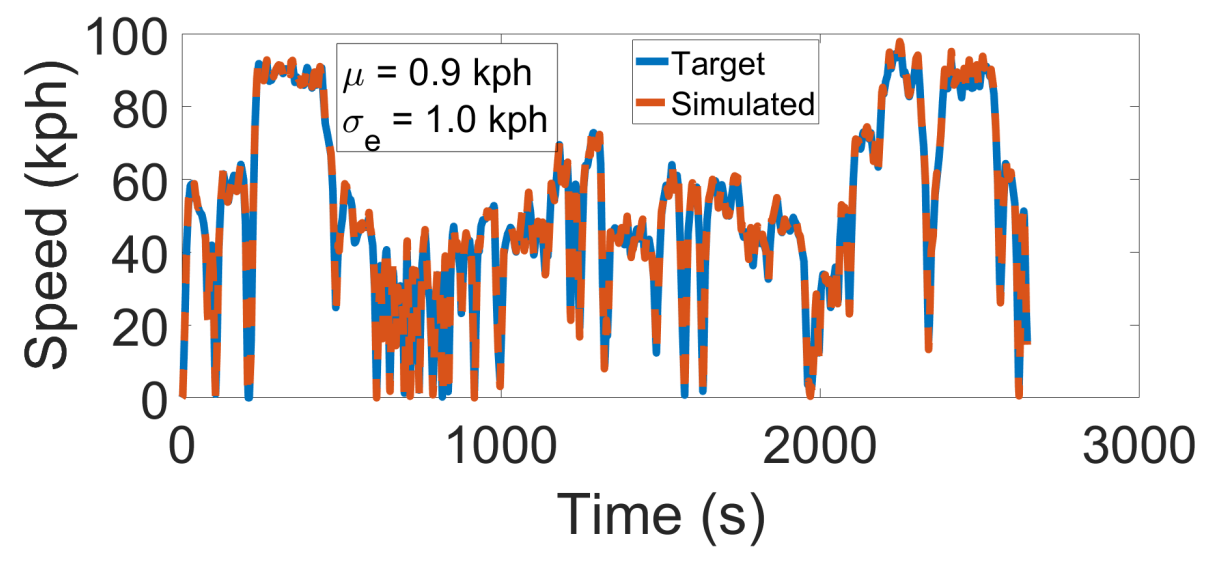

(a) Validation of vehicle speed

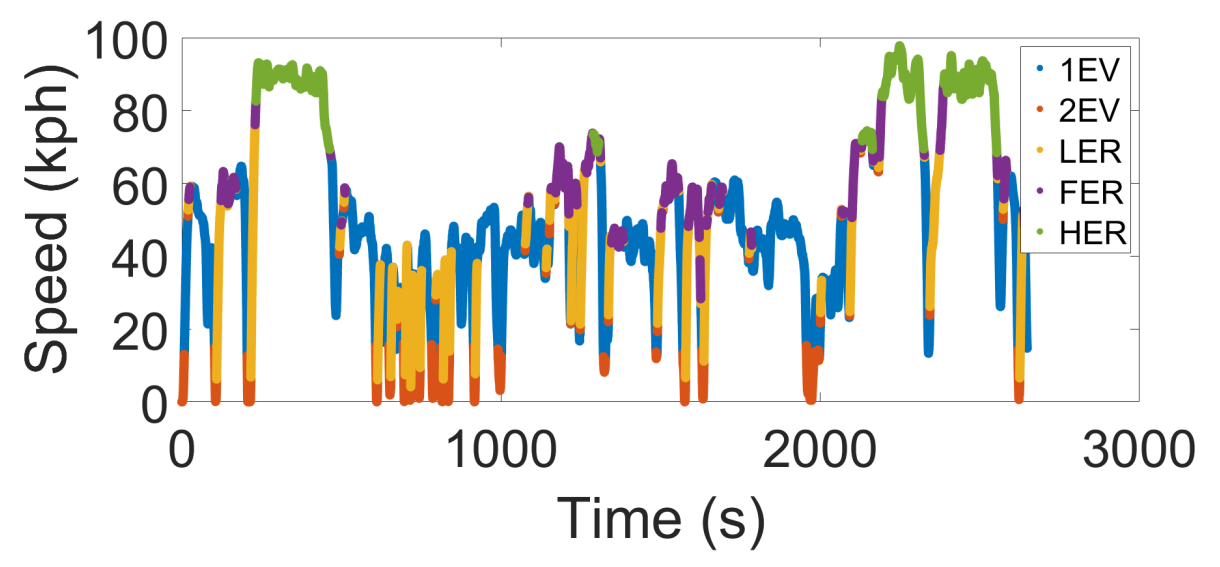

(b) Vehicle drive modes during simulation

Figure B.3: Validation of control model for MTU drive cycle in Normal-CS (Initial SOC $=16 \%)$ mode with active cruise control using MTU APSRC Data $(\epsilon=$ average error, $\sigma_{e}=$ standard deviation of error) Details in Appendix A (Filename: MTU DC 053118 Normal Undergraduate CS 0400pm 0162 2persons.mat) 


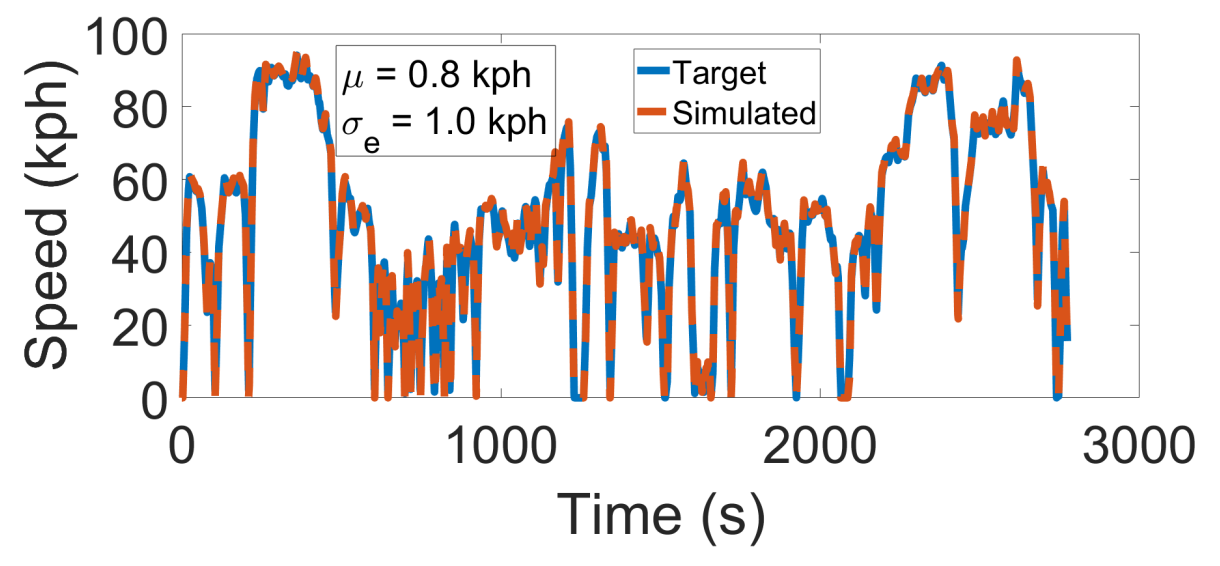

(a) Validation of vehicle speed

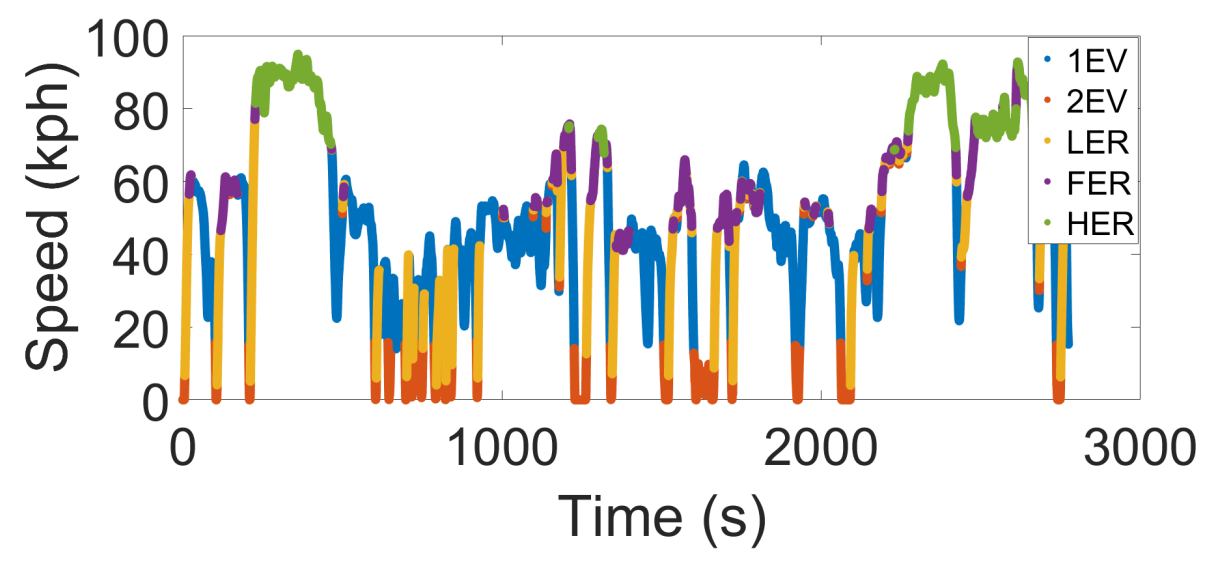

(b) Vehicle drive modes during simulation

Figure B.4: Validation of control model for MTU drive cycle in Hold-CS (Initial $\mathrm{SOC}=16.5 \%)$ mode with active cruise control using MTU APSRC Data $(\epsilon=$ average error, $\sigma_{e}=$ standard deviation of error) Details in Appendix A (Filename: MTU DC 053118 Normal Undergraduate CS 0300pm 0164 2persons.mat) 
Table B.1: Data Files

\begin{tabular}{|c|c|c|}
\hline File Name & Test File & Condition \\
\hline \multirow[t]{3}{*}{ Figure B.1 } & Load mat file MTU DC & MTU CS, initial \\
\hline & 0523181142am Normal CS 2per- & $\mathrm{SOC}=15 \%$ \\
\hline & son.mat and run model.slx & Normal Drive \\
\hline \multirow[t]{3}{*}{ Figure B.2 } & Load mat file MTU DC 052918 & MTU CS, initial \\
\hline & 0357 Undergraduate 015 DC CS & $\mathrm{SOC}=15.5 \%$ \\
\hline & 1Person.mat and run model.slx & Normal Drive \\
\hline \multirow[t]{4}{*}{ Figure B.3 } & Load mat file MTU DC 053118 & MTU CS, initial \\
\hline & Normal Undergraduate CS & $\mathrm{SOC}=16 \%$ \\
\hline & 0400pm 01622persons.mat and & Moderate Traf- \\
\hline & run model.slx & fic \\
\hline \multirow[t]{4}{*}{ Figure B.4 } & Load mat file MTU DC 053118 & MTU CS, initial \\
\hline & Normal Undergraduate CS & $\mathrm{SOC}=16.5 \%$ \\
\hline & 0300pm 01642persons.mat and & Moderate Traf- \\
\hline & run model.slx & fic \\
\hline
\end{tabular}

